\title{
Situation analysis of reproductive health of adolescents and youth in Pakistan
}

Iram Kamran

Population Council

Rehan M. Niazi

Population Council

Kiren Khan

Faisal Abbas

Follow this and additional works at: https://knowledgecommons.popcouncil.org/departments_sbsr-rh

Part of the Demography, Population, and Ecology Commons, Family, Life Course, and Society Commons, and the International Public Health Commons How does access to this work benefit you? Let us know!

\section{Recommended Citation}

Kamran, Iram, Rehan M. Niazi, Kiren Khan, and Faisal Abbas. 2019. "Situation analysis of reproductive health of adolescents and youth in Pakistan." Islamabad: Population Council. 


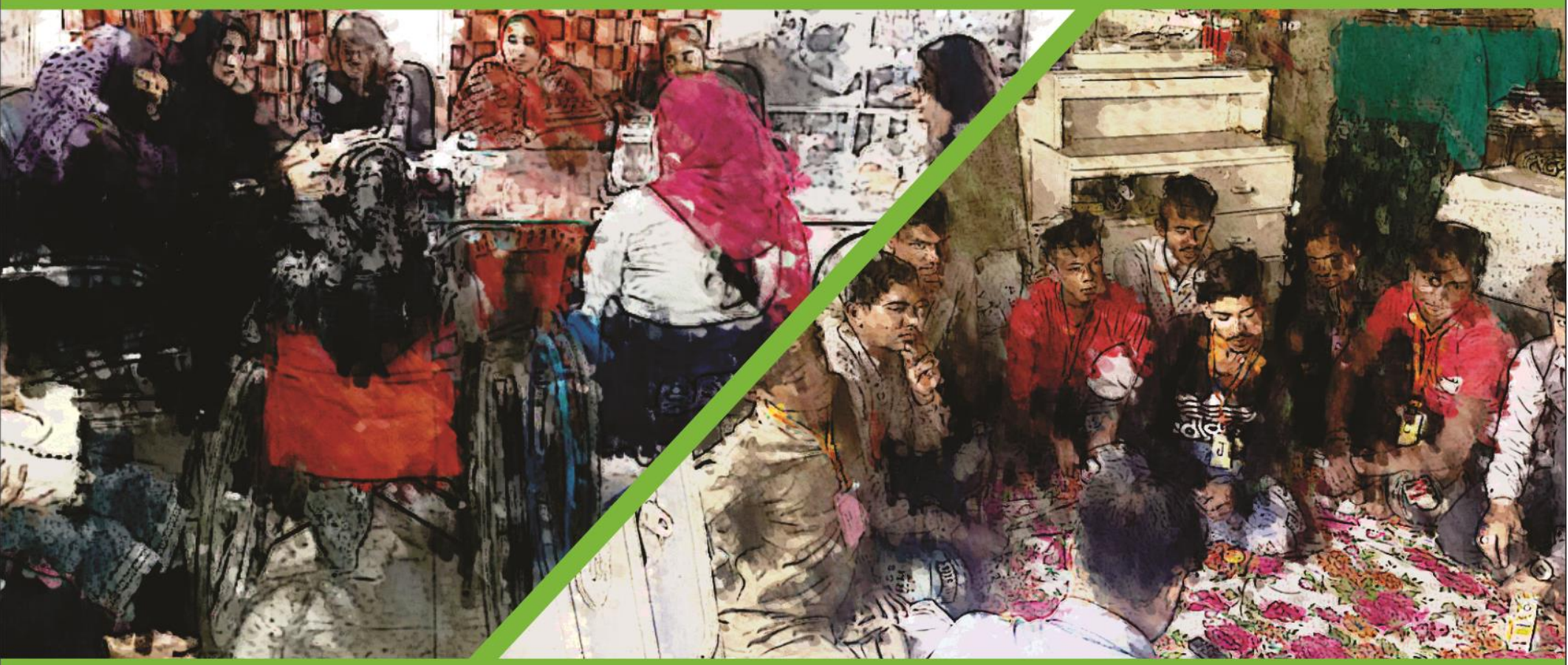

\section{Situation Analysis of Reproductive Health of}

Adolescents and Youth in Pakistan

December 2019

NV UKaid
00 GINFPA 



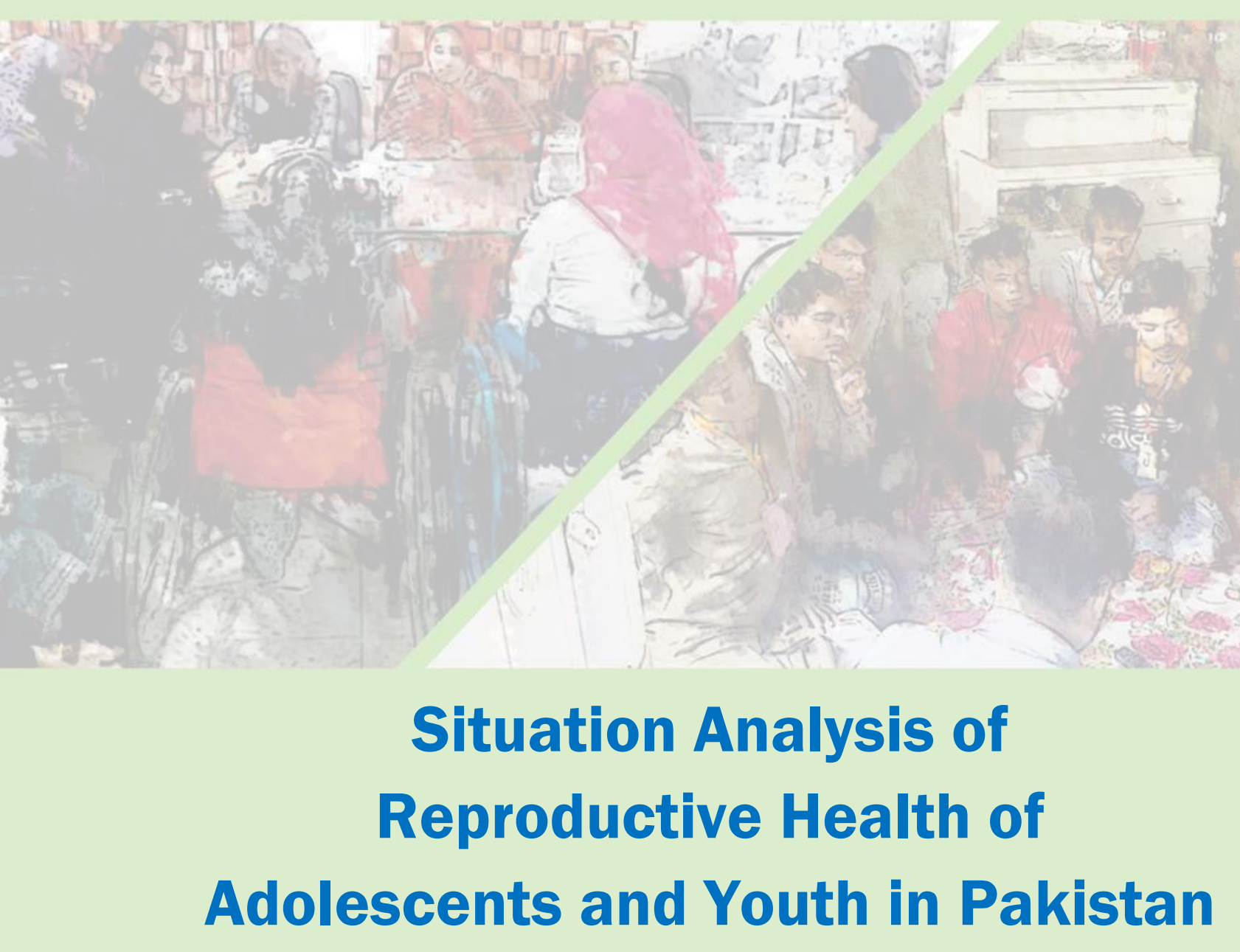

December 2019 


\section{POPULATION COUNCIL \\ Ideas. Evidence. Impact.}

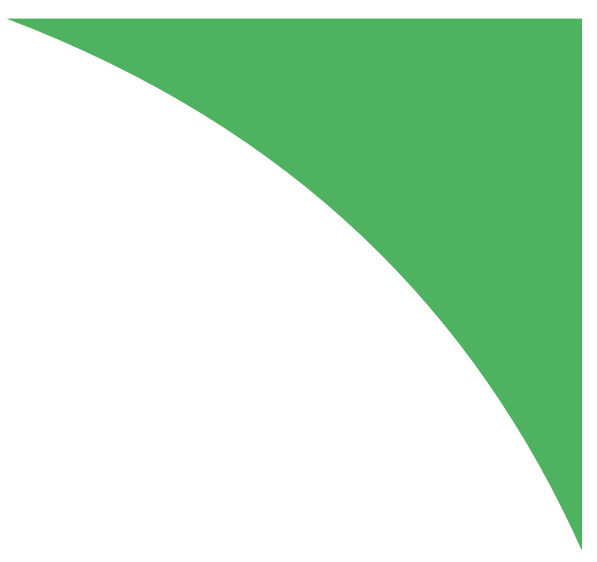

The Population Council confronts critical health and development issues-from stopping the spread of HIV to improving reproductive health and ensuring that young people lead full and productive lives. Through biomedical, social science, and public health research in 50 countries, we work with our partners to deliver solutions that lead to more effective policies, programs, and technologies that improve lives around the world. Established in 1952 and headquartered in New York, the Council is a nongovernmental, nonprofit organization governed by an international board of trustees.

Population Council

$3^{\text {rd }}$ Floor, NTC Building (North), Sector F-5/1

Islamabad, Pakistan

Tel: +92519205566

Fax: +9251282 1401

Email: info.pakistan@popcouncil.org

http://www.popcouncil.org 


\section{Table of Contents}

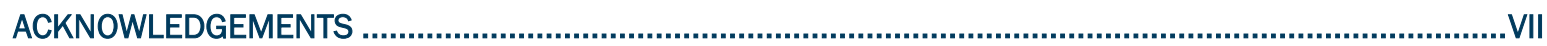

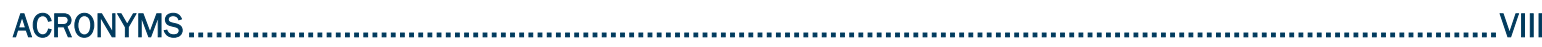

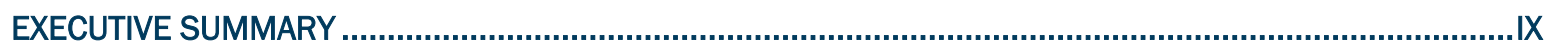

CHAPTER- 1 INTRODUCTION AND METHODOLOGY........................................................................... 1

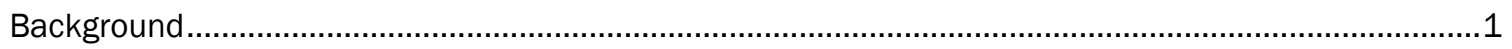

Research Objectives and Questions...........................................................................................

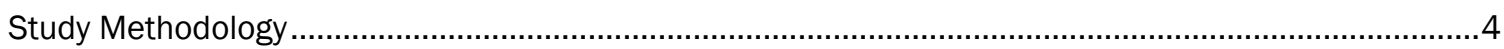

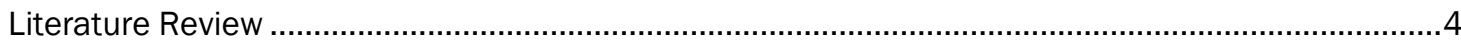

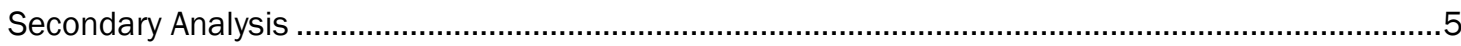

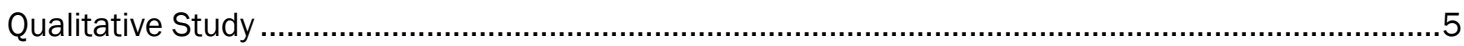

Ethical Standards and Compliance ………………………………………………………....

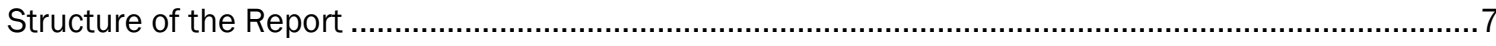

CHAPTER- 2 A LITERATURE REVIEW ............................................................................................ 8

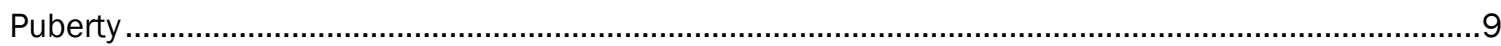

Marriage among Adolescents and Youth ...............................................................................

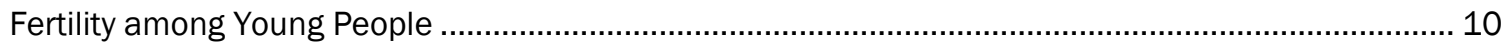

Health of Adolescent Mothers and Their Children.......................................................................... 10

Knowledge, Use, and Preferences about Family Planning …………………………………….... 11

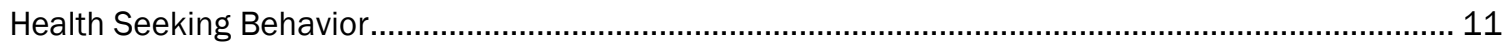

Knowledge of Sexual Reproductive Health ............................................................................ 11

Gender-based Violence .............................................................................................................. 12

CHAPTER- 3 ADOLESCENT AND YOUTH REPRODUCTIVE HEALTH SITUATION IN PAKISTAN ................... 13

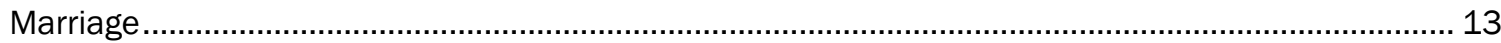

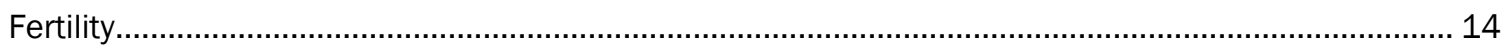

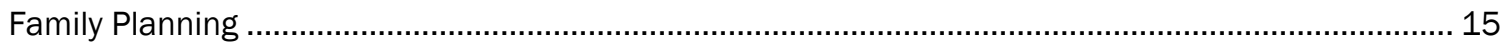

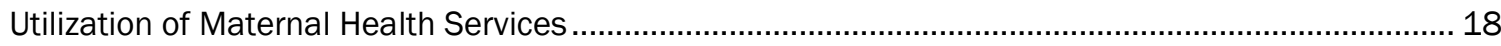

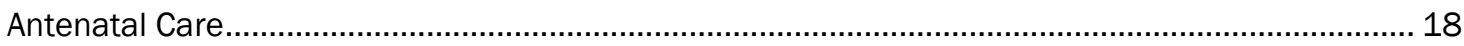

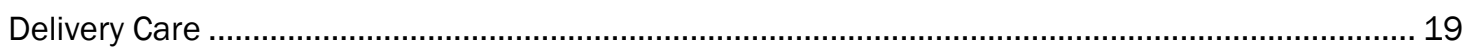

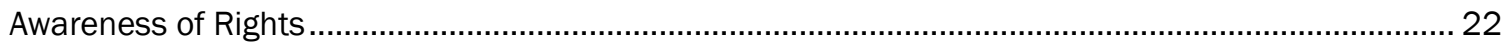

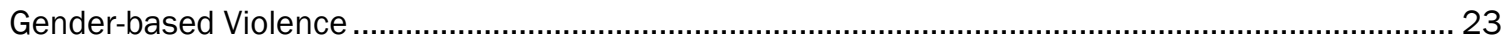

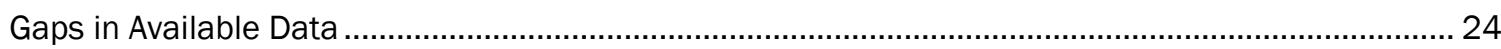

CHAPTER- 4 TRANSITION FROM CHILDHOOD TO ADOLESENCE - EXPERIENCES AND ISSUES..................26

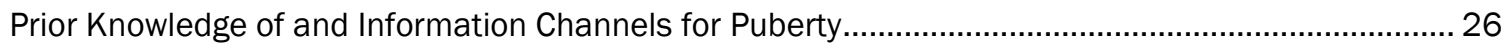

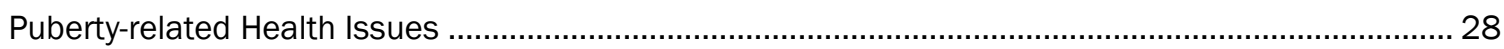

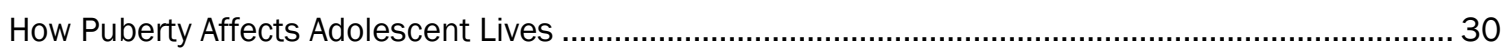

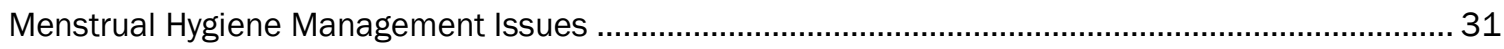

General Observations about Respondents with Disabilities ........................................................... 32

CHAPTER- 5 REPRODUCTIVE HEALTH ASPECTS - KNOWLEDGE AND PREFERENCES ............................34

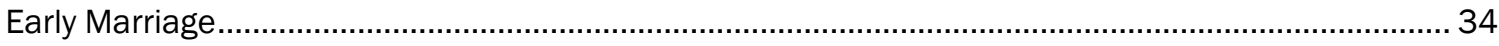

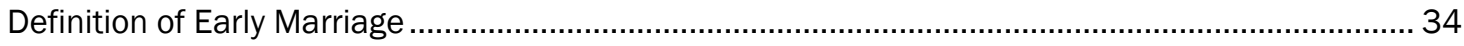

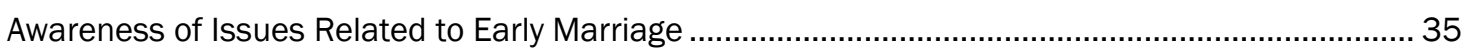

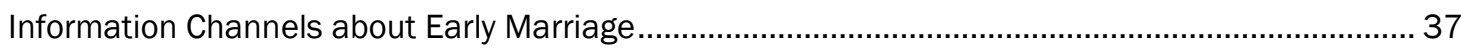

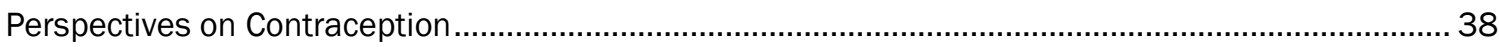




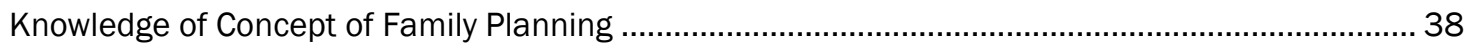

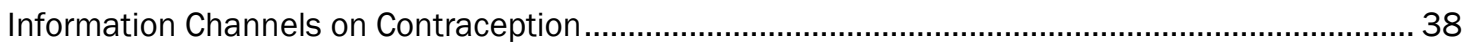

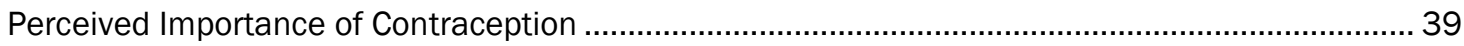

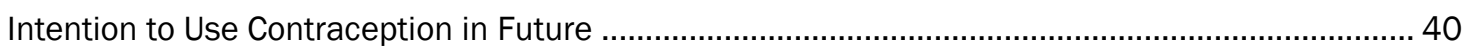

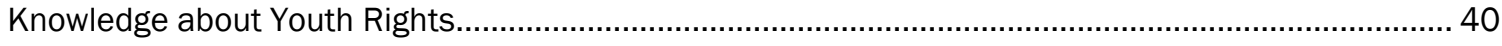

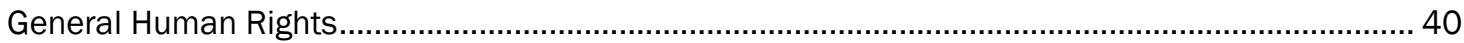

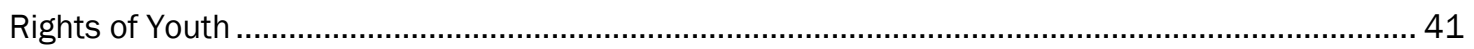

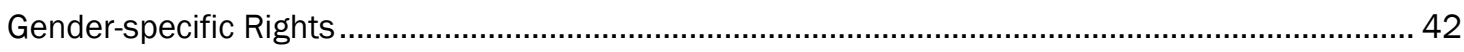

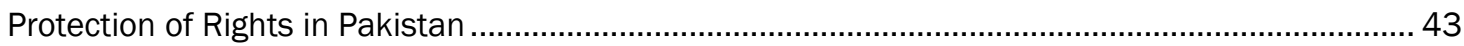

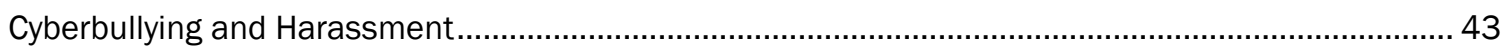

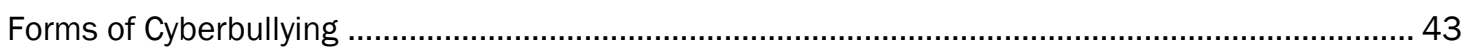

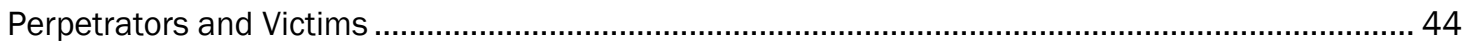

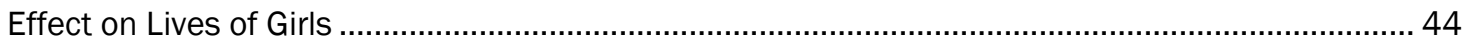

Preferred Sources for Reproductive Health Information................................................................. 46

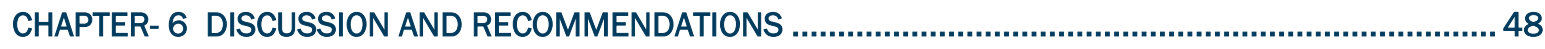

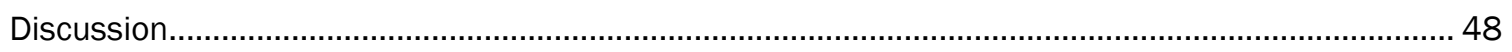

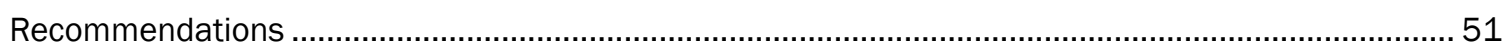

Reach out to adolescents through the health system ............................................................... 51

Develop a locally acceptable model of Life skills-based education for adolescents of

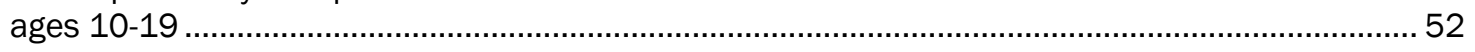

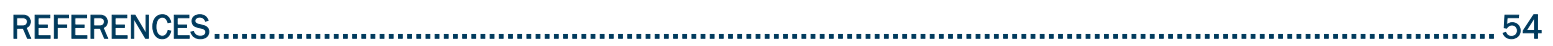

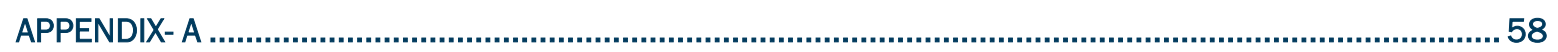

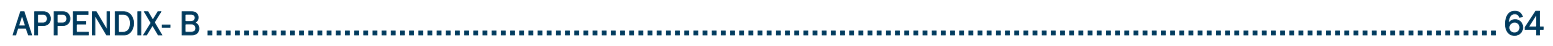




\section{List of Tables}

Table 1.1: Number and location of IDIs and FGDs conducted with unmarried adolescents (15-19 years) by gender and schooling status.

Table 3.1: Singulate mean age at marriage in Pakistan, by region, sex, and year ................................ 13

Table 3.2: Percentage of currently married women ages 15 to 29 who have heard of any contraceptive method, by age group and by background characteristics

Table 3.3: Percent of married women ages 15 to 29 years using any* contraceptive method by age group and by background characteristics......................................................................... 18

Table 3.4: Percentage of births to married women assisted by a skilled provider, by age group and

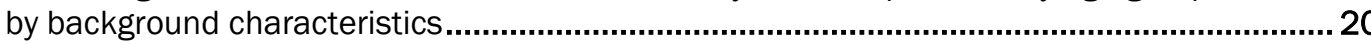




\section{List of Figures}

Figure 3.1: Fertility preferences among married women of ages 15 to 29 in Pakistan, by residence status and age group.

Figure 3.2: Percent distribution of births to women ages 15 to 29 in the 5 years preceding the survey, by fertility planning status of the birth and by age group 15

Figure 3.3: Percent of married women ages 15 to 29 years using any modern contraceptive method by year and age group.

Figure 3.4: Trend in percent distribution of married women of ages 15 to 29 who had a live birth in the 5 years preceding the survey who utilized antenatal care services, by residence . 19

Figure 3.5: Trend in percent distribution of married women of ages 15 to 29 who had a live birth in the 5 years preceding the survey who utilized antenatal care services, by wealth quintile.... 19

Figure 3.6a: Percent distribution of live births assisted by a skilled provider to married women ages 15 to 29 in the 5 years preceding the survey by region .....................................................21

Figure 3.6b: Percent distribution of live births assisted by a skilled provider to married women ages 15 to 29 in the 5 years preceding the survey by wealth status ................................... 21

Figure 3.6c: Percent distribution of live births assisted by a skilled provider to married women ages 15 to 29 in the 5 years preceding the survey, by educational attainment

Figure 3.7: Percentage of married women of ages 15 to 29 who experienced gender-based violence by age group and by residence.

Figure 3.8: Percentage distribution of married women ages 15 to 29 who have ever experienced physical violence by their husbands, by age group. 


\section{ACKNOWLEDGEMENTS}

We would like to acknowledge the United Nations Population Fund (UNFPA) for commissioning this study "Situation analysis of reproductive health of adolescent and youth in Pakistan" from the Population Council, Islamabad. We would like to thank the Department for International Development, UK (DFID) for their generous financial support. We thank colleagues from UNFPA who guided us and participated through this project, including Dr. Bakhtior Kadirov, Deputy Representative, Dr. Muhammad Asif Wazir, Technical Specialist - SDG/ Population Dynamics, and Ms. Sabrina Khan, Programme Analyst - Youth SRHR.

A special appreciation is reserved for Dr. Zeba A. Sathar, Country Director Population Council, Islamabad, for her continuous support and overall guidance. This study greatly relied on the leadership of Dr. Ali Mohammad Mir, Director Population Council, Islamabad: we are extremely grateful for his visionary and technical inputs at every stage of the research and report writing. This study could not have been completed without his invaluable backing. We also acknowledge the oversight of Ms. Samia Shah, Project Director, Population Council, Islamabad. We also express our gratitude to Michelle J. Hindin, Director, Reproductive Health and Karen Kirk, Research Coordinator, Population Council, New York office, for their technical review of the report.

We are also very grateful to our Technical Advisory Group members for their intellectual input in finalizing our survey tools.

We extend our thanks to Mr. Maqsood Sadiq, Deputy Program Manager, Population Council for secondary data analysis in detail. We greatly appreciate the efforts of our qualitative data analysis team, including Ms. Arfa Ahmed, Mr. Haider Abbasi, and Ms. Faryal llyas, who processed and analyzed data, and facilitated the report writing against a stringent timeline.

We appreciate the support of The Health and Nutrition Development Society (HANDS) and its dedicated team in carrying out data collection and producing transcriptions in a timely manner. Special thanks are due to each of our young respondents, who enabled us to produce this research, and members of our field team for their excellent contributions and dedication.

Our gratitude is also due to the Administration and Financial Management team at the Population Council Islamabad office, who worked hard to facilitate the implementation of field activities. We also thank Mr. Ali Ammad for formatting and laying out this report.

\section{Authors:}

Iram Kamran

Rehan Niazi

Kiren Khan

Faisal Abbas 


\section{ACRONYMS}

\begin{tabular}{|c|c|}
\hline AIDS & Acquired Immune Deficiency Syndrome \\
\hline AJK & Azad Jammu and Kashmir \\
\hline ASFR & Age-Specific Fertility Rate \\
\hline $\mathrm{BHU}$ & Basic Health Unit \\
\hline BMJ & British Medical Journal \\
\hline CRC & Convention on the Rights of the Child \\
\hline DFID & Department for International Government, UK \\
\hline FATA & Federally Administered Tribal Areas \\
\hline FGDs & Focus Group Discussions \\
\hline FP & Family Planning \\
\hline GB & Gilgit Baltistan \\
\hline GBV & Gender-based Violence \\
\hline HIV & Human Immunodeficiency Virus \\
\hline HPV & Human Papillomavirus \\
\hline ICESCR & International Covenant on Economic, Social, and Cultural Rights \\
\hline ICPD & International Conference on Population and Development \\
\hline ICRW & International Center for Research on Women \\
\hline ICT & Islamabad Capital Territory \\
\hline IDls & In-depth Interviews \\
\hline IRB & Institutional Review Board \\
\hline IUCD & Intrauterine Contraceptive Devices \\
\hline $\mathrm{KP}$ & Khyber Pakhtunkhwa \\
\hline LHW & Lady Health Worker \\
\hline MICS & Multiple Indicator Cluster Survey \\
\hline NIPS & National Institute of Population Studies \\
\hline OOS & Out-of-school \\
\hline PBS & Pakistan Bureau of Statistics \\
\hline PDHS & Pakistan Demographic and Health Survey \\
\hline PSLM & Pakistan Social and Living Standards Measurement Survey \\
\hline PYG & Progressive Young Girls \\
\hline $\mathrm{RH}$ & Reproductive Health \\
\hline $\mathrm{RTI}$ & Reproductive tract Infection \\
\hline SDGs & Sustainable Development Goals \\
\hline SMAM & Singulate mean age at marriage \\
\hline SRH & Sexual and Reproductive Health \\
\hline STIS & Sexually Transmitted Infections \\
\hline TAG & Technical Advisory Group \\
\hline UK & United Kingdom \\
\hline UNFPA & United Nations Population Fund \\
\hline UNICEF & United Nations Children's Fund \\
\hline WHO & World Health Organization \\
\hline
\end{tabular}




\section{EXECUTIVE SUMMARY}

This report presents a situation analysis of reproductive health of adolescents and youth in Pakistan. It is intended to contribute to evidence-based policies and programs for realizing reproductive rights and choices for young people through health information and services, education programs, and strategic partnerships. The study included a literature review; secondary analysis of data from the Pakistan Demographic Health Surveys (2006-07, 2012-13 and 2017-18); and Multiple Indicator Cluster Surveys (MICS Punjab 2017-18 and Sindh 2014) and a qualitative study of perspectives of unmarried adolescent boys and girls (ages 1519), including both school-going and out-of-school individuals, as well as boys and girls with disabilities, in peri-urban areas of Islamabad, Lahore, Karachi, Peshawar, and Quetta. Major themes of the research include puberty, marriage, fertility, family planning, utilization of reproductive health services, rights awareness, and gender-based violence. Findings about married young people are based on secondary data analysis, while qualitative findings concern unmarried adolescents.

\section{Key Findings}

Puberty: Available quantitative data do not cover puberty. However, this subject was discussed at length by the unmarried adolescents who participated in the study's qualitative component. Their responses are summed up in Table A below.

In discussing their experiences of puberty, respondents not only identified the specific health issues they face but indirectly also provided insights into how the lack of open discussion of sexual and reproductive health exposes them to unnecessary shock, pain, and guilt in negotiating natural physiological changes. For example, most girls confessed they were shocked when they began menstruating because nobody had told them it would happen. Several other studies have documented girls' lack of knowledge about the menstrual cycle as well as menstrual hygiene management. Some girls report being anxious about stains at school because there are no arrangements to change their sanitary napkins-one respondent even mentioned that the school head forbade students from changing at school due to lack of disposal arrangements. Even at home, girls must hide their condition from fathers and brothers. There is no mention of basic measures that could alleviate some of their problems, such as tracking their cycle on a calendar or app to be prepared ahead of time, or taking over-the-counter pain medication for cramps.

Many girls also complained about vaginal discharge (leucorrhea), although they said this is generally not considered a reason to go to the doctor. Girls need to be oriented by health care providers so they can distinguish normal, healthy discharge from symptoms that require medical attention. This is particularly important because, according to the PDHS, a large proportion of men and women who suspect they have sexually transmitted infections (STIs) do not visit a health practitioner.

While available research about boys' issues in puberty is sparse, our study indicates that they too can struggle with health issues such as urinary tract infections and rashes, as well as weakness and other issues that they at times perceive to be linked to nocturnal emissions and to masturbation. Boys commonly have a number of misperceptions about the health effects of masturbation and clearly experience a lot of guilt over it for which they need counseling. They also need guidance to avoid urinary tract infections. 
Table A: Responses about Puberty at a Glance, by Gender

Girls

Prior Knowledge of

Puberty-related Changes

Common Sources of Information about

Puberty

Puberty-related Health

Issues

Life
Two-thirds did not have prior

knowledge of menstruation

Mothers, older sisters

- Vaginal discharge (Leucorrhoea)

-Menstrual issues, including pain in abdomen, feeling weak, pain in legs

-Psychological issues, including feeling of shame associated with menstruation

Mobility restrictions; responsibility for household chores; taking the veil; menstruation-related discomfort, absence from school, and hygiene management challenges

\section{Boys}

Majority knew in advance about puberty-related physical changes, mainly from friends

Friends, social media

\begin{abstract}
-Concerns with nocturnal emissions
-Masturbation-related issues

-Urinary tract infections

-Sexually transmitted diseases

-Concerns with appearances/delay in secondary sexual characteristics
\end{abstract}

Increased freedom and mobility; household economic responsibilities; increased propensity to masturbate, watch pornography and (in a few cases) engage in unsafe sexual activities including paid sex

Upon reaching puberty, girls experience greater restrictions on their mobility, attire, and interactions with outsiders, including on mobile phones and social media. In marked contrast, boys find greater freedom to go outside and begin to be seen as bread-earners, with associated prestige. However, the newfound freedom can also introduce risks. At this sensitive time in their psychological development, when negative exposures can influence their perceptions, behaviors, and later relationships, many boys shared that their peers are attracted to pornography. Use of pornography has been found to be associated with perpetration of violence, and it is possible that boys' indulgence distorts their ideas about masculinity and brings them into interaction with individuals who might further mislead them. Sexual activity outside marriage is a punishable offence in Pakistan and therefore not openly practiced or documented in data. Yet, even in the limited sample of our qualitative study, we found that some respondents from Islamabad and Lahore-all of them out-of-school boys-mentioned about engagement of their friends in high-risk sexual activities including paid sex and relying on their peers to provide them information about contraception and other reproductive health related topics. One respondent even shared that his friend contracted HIV after engaging unsafe sex with an individual having multiple partners eventually died of AIDS. These reports suggest that adolescent boys, especially those out of school and on the streets, need to be counseled about the risks associated with their behavior, and provided reproductive health services, including voluntary screening for STIs and HIV/AIDS. Individuals engaging in high risk commercial sex need of education about health care to promote safe practices.

Marriage and Fertility: The median age at first marriage is 20.4 years among women age 25 to 49 and 25.9 years among men age 30 to 49 as reported by PDHS 2017-18. The singulate mean age at marriage (SMAM) 
has risen for both women and men to about 23 years and 27 years, respectively. Nevertheless, 14 percent of female and 3 percent of male adolescents of ages 15 to 19 are also currently married.

About a fifth of girls of ages 15 to 19 have begun childbearing in Pakistan. Adolescent mothers account for 44 of every 1,000 live births in the country. Compared to older mothers, these teenage mothers are three times more likely to be anemic, have a lower pre-pregnancy body mass index, and are also three times more likely to have chorioamnionitis (Shah et al. 2011). In addition, their newborns are more prone to preterm birth and low birth weight and have a higher risk of neonatal death.

According to PDHS, age-specific fertility rates (children born per 1,000 women) have declined among young women between 2006-07 and 2017-18 from 51 children to 46 in the 15-19 age group, 178 to 171 in the 20-24 age group, and 237 to 215 in the 25-29 age group. However, trend analysis of fertility preferences shows that the proportion of adolescent married girls who want more children has increased from 89 percent to 96 percent between 2006 and 2018.

On the other hand, our discussions with unmarried adolescents in this study suggest that they do not generally condone marriages in which the girl is too young. They are surprisingly well aware of the health risks associated with early childbearing and to some extent also the social difficulties a child bride might face negotiating the role of a wife and a mother. However, in a few number of cases, they believe that a girl who is $15-17$ years of age is not too young to be married. This suggests a need to convey more detailed information to young people about why marriage under the age of 16 is not only legally prohibited, but also medically inadvisable, and why contraception must be used by young married couples.

While boys, along with girls, were not in favor of early marriages, several of them mentioned that religious teachers in their community suggested they should get married early to avoid being driven to temptations such as viewing pornography and masturbation. On the other hand, girls mentioned that parents sometimes married their daughters off early if they suspected their daughters were getting involved in romantic relationships. These observations suggest that, to some extent, early marriages may be a preemptive measure by parents who are afraid that their children's growing interest in the opposite sex might 'corrupt' them. In discussion of rights, girls frequently emphasized the need to protect girls' right to consent in marriage.

Family Planning: About 97 percent of currently married women of 15 to 29 years have heard of at least one method of contraception. Knowledge levels rise steadily with age, from about 91 percent of women in the 15 to 19 age group to nearly 99 percent among women of 25 to 29 years (PDHS 2017-18). Urban-rural differences are generally narrow. Among the regions, Balochistan and Sindh have the lowest proportions of women aware of contraceptive methods. Among adolescent married women (ages 15-19) knowledge of family planning is lowest in Gilgit-Baltistan followed by Sindh, and Balochistan. On the other hand, a surprisingly high proportion of young women in the relatively less-developed Federally Administered Tribal Areas (FATA) know about at least one contraceptive method; the proportion is higher than in Punjab and the Islamabad Capital Territory (ICT).

A little above one fifth (22\%) of married women of ages 15 to 29 in Pakistan use any contraceptive method of family planning. Contraceptive use among married women of ages 15 to 29 rises with age, is higher with more educational attainment and wealth, and varies by region of residence. The proportion of young married women using modern contraceptive methods increased in 2012-13 compared to 2006-07 however, there is a slight stagnation or decrease in use of modern contraceptives in 2018 than in 2012-13 for all age groups. Meanwhile, 17.9 percent of married women of ages 15 to 19, 18.6 percent of women of ages 20 to 24 , and 20.4 percent of women of ages 25 to 29 have unmet need for family planning. 
Qualitative findings are more encouraging in this respect. Virtually all the unmarried adolescents who participated in this study were aware and supportive of the concept of family planning. They felt it was necessary to ensure a healthy interval between births and also to limit family sizes so that children could be well looked after. They were also aware of some specific methods and highly motivated to use contraception, especially the boys, who said they would consult health professionals to ensure birth spacing and the good health of their future wife.

Generally, there was not much difference in the sources of information about contraception mentioned by girls and boys. Mainly, they had come to know about birth spacing through TV commercials and programs, friends, the Internet, and cousins. Some boys and girls also said they had overheard conversations about contraception between their mothers or other female relatives in the household and the Lady Health Worker.

Utilization of reproductive health services: Access to maternal care has greatly improved in Pakistan in recent years. Nevertheless, 11 percent of women of aged 15 to 29 do not use antenatal care services and close to one third of births among them occur without the aid of a skilled service provider. A closer look at the data shows that these gaps are wider in rural areas, in some regions-especially Balochistan, and among women who are less educated and poorer. Collectively, the low use of contraception among married adolescent girls, combined with the higher risks pregnancy poses to their health, and the still significant proportions who do not utilize antenatal or delivery care indicate high maternal health risks for young married women. It is therefore not surprising that most respondents in the qualitative study had observed cases of poor maternal health among young mothers in their own circles.

Awareness of reproductive health rights: In the absence of directly relevant data about awareness of reproductive health rights, we used exposure to mass media as a proxy for rights awareness in the secondary analysis. Among young married women of ages 15 to 29, the proportions who read a newspaper, watch television, or listen to the radio at least once a week are about 4 percent, 50 percent, and 5 percent, respectively. Among married women of ages 15-19, about 5 percent read the newspaper, 38 percent watch TV, and 3 percent listen to the radio, and for women aged 25-29, these figures are 4 percent, 53 percent, and 5 percent, respectively. Use of all media is higher in the urban areas, wealthier, and more educated segments.

In conversations about rights in the qualitative study, we found adolescent boys and girls to be broadly aware of human rights but more vocal about their rights as youth. Girls especially spoke more of their right to education and to consent in their marriage, while boys frequently mentioned the right to employment. However, relatively few respondents spoke about the right to be safe from child labor, harassment and violence, and none talked about domestic violence. At the same time, when they spoke of gender rights, the respondents referred only to girls, apparently not observing that boys too can face gender-related hardships, such as being expected to earn for the household while they are still minors. In general, respondents were not aware what forum or organization might help them secure their rights except in the case of inheritance, regarding which some girls voiced optimism that they could go to court against male relatives if their right was denied. On the whole, however, the responses did not indicate that the boys and girls have rights-based attitudes. Young people's awareness of rights, laws, and also justice institutions and redress mechanisms needs to be built.

Gender-based violence: Available quantitative data and literature point to considerable prevalence of genderbased violence. In the recent International Men and Gender Equality Survey for Pakistan (2018), about 59 percent of women reported experiencing any kind of violence and about half of men (50\%) reported ever perpetrating violence. More than one tenth of men and women reported abuse during childhood. The survey also revealed a high degree of intergenerational transmission of violence. Gender-based violence is also inflicted through a number of harmful customs and practices in Pakistan, such as honor killing, vani (marriage 
to settle disputes), and watta satta (bridal exchange). Moreover, emotional violence is common. Common reasons identified for verbal spousal violence include financial matters, infertility or not having a son, husband beating the children, and wife's refusal of sex. As in many other countries, low reporting of physical, sexual, and other types of violence, especially by women victims, is also an issue in Pakistan.

In the qualitative study, we asked unmarried adolescents about one form of violence in their lives, i.e., cyberbullying. According to most respondents, it is a common activity and largely perpetrated by boys, who have more easy access to mobile phones. Girls may be tricked by fake accounts or blackmailed by former boyfriends with threats of publicly sharing their edited photographs. The girls generally lack support and fear punishment from parents, which can range from greater restrictions on their mobility and mobile use to beatings, being withdrawn from school, and even being forced into early marriage. The responses indicate that there is a need to educate young people and also parents about the ways in which social media can be manipulated and the measures they can take to reduce their vulnerability and block or report perpetrators.

\section{Recommendations}

Our two broad recommendations pertain to making reproductive health information and services more accessible to young people.

Reach out to young people through the health system: Health care providers and facilities need to have mechanisms in place to cater to the counseling, information, and service needs of both married and unmarried young people. Health staff must also be trained in adolescents' reproductive health related counseling and treatment modalities. Where feasible, toll-free helplines can be set up to counsel both boys and girls. In terms of specific measures:

- Girls should be counseled on menstrual hygiene management, period tracking, and pain relief. Very young adolescents need to be told about menstruation before it occurs. Girls also need to be counseled about leucorrhea and when they should see a health care provider. Similarly, young adolescent boys need to be counseled in advance about nocturnal emissions, the urge to masturbate, and how to avoid urinary tract infections. The boys will need male providers who can counsel, inform, and treat them in a friendly, pragmatic, and open manner.

- Adolescents who are out of school may require special interventions. For example, homebound girls could be reached through Lady Health Workers. Medical camps could be organized for street children (male and female) and transgenders with a special focus on providing them the information and counseling they need to avoid unsafe sexual practices.

- Pre-marriage information and counseling should be provided to young couples about family planning, specific birth spacing methods, other aspects of sexual and reproductive health care, joint decisionmaking about fertility, and how to cope with social pressures to commence early childbearing.

- Health service providers must be trained to recognize and empathetically cater to survivors of genderbased violence. There should be a mechanism and guidelines for allowing GBV survivors legal redressal based on existing protocols such as the National Clinical Handbook for Health Care Provision to GBV Survivors in Pakistan and others.

- Psychological health facilities for adolescents should also be created at tehsil and district headquarters level. In addition, safe spaces should be created at community level for them to network with peers and be mentored. Opportunities for healthy activities can be created here such as sports, young people's associations, and clubs. 
- Both young people and service providers should be oriented to client rights, and rights-based attitudes and approaches encouraged.

Develop a locally acceptable model of life skills-based education for adolescents of ages 10-19: In Pakistan, as in other conservative societies, the idea of comprehensive life skills-based education (LSBE) may at first be considered incompatible with sociocultural norms. However, there is a need for stakeholders to realize that whether or not LSBE is provided formally to young people, they will learn about sexual and reproductive health matters from other sources, which might not always be the best-informed or best-intentioned:

- A wide-ranging consultative and participatory process should be undertaken to cultivate an indigenously owned narrative and model of comprehensive sexuality education for young people which should form the basis of the curricula for life skills-based education to be imparted within schools, including also religious seminaries, throughout the country. To the extent possible, this model should also cover themes related to gender-based violence and harmful customary practices.

- In order to work, the model developed for life skills based education must draw on all the main sectors on which young people rely for guidance, including their families, especially parents; schools; the health community, including public and private sector doctors and health workers, as well as hakims and homeopaths; and religious scholars and leaders. Involvement and endorsement of the latter is particularly important to destigmatize discourse on sexual and reproductive health, and make young people, their families, and communities receptive to the idea of life skills based.

- Religious scholars have recently endorsed family planning in Pakistan to promote health timing and spacing of pregnancies (HTSP). Their endorsement of LSBE may be obtained through a similar approach and building on the earlier work of obtaining their support for HTSP.

- In imparting sexuality education, segmented approaches will be needed to reach young people in and out of school, as well as girls and boys who can access slightly different channels of information. Educational institutions could be taken on board through schools' life skills education and madrassa curriculums. Health education materials can be made available at health facilities. Forums of nongovernmental organizations (NGOs) may be used for peer-based education.

- Media messaging and social media should also be used for information sharing. 


\section{CHAPTER- 1 INTRODUCTION AND METHODOLOGY}

\section{Background}

Adolescents comprise one sixth of the world's population and account for 6 percent of the global burden of disease and injury (WHO 2019). In Pakistan, which has not completed its demographic transition, the proportion of adolescents and youth in the population is even higher: according to the 2017 Census and Pakistan Demographic and Health Survey 2017-18, 68 percent of the population is less than 30 years of age and 27 percent is aged 15-29 years. Notably, the WHO and United Nations Population Fund (UNFPA) use the term "young people" for those between 10 and 24 years of age. "Adolescents" are defined by the WHO as persons of ages 10 to 19. The United Nations (UN) defines youth as persons of ages 15 to 24 . On the other hand, previous national and current provincial youth policies of Pakistan classify youth as those between the ages of 15 and 29 years (Government of Khyber Pakhtunkhwa 2016 and Government of Punjab 2012).

The adolescent population has complex health care needs. Reproductive health and full enjoyment of the associated human rights are at the very heart of adolescents' transition into adulthood. They play vital parts throughout life in adolescents' identity, health, wellbeing and personal fulfillment. Unless reproductive health and rights are supported and upheld across a range of dimensions and within a range of settings, young people's lives will be negatively impacted. The choices and decisions that today's adolescents and youth make, or are forced to make by others, about their reproductive health, marriage and childbearing will critically influence whether or not they can take full advantage of opportunities for education, employment and societal participation. A great many adolescents and youth in Pakistan are at risk of experiencing poor reproductive health, which has a number of negative implications for adolescents and youth, and for society at large.

According to the 2017-18 Pakistan Demographic and Health Survey (PDHS), 8 percent of women aged 2549 were married by the age of 15 and 29 percent by 18 . Poor reproductive health of adolescents and youth is associated with adverse consequences of early childbearing and parenthood, including neglect and abuse, pregnancy complications, maternal death and disability. Teen mothers are more likely to live in poverty and to be dependent on welfare. Ensuring that adolescents have access to the health services they need can help prevent such lifelong impacts, and also contribute in checking the intergenerational transmission of poverty, for example, by reducing rates of adolescent pregnancy (WHO 2019). The PDHS (2017-18) shows that use of any contraception is only 7.4 percent among married people aged 15-19 years; only 5.9 percent use any modern method. Youth in Pakistan express the desire to be provided FP information, if possible privately, preferably through the internet, social media and mobile voice messages including videos or pictures for the uneducated. 
In addition to barriers faced by the general population in accessing health care services, such as low availability of services or lack of knowledge about whether and where to seek health services, adolescents commonly confront age-specific hurdles, such as lack of money or independent access to insurance, and legal requirements of parental consent, or societal norms and traditions that may cause young people to delay or avoid seeking services. In the case of reproductive health services, even where youth-friendly legislation exists, cultural biases may lead to negative provider attitudes that discourage adolescents from seeking services or hinder their full access (WHO 2019).

In conservative societies like Pakistan, where cultural sensitivities discourage discussion of sexual and reproductive health, and sexuality education is a controversial subject, it is even harder for young people to access reproductive health services, especially if they are unmarried. Discourse, policies, and action around reproductive health in Pakistan are predominantly focused on adult, married people, primarily women. Yet, many studies indicate that sexual exploitation and abuse of children, especially those who are poor or living in the street, is more widespread than is commonly discussed (Khan and Pine 2003). Adolescents are also exposed to sexually transmitted infections (STIs), HIV/AIDS, unwanted pregnancy, and other risks as sex workers. Moreover, studies on induced abortion in the country reveal "a small but potentially significant adolescent component," including unmarried girls (Khan and Pine 2003). The urgency of some of these issues is affirmed almost daily in national news, indicating an urgent need for the health system to engage with and respond with sensitivity to the SRH needs of young people.

Instead, at present, the myths and stigma related to SRH affect even young married couples, preventing them from acquiring knowledge related to sexual and reproductive wellbeing, and limiting their ability to make independent decisions regarding family planning, birth spacing, and other issues (Chandra-Mouli et al. 2018). The singulate mean age at marriage (SMAM) is 22.8 years for females and 27 years for males in Pakistan. ${ }^{1}$ Young couples face considerable social pressure to have their first child (Hamid, Johansson and Rubenson 2011), and the adolescent birth rate in the country is 46 , while unmet need for family planning among young mothers (ages 15-24) is 18 percent. Use of SRH services seems to largely revolve around pregnancy and childbirth, and to a limited extent family planning (only 35 percent of married women of reproductive age use any family planning method). Meanwhile, among ever married young people (ages 15-24), only 2 percent of females and 6 percent of males have comprehensive knowledge of HIV/AIDS, and large proportions of young men and women report that they do not seek any treatment for STI symptoms (PDHS 2017-18).

It is important to improve access to SRH information and services for all young people in Pakistan, but this need is most urgent among the more vulnerable segments, whose current and future needs may be higher and the barriers simultaneously greater due to intersecting factors such as gender, poverty, and lack of education. Sathar et al. (2016) identify stark differences in educational attainment, workforce participation, recreation, and health-seeking behavior across adolescents and youth belonging to different groups, especially by age, wealth status, and most acutely, gender. Based on these differences, the authors emphasize the need for segmented approaches in assessments and programming for adolescents and youth, with a special focus on the needs of homebound, older adolescent girls.

A recent qualitative study in Punjab province found that adolescent girls and boys have different reasons for dropping out of school, with dramatically different outcomes on their life trajectories; girls are more likely to be confined to their homes, helping through household and unpaid work, while boys are expected to start earning (Kamran et al. 2018). Harmful practices that result from unequal gender norms can further impede access to reproductive health services and limit women's rights and choices in all areas of their lives (Erken et al. 2019). At the same time, the very real risks to boys cannot be ignored, even more so because "social taboos against boys admitting to sex with male clients are even greater than they are for girls" (Khan and

\footnotetext{
${ }^{1}$ The singulate mean age at marriage is the average length of single life expressed in years among those who marry before age
} 50 . 
Pine 2004). Reports indicate that a significant proportion of male sex workers, a high-risk group for HIV/AIDS, are young (13-19 years of age) (World Bank 2012).

With the adoption of the Sustainable Development Goals (SDGs) in 2016, the global community, including Pakistan, has recognized universal health coverage as a critical priority. Within this context, the need to ensure health coverage for adolescents is especially emphasized. According to the World Health Organization (WHO 2019), while rapid declines have been achieved among infants and young children in many parts of the world, progress in improving health indicators for adolescents has been much slower. This is worrisome for several reasons.

Provincial population policies in Pakistan acknowledge a need to enhance young people's access to information and services related to reproductive health. In particular, the need to discourage early marriages and childbearing is recognized, along with making family planning services accessible to young married couples so they can avoid the high risks of pregnancy in adolescence. In this regard, following the Council of Common Interest's Recommendation 4.1, "Family planning and reproductive health rights bill (FP and RH) ensuring mandatory family planning/ reproductive health services by all general health care facilities in public and private sector" (Government of Pakistan 2018), the provincial government of Sindh has recently passed the "Sindh Reproductive Healthcare Rights Bill," which discusses reproductive healthcare rights of men and women and taking care of complications related to pregnancy and childbirth.

In addition, provincial governments plan to enforce laws against child marriage. The Sindh government, in 2013, adopted the Sindh Child Marriage Restraint Act, increasing the minimum age of marriage to 18 years for girls and making child marriage a punishable offence (Government of Sindh 2013). Provincial governments also plan to introduce premarital counseling on family planning for couples (and also against gender-based violence and sexual exploitation in Punjab), and educate adolescents about family planning through formal and informal mechanisms in age-appropriate and culturally sensitive ways. There are also plans to establish adolescent counseling centers or helplines in the three provinces, as well as Adolescent Health Centers in Punjab have been established in seventeen Family Health Clinic Training Centers (FHC TC) located in teaching hospitals. As yet, however, no holistic strategy has been articulated to make mainstream $\mathrm{SRH}$ services more accessible to all young people.

UNFPA's new global strategy on adolescents and youth supports the implementation of Youth 2030, the United Nation's Youth Strategy launched in 2018, which prioritizes young people's greater access to quality education and health services, including youth-friendly and rights-based sexual and reproductive health services. UNFPA's strategy for adolescents and youth-“My body, my life, my world!"-puts young people at the center of sustainable development. The strategy frames UNFPA's work with adolescents and youth through three interlinked dimensions: My Body: ensure access to integrated sexual and reproductive health services and information for all adolescents and youth; My Life: address determinants of adolescent and youth's health and well-being, upholding rights and investing in human capital; and My World: promote adolescent and youth's leadership and their fundamental right to participate in sustainable development, humanitarian action and in sustaining peace.

The strategy draws on sound evidence in designing comprehensive strategies to deliver rights and choices. Through a lifecycle approach, it builds on links between adolescence and youth and both earlier and later stages of life. Making a real difference in the lives of young people rests on shared leadership and shared responsibility. Youth-led and youth-serving organizations, governments, community leaders, UN entities, civil society, academia, the private sector and the media all have essential roles to play.

The situation analysis of reproductive health of adolescents and youth in Pakistan documented in this report is expected to provide evidence for policies and programs aimed at realizing adolescents' and youth's reproductive rights and choices through ensuring the availability of accessible, acceptable, and affordable 
reproductive health information and services, linking health-care services, life skills-based education and outof-school programs, as well as building and coordinating strategic partnerships.

\section{Research Objectives and Questions}

The aim of this study was to assess the current situation of reproductive health among adolescents and youth in Pakistan to provide evidence for appropriate policies and programs related to young people and adolescents' reproductive health (RH), family planning (FP), and gender-based violence (GBV) in Pakistan.

The study is based on the following two objectives:

- Undertake a situation analysis of RH status among adolescents and youth in Pakistan; and

- $\quad$ Provide inputs into policies and programs related to RH/FP and GBV in the country.

The following research questions are the focus of this study:

1. What is the current status/profile of adolescents 15-19 years and those in the age group 20-29 years in Pakistan in the context of reproductive health issues, including fertility, infertility, RH morbidities, healthseeking behavior, and service utilization?

2. How do persons aged 15-29 years perceive reproductive health, what RH issues do they face (e.g., related to puberty and hormonal changes in the body, childbearing age, maternal and child health complications, reproductive tract infections, etc.), how do they deal with such $\mathrm{RH}$ issues, what are their concerns, and how accurate is their knowledge?

3. What are their sources or channels of information about RH, what are the barriers they face in accessing information and services (for both genders), and what are their preferred sources of information and services?

\section{Study Methodology}

The study consists of three components, including a literature review, a quantitative component involving secondary analysis of survey data, and a qualitative study. This report presents the combined findings of all three components.

\section{Literature Review}

The literature review covers studies related to the reproductive health issues of adolescents and youth produced in or after 2008, with a focus on Pakistan. The literature includes published national and international empirical research papers and grey literature.

The literature was identified and retrieved using online search engines such as Google, Google Scholar, PubMed, Medline, PLOS One, BMJ, Adolescent Health, The Lancet, and websites of national and international organizations such as the Pakistan Bureau of Statistics (PBS), National Institute of Population Studies (NIPS), World Health Organization (WHO), Population Council, International Center for Research on Women (ICRW), United Nations Children's Fund (UNICEF), and United Nations Population Fund (UNFPA). Search terms used for retrieving literature included: adolescent, youth, and Pakistan coupled with thematic areas such as sexual health, reproductive health, marriage, fertility, etc. Bibliographies and references of retrieved literature were used to find further relevant articles through a snowball method. 


\section{Secondary Analysis}

We analyzed data from the latest rounds of the Pakistan Demographic Health Surveys (2006-07, 2012-13 and 2017-18) and Multiple Indicator Cluster Surveys (MICS Punjab 2017-18 and Sindh 2014) to develop a detailed picture of the status of adolescents (15-19 years) and youth (20-29 years) in each province, segmenting by age group, gender, residence, and wealth index. Initial findings of this analysis also helped identify some of the gaps to explore further through the qualitative component.

\section{Qualitative Study}

Our qualitative investigation consisted of focus group discussions (FGDs) and in-depth interviews (IDIs) with young people. It was conducted in peri-urban areas of the Islamabad Capital Territory (ICT) and the four provincial capitals, including Lahore, Punjab; Karachi, Sindh; Peshawar, Khyber Pakhtunkhwa (KP); and Quetta, Balochistan. The capitals were chosen to capture perspectives of adolescent and youth from periurban areas which is reflection of both urban and rural areas and marginalized segment of the urban areas.

To guide the qualitative component, the study team formed a technical advisory group (TAG) consisting of experts from relevant spheres in consultation with UNFPA. After obtaining approval from the UNFPA for the study design and protocol, and prior to primary data collection, we held a consultative meeting with TAG members to incorporate their expert inputs in finalizing the study methodology and tools. A key decision taken at the recommendation of the TAG was to focus the qualitative component entirely on unmarried adolescents and youth, as they are least covered in available literature and data. At a later stage, preliminary findings of the qualitative study were shared with TAG members electronically for their valuable feedback, which is incorporated in this report.

In all, we conducted 24 FGDs and 40 IDIs in which more than 250 adolescent boys and girls participated. At each of the five study locations, we conducted two IDIs and one FGD with each of the four categories of respondents, i.e., female school-going, female OOS, male school-going, and male OOS adolescents. In addition, we conducted four FGDs two each with adolescent girls and boys with disabilities (such as deafness and paralysis) and with mixed status of schooling in Islamabad and Karachi. The distribution of these exchanges is shown in Table 1.1.

The FGDs and IDIs were conducted using instruments developed by the Population Council in consultation with UNFPA and approved by the Council's Institutional Review Board, including a guide for IDIs and a guide for FGDs to be conducted with in-school and out-of-school (OOS) unmarried girls and boys aged 15-19. The FGDs were designed to probe community perceptions, norms, values, and practices around reproductive health of adolescents and youth, as well as RH-related morbidities, associated social issues, and health careseeking behaviors. These discussions also helped identify similarities and variations at the community level across the geographic locations. On average, each FGD included 9 participants. Care was taken to ensure that the FGD participants were homogeneous in terms of age and socio-economic circumstances.

The IDIs were conducted to examine how adolescents and youths view their reproductive health, the issues they experience, their sources of information and services, and their preferences regarding these sources. 
Table 1.1: Number and location of IDIs and FGDs conducted with unmarried adolescents (15-19 years) by gender and schooling status

\begin{tabular}{|c|c|c|c|c|c|c|c|c|c|c|c|c|}
\hline \multirow[b]{3}{*}{ Location } & \multicolumn{5}{|c|}{ IDIs } & \multicolumn{7}{|c|}{ FGDs } \\
\hline & \multicolumn{2}{|c|}{ In-School } & \multicolumn{2}{|c|}{$\begin{array}{l}\text { Out-of- } \\
\text { School }\end{array}$} & \multirow[b]{2}{*}{ Overall } & \multicolumn{2}{|c|}{ In-School } & \multicolumn{2}{|c|}{ Out-of-School } & \multicolumn{3}{|c|}{ Girls and boys with disabilities } \\
\hline & Girls & Boys & Girls & Boys & & Girls & Boys & Girls & Boys & Girls & Boys & Overall \\
\hline Peshawar & 2 & 2 & 2 & 2 & 8 & 1 & 1 & 1 & 1 & 0 & 0 & 4 \\
\hline Karachi & 2 & 2 & 2 & 2 & 8 & 1 & 1 & 1 & 1 & 1 & 1 & 6 \\
\hline Quetta & 2 & 2 & 2 & 2 & 8 & 1 & 1 & 1 & 1 & 0 & 0 & 4 \\
\hline Lahore & 2 & 2 & 2 & 2 & 8 & 1 & 1 & 1 & 1 & 0 & 0 & 4 \\
\hline Islamabad & 2 & 2 & 2 & 2 & 8 & 1 & 1 & 1 & 1 & 1 & 1 & 6 \\
\hline Total & 10 & 10 & 10 & 10 & 40 & $\begin{array}{c}5 \\
(43)^{*}\end{array}$ & $\begin{array}{c}5 \\
(48)^{*}\end{array}$ & $\begin{array}{c}5 \\
(46)^{*}\end{array}$ & $\begin{array}{c}5 \\
(43)^{*}\end{array}$ & $\begin{array}{c}2 \\
(15)^{*}\end{array}$ & $\begin{array}{c}2 \\
(17)^{*}\end{array}$ & $\begin{array}{c}24 \\
(252)^{*}\end{array}$ \\
\hline
\end{tabular}

*Number of respondents who participated in FGDs.

A major challenge was identification of a sufficient number of respondents for each category at the study locations. We addressed this by seeking the help of local organizations working with youth and with community health workers, who have close connections with communities and households. These facilitators helped introduce the research team to communities and build linkages with parents and community leaders. Prior to conducting the FGDs and IDIs, we held a dialogue with the community leaders and parents of adolescent girls and boys to explain to them the purpose of the research. Participants of FGDs and IDIs were also identified with the help of these facilitators, involving parents as well. (Participants of the four FGDs with adolescents with disabilities were identified through an organization working with them.)

In view of the sensitivity of the topics discussed with respondents, the field research team was especially trained to be culturally sensitive and to fully understand and comply with ethical standards during data collection, as detailed in the subsection below.

In settings with more mobility restrictions on girls, obtaining parents' consent for their daughters' participation was at times difficult, particularly for FGDs, for which girls had to step outside their homes and gather at a common place, although we made every attempt to find a safe, neutral, and private venue.

The IDIs and FGDs were audio recorded and transcribed immediately in the field. An effort was made to complete the transcription on the same day that the IDI or FGD was conducted to ensure that maximum substance and observations were preserved. Supervisors reviewed all transcriptions for accuracy of information and observations.

In the analysis phase, following "grounded theory," the data were sorted based on emerging themes and subthemes across the categories of respondents. Different thematic areas were closely analyzed. Strengths of different responses under each of the themes were also calculated to assess the intensity of individual points across study districts and respondent types. 


\section{Ethical Standards and Compliance}

The Population Council requires all studies involving human subjects to be reviewed by its Institutional Review Board (IRB) before the activity is initiated. The purpose of an IRB review is to ensure that appropriate steps are taken to protect the rights and welfare of humans participating as subjects in a research study. Accordingly, approval of the IRB was obtained for this study's protocol before commencing data collection.

A 3-day training was organized for the data collection teams on the research tools and especially on ethical standards to be followed during the implementation of field work. The training ensured that research team members were aware of differences in culture, local customs, religious beliefs and practices, personal interaction and gender roles, age and ethnicity across the study locations, and were mindful of the potential implications of these differences when carrying out the research activities. Special attention was also given in training to research ethics and ensuring that the team understood the meaning of informed consent and how to obtain informed consent, and ensure privacy, confidentiality, and voluntary participation.

Prior to conducting IDIs and FGDs, the research team obtained informed consent from all the study respondents, as well as from parents of 15- to 17-year-old respondents. The research team provided the respondents and parents an in-depth briefing on the study, its objectives, procedures, and uses. The team also explained the approximate time required for the interviews and group discussion and the possible risks (if any) respondents might face. The team assured the respondents that the anonymity and confidentiality of their responses would be ensured.

Participation was voluntary and respondents were not compensated in any way. The participants were informed that they might refuse to answer any question that made them uncomfortable, might terminate the interview at any time, and that no sanctions would be taken against those who refused to participate. The FGDs and IDIs were conducted in private, maintaining as much auditory privacy as possible.

All data collected was kept confidential. It was stored securely, without identifiers of individuals.

\section{Structure of the Report}

Chapter 2 presents the findings of our review of existing literature on reproductive health among adolescents in Pakistan, focusing on studies conducted in the last ten years. Chapter 3 presents findings of the secondary analysis of PDHS series and MICS, regarding the current situation of adolescents and youth in Pakistan in terms of their educational, work, and marital status, as well as available reproductive health related indicators. Results of the qualitative study are presented in Chapters 4 and 5 , with Chapter 4 focusing on knowledge about $\mathrm{RH}$ issues and rights among unmarried adolescents, and Chapter 5 describing their perceptions about RH services. Finally, in Chapter 6, findings from the three components of the study are collectively analyzed and specific recommendations presented. 


\section{CHAPTER- 2 A LITERATURE REVIEW}

Pakistan is one of the youngest countries in the world. At present, about 68 percent of the country's population is less than 30 years of age (PBS 2017). About 27 percent of the population falls in the age group of 15-29 years, with equal proportions of male and female youth.

Young people, especially adolescents, are at a stage of life when they undergo rapid transition at multiple levels, including physical, cognitive, emotional, social, and also sexual. Global development discourse and practice increasingly recognize the importance of investing in people at this stage in their lives, when they are forming behaviors and making choices among emerging pathways of opportunity as well as risk that affect their entire life course (McCarthy, Brady and Hallman 2016). Investments in the health, education, productive skills, and other aspects of wellbeing of young people are essential to help them thrive, to expand the opportunities available to them in the future, and to protect them from risks, such as dropping out of school, substance abuse, or pregnancy in adolescence, that might permanently deflect them from a fullyhealthy, productive, and satisfying future (Katharine, Brady and Hallman 2016; Sathar, Wazir, and Sadiq 2013; Sheehan, et al. 2017; Zaidi, Sathar, UI Haq, and Zafar 2012).

Pakistan is a signatory to the Convention on the Rights of the Child (CRC), the International Conference on Population and Development (ICPD), and the International Covenant on Economic, Social, and Cultural Rights (ICESCR). Provincial population and youth policies (Balochistan Youth Policy (Draft); Punjab Youth Policy 2012 ; KP Youth Policy 2016; Sindh Youth Policy 2018) in the country recognize sexual and reproductive health of adolescents and young people as one of the areas requiring special attention, especially for avoiding early pregnancies among young married couples. However, thus far, young people's access to basic sexual and reproductive health services, such as family planning and sexuality education, remains low, especially in remote rural areas in the country (Shirkatgah 2017).

This section presents the findings of a literature review conducted as part of the "Situation Analysis of Sexual and Reproductive Health of Adolescents and Youth in Pakistan." The methodology adopted to conduct the review has been outlined in Section 1. Its scope includes studies conducted during the last ten years concerning the perceptions of young people (15 to 29 years) (WHO) about SRH and their access to SRH information and services in the four major provinces of Pakistan: Punjab, Sindh, Khyber Pakhtunkhwa, and Balochistan.

The discussion is structured according to thematic areas such as puberty, marriage, and fertility. 


\section{Puberty}

Puberty is a period of great emotional and psychological stress for young persons as they transition from child to adulthood. Available literature includes very few provincial or national level studies on the puberty issues of adolescents and youth in Pakistan. Data about this stage of life is not available in the major data sets, such as MICS or PDHS either. Some studies of girls' puberty and related issues are available, but there is scant literature on puberty-related issues of boys (Huda et al. 2017; Talpur and Khawaja 2012 and Shahid, Peerzada and Memon 2012). Psychosocial issues related to reproductive health are also under-researched in Pakistan, as is common with many other lower- and middle-income countries (WHO 2009).

Menstrual hygiene is of immense importance for girls. In their study, Latif, Mayedah, and Bano (2018) found that girls commonly lack knowledge related to the menstrual cycle and hygiene during adolescence, not only exposing them to the risk of reproductive tract infections (RTI), but also affecting their self-esteem and educational attainment.

Physiological and hormonal changes at puberty impact girls' mental health, moods, and activity level (Sawyer et al. 2012 and Mokari, Shiva, and Leila 2016). Biological and physical structural changes at this time can bring anxiety (Compton et al. 2010) in almost all adolescents, regardless of socio-economic group (Sawyer et al. 2012). In a study by Samani et al. (2012), a little less than two thirds (62\%) of female students reported experiencing medium to severe anxiety during puberty.

Huda et al. (2017) empirically tested knowledge about puberty-related changes and self-care among adolescent boys in Pakistan. Their study concluded that almost 53 percent of the respondents were aware of pubertal changes and about three fourths were ashamed or sensitive about the physical changes.

Puberty is a stage when many questions arise in the minds of adolescents; however, they may be unable to find answers due to shyness, lack of open discussion within the family, and the patriarchal nature of the social setup in countries like Pakistan (Huda et al. 2017). Latif, Mayedah and Bano (2018) found that adolescent girls in both rural and urban areas of Rawalpindi generally seek information about pubertal changes, in the first instance, from their mothers, sisters, and other close family members. At a later stage, they consult their friend circles; media, such as television, books, and newspaper; and social media. If their physical condition is in any way complicated and they need medical help, these adolescent and young girls visit a healthcare provider such as a doctor or Lady Health Worker (LHW).

Adolescent boys generally acquire information about SRH from peers, friends, and relatives, mostly male. They also obtain information from religious leaders (maulvis) and elders (Latif, Mayedah and Bano 2018). More studies are needed to understand how adolescents and youth obtain information about various aspects of sexual and reproductive health.

\section{Marriage among Adolescents and Youth}

Globally, the total number of women married before the age of 18 currently stands at 700 million of which 250 million were married as early as before 15 years of age (UNICEF 2014). Patriarchy, religion, and sociocultural norms lead to early (girl) marriage and childbearing in Pakistan (Qidwai and Ashfaq 2010). According to the United Nations Children's Fund (UNICEF), about 3 percent of young women of ages 20-24 years were married before their fifteenth birthday, while about one fifth (21\%) were married before the age of 18 years (UNICEF 2017). ${ }^{2}$ The latest PDHS (2017-18) reports that 29 percent of women were married before the age

2 The minimum legal age at marriage in Pakistan is 16 years for girls and 18 years for boys according to the Child Marriage Restraint Act 1929. The province of Sindh, in 2013, adopted the Sindh Child Marriage Restraint Act, increasing the minimum age of marriage to 18 years for girls and making child marriage a punishable offence. Although Punjab introduced penalties, the province has not increased the minimum age of marriage for girls to 18 years. 
of 18 years in Pakistan compared to 5 percent of men, and a little less than two thirds (61\%) of women but only one fourth (24\%) of men of ages $25-49$ were married by the age of 22 years.

The median age at first marriage in Pakistan is 20.4 years while 20.7 years is the age of first sexual intercourse. In the PDHS 2017-18, only 5 percent of men but 27 percent of women (25-49 years) reported they had first sexual intercourse by the age of 18 .

No data are available about sexual activity out of wedlock in Pakistan. Nor are data available on whether the marriages contracted were forced, arranged, or reflect the wishes of both spouses. The recent PDHS did ask married women whether they were consulted regarding the choice of their husband: about 80 percent in the 15-19 years age group and almost 83 percent in the 20-24 and 25-29 years age groups reported they had a say in choosing their first husband. However, as yet no dataset addresses the question of whether a girl can inform her parents who she wants to marry. The Forced Marriage Unit of the United Kingdom (UK) has documented 439 cases of forced marriage in Pakistan and ranks it among the top four focus countries for forced marriage, alongside Bangladesh, Somalia, and India. ${ }^{3}$

Notably, Pakistan has one of the highest rates of consanguineous marriages, with 29 percent women reporting they married paternal cousins and 21 percent reporting they married maternal cousins (PDHS 2017-18). The high level of consanguinity is one of the reasons for congenital malformation and other anomalies in neonates.

\section{Fertility among Young People}

Pakistan has the fifth most largest population in the world of about 208 million and a relatively higher total fertility rate (TFR) (3.6 children per woman) compared to other South Asian countries for example India where the TFR is 2.24, and Bangladesh, where it is 2.05. (The South Asian average is 2.4 children per women [PDHS 2018; UN 2019]). According to UNFPA, Pakistan also has one of the highest adolescent fertility rates: adolescent mothers account for 44 of every 1,000 live births compared to 26 of every 1000 live births in South Asia (UN 2019).

Adolescent pregnancy is commonly associated with poverty: young women belonging to the poorest wealth quintile are more likely to become adolescent mothers compared to those in the highest wealth quintiles; in Latin America, for example, this likelihood is three times higher (Rodríguez-Vignoli and Cavenaghi 2014).

Data about adolescent pregnancy are not routinely available, especially births occurring outside of marriage are not documented (UN 2019; Mubeen and Baig 2016).

According to the latest PDHS (2017-18) data, about one in five women of age 15-19 years (19 percent) has begun childbearing in Pakistan. There is regional variation across Pakistan in the proportion of girls aged 1519 who have given birth or are pregnant with their first child.

\section{Health of Adolescent Mothers and Their Children}

Early pregnancy is one of the leading causes of death among teenaged girls across the globe (WHO 2016). Approximately 16 million girls aged 15 to 19 years give birth each year in developing regions (UNFPA 2015 and Neal et al. 2012). Complications from pregnancy and childbirth are the second leading cause of mortality amongst girls in the 15-19 age group, with close to 70,000 deaths annually (WHO 2014).

\footnotetext{
3 https://www.dawn.com/news/1409636
} 
Compared to older mothers, adolescent mothers in Pakistan are three times more likely to be anemic, have a lower pre-pregnancy body mass index, and are also three time more likely to have chorioamnionitis (intrauterine inflammation or infection during pregnancy that causes inflammation in the fetal amnion and chorion membranes) (Shah et al. 2011). In addition, their newborns are more prone to preterm birth and low birth weight and have a higher risk of neonatal death (Naqvi and Naseem 2010; Pradhan, Wyner and Fisher 2015; and Tufail and Hashmi 2008).

\section{Knowledge, Use, and Preferences about Family Planning}

Studies conducted in India and Pakistan find significant association of child marriage with no contraceptive use before first birth, intervals of less than 2 years between pregnancies, and high fertility (Nasrullah et al 2014; WHO 2014; and UNFPA 2013).

Although general knowledge about family planning is universal across the country, contraceptive prevalence rates (any method) remain low.

Currently, 17 percent of married women (ages 15-49 years) have unmet need for family planning (PDHS 2017-18). At the subnational level, this unmet need is highest in Balochistan (22\%) and lowest in Punjab (16\%). Among young married women, unmet need varies slightly across age groups: it is 20.4 percent among women aged 25-29 years, 18.6 percent in the 20-24 age group, and 17.9 percent among women of ages 15-19 (PDHS 2017-18).

\section{Health Seeking Behavior}

The health care system in Pakistan includes both public and private health care providers. This mixed health care system remains largely unable to cater to the sexual and reproductive health needs of adolescents and young people in the country (Shaikh, Haran, and Hatcher 2008). There are limited or no awareness clinics for adolescent youth (only 17 centers in Punjab). Moreover, health facilities predominantly focus on treatment rather than a preventive approach.

\section{Knowledge of Sexual Reproductive Health}

Sexual and reproductive health has been defined as a condition when people are able to have a responsible, satisfying, and safe sex life; have the capacity to reproduce; and have the freedom to decide if, when, and how often to do so (IPPF and UNFPA 2017). In the context of young people, SRH rights include, but are not limited to, the right to life, healthcare, information and education, freedom of thought, liberty, privacy, fertility choice (deciding the number and spacing of children), consent to marriage and equality in marriage, equality, and freedom from violence (lqbal et al. 2017).

Adolescents and youth, especially unmarried girls and boys, face barriers in accessing sexual and reproductive health services, such as needing a chaperone to accompany them, and lack of programs targeted at young people. The country's socio-cultural milieu also discourages discussion about sexuality and reproductive health with young people, making it difficult to provide sex education and build awareness about sexually transmitted infections (STIs) (Sathar et al. 2016). According to the latest PDHS (2017-18), the proportions of young married men and women who have heard about HIV/AIDS or have comprehensive knowledge about it are quite low. Those who have heard about HIV/AIDS include 13.2 percent of girls and 22.3 percent of boys aged $15-19$ years; 21.5 percent of women and 51.8 percent of men aged 20-24 years; and 34.7 percent of women and 63.3 percent of men aged 25-29 years. Negligible proportions of adolescent girls and boys (15-19 years)-0.2 percent and 1 percent, respectively-have comprehensive knowledge of HIV/AIDS. These proportions are only slightly higher among women and men of ages 20-24, at 2.1 percent 
and 6.8 percent, respectively. In the 25-29 age group, 4.1 percent of women and 10.6 percent of men have comprehensive knowledge of AIDS/HIV.

In a mixed methods study from Lahore district, Iqbal et al. (2017) reported that almost three fourths (71\%) of respondents acquired information related to adolescent reproductive health and rights from their friends and one in ten $(9 \%)$ from services and health care providers.

\section{Gender-based Violence}

Violence against women is a violation of basic human rights. This issue is rooted in gender-based inequalities and patriarchal societal norms. Gender-based violence (GBV) can undermine the confidence of victims and be a hurdle in achieving gender equity and sustainable development (Heise 2018). James and Anke (2014) estimate the global cost of gender-based violence to be close to US $\$ 8$ trillion. Gender-based violence against adolescents and youth, whether male or female, undermines their cognitive abilities and limits their participation in economic and civic life, thus proliferating gender-based structural inequities.

Although data are available on the incidence of gender-based violence, globally, there is no data that covers the frequency of its physical occurrence. In Pakistan, available data sets only report whether a woman faces any form of gender-based violence or not; the PDHS 2012-13 and 2017-18, for example, only report whether violence occurs and focuses on spousal violence. No regularly-updated data sets are available on genderbased violence against unmarried adolescents and young boys and girls. In Pakistan's male-dominated society, women often lack agency, making it all the more important to have data on gender-based violence for informed policy making.

Findings of the recent International Men and Gender Equality Survey for Pakistan (Ashfaq, Kamran, and Niazi 2018) highlight the extent of gender-based violence in Pakistan. About 59 percent of women in the survey reported experiencing any kind of violence and about half of men (50\%) reported ever perpetrating violence. More than one tenth of men and women reported abuse during childhood. The survey also revealed a high degree of intergenerational transmission of violence.

Gender-based violence is also inflicted through a number of harmful customs and practices in Pakistan, such as honor killing, vani (marriage to settle disputes), and watta satta (bridal exchange). These deleterious customs propagate the suppression of women and persist due to lack of women's empowerment.

Emotional violence is also common. In a systematic review study from Pakistan, the common reasons identified for verbal spousal violence included financial matters, infertility or not having a son, husband beating the children, and wife's refusal of sex (Ali et al. 2015).

As in many other countries, low reporting of physical, sexual, and other types of violence, especially by women victims, is also an issue in Pakistan. Ashfaq, Kamran, and Niazi (2018) find that victims of violence do not report violence due to fear of stigmatization in the community, husbands' anger, risk of separation from children, and lack of trust on law enforcing agencies (i.e., police and judiciary). 


\section{CHAPTER- 3 \\ ADOLESCENT AND YOUTH REPRODUCTIVE HEALTH SITUATION IN PAKISTAN}

The analysis presented in this section is based on data available in the Pakistan Demographic and Health Surveys (2006-07, 2012-13 and 2017-18), and Multiple Indicator Cluster Surveys (Punjab 2017-18 and Sindh 2014).

Data are analyzed to describe the current situation and trends in behaviors among young people (ages 15 to $29)^{4}$ related to sexual and reproductive health, including marriage, fertility, seeking of maternal health care, family planning, awareness of rights, and gender-based violence. Data are also analyzed to examine bivariate relationships between various demographic traits of young people and their SRH-related behaviors.

\section{Marriage}

Among young people 15-29 years of age, about 46 percent women and 24 percent men are currently married. About 14 percent of young women of age 15-19 years are currently married as compared to 3 percent men. In the age group of 20-24, about 49 percent women and 24 percent men are currently married while about 78 percent of women and 54 percent of men of age 25-29 years are currently married (PDHS 2017-18).

The singulate mean age at marriage (SMAM) is gradually rising in Pakistan except Khyber Pakhtunkhwa at national and subnational levels, for both women and men (Table 3.1).

Table 3.1: Singulate mean age at marriage in Pakistan, by region, sex, and year

\begin{tabular}{l|c|c|c|c}
\hline \multirow{2}{*}{ Region } & \multicolumn{2}{|c|}{ Female } & \multicolumn{2}{c}{ Male } \\
\cline { 2 - 5 } & $1990-91$ & $2017-18$ & $1990-91$ & $2017-18$ \\
\hline Pakistan & 21.6 & 22.8 & 26.5 & 27 \\
\hline Punjab & 21.9 & 23.1 & 26.9 & 27.2 \\
\hline Khyber Pakhtunkhwa & 21.6 & 22.1 & 27.3 & 26.7 \\
\hline Sindh & 21.6 & 22.8 & 25.9 & 26.9 \\
\hline Balochistan & 20.4 & 22.6 & 25.4 & 26.4 \\
\hline
\end{tabular}

Source: Pakistan DHS 1990-91 and 2017-18.

4 Unless otherwise specified, use of the term “young” in this chapter denotes persons of ages 15 to 29. 


\section{Fertility}

Age-specific fertility rates for Pakistan, Punjab, and Sindh indicate that fertility is highest among women aged 25 to 29 and declines at higher ages (PDHS 2017-18; MICS Punjab 2014; MICS Sindh 2014). Age specific fertility rates (ASFR) are higher in rural areas compared to urban areas. PDHS 2017-18 shows that age specific fertility rate (expressed as per 1,000 women) is reducing from 51 children born per 1,000 women in 2006-07 to 46 in the year 2017-18 for the age group 15-19 years. ASFR for the age group 20-24 declined from 178 per 1,000 children born in the year 2006-07 to 171 children born in the year 2017-18 and also for the age group 25-29 ASFR declined in 2006 from 237 per 1,000 children to 215 in the year 2017-18 (PDHS 2006-07 and 2017-18).

Nationally, over half (53\%) of married women of ages 15 to 29 want to have more children in the near future, while about 30 percent want to wait two or more years before having a child. The remaining approximately 17 percent want to limit births. The desire to space or limit births is higher among urban women, while more rural women want to have a child within two years (See Table 1B in Appendix).

Figure 3.1 depicts fertility preferences among young women in different age groups nationally and in urban and rural areas. Comparing age groups, the desire to limit births is highest, as expected, among the oldest women in the group (ages 25 to 29), while women aged 20 to 24 have the highest preference to space births, presumably because they already have children. The proportion of women who are ready to have more children within the next two years is highest among the adolescent mothers (ages 15 to 19). This pattern is largely similar across urban and rural areas, with slightly higher proportions of rural women wanting more children, and slightly lower proportions wanting to space, or limit births compared to urban women. Another difference is that the proportion of women who wish to space births is higher among adolescent women (age 15 to 19 ) in rural areas and among 20 to 24 year old women in urban areas.

Figure 3.1: Fertility preferences among married women of ages 15 to 29 in Pakistan, by residence status and age group

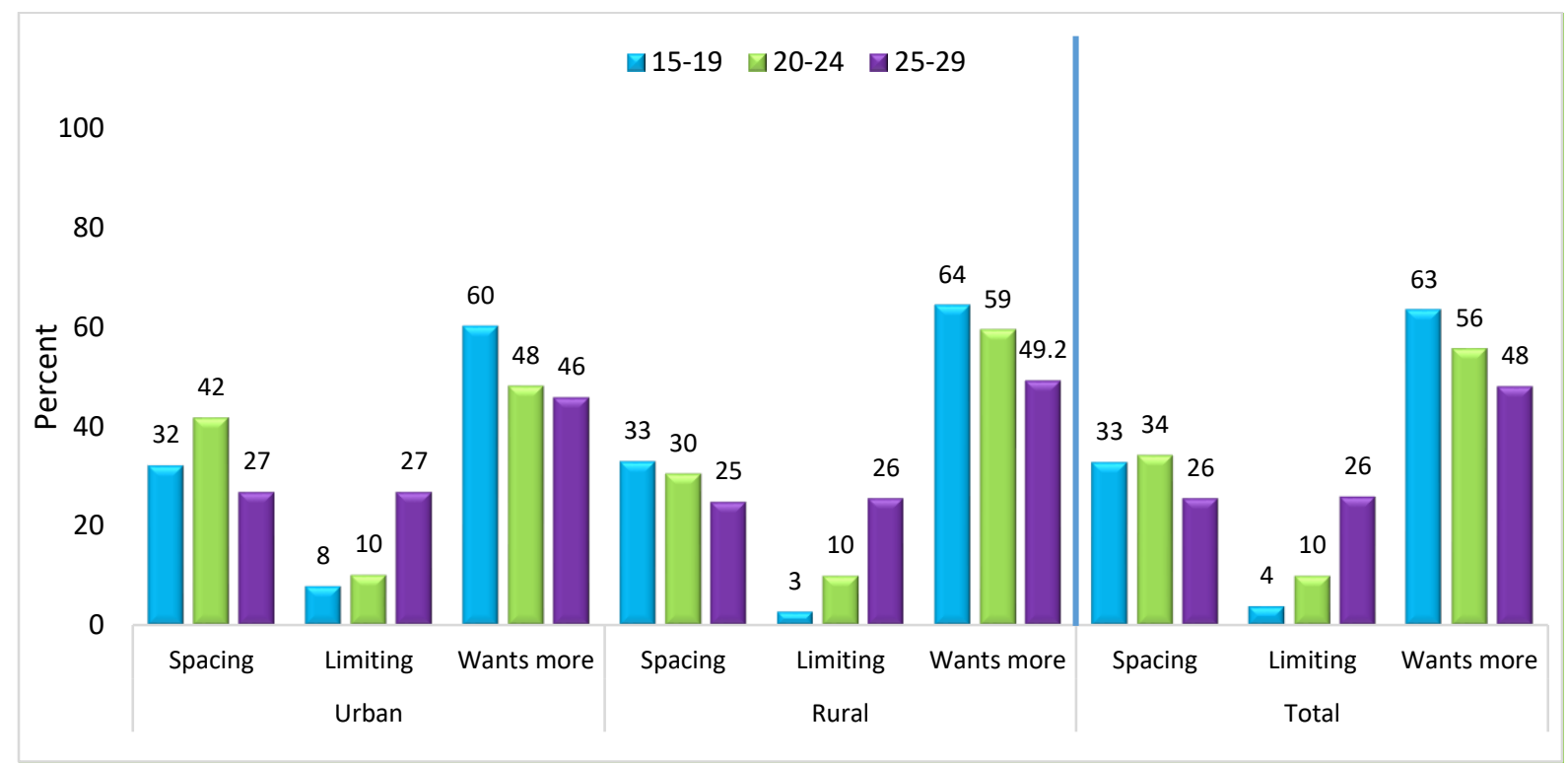

Source: Pakistan DHS 2017-18.

Note: wants within 2 years, unsure of timing, undecided = Wants more children

Wants no more and Sterilized (respondent or Partner) $=$ Limiting

Wants after $2+$ years $=$ spacing 
Figure 3.2 shows trend analysis of fertility planning status (whether their births/pregnancies in the 5 years preceding the survey were wanted at the time, at a later time, or they wanted no more at all). Data shows that the proportion of women of ages 15 to 19 who wanted their births/ pregnancies at that time has increased over the period from 89 percent in 2006 to 96 percent in 2018. This pattern also remains the same for other age groups. Interestingly, the proportion of women (age group 15-19) wanted no more children has also decreased from 1 percent in 2006 to almost zero percent in 2018. Moreover, the proportion of women of ages 15-19 who wanted children later is also declining.

\section{Figure 3.2: Percent distribution of births to women ages 15 to 29 in the 5 years preceding the survey, by} fertility planning status of the birth and by age group

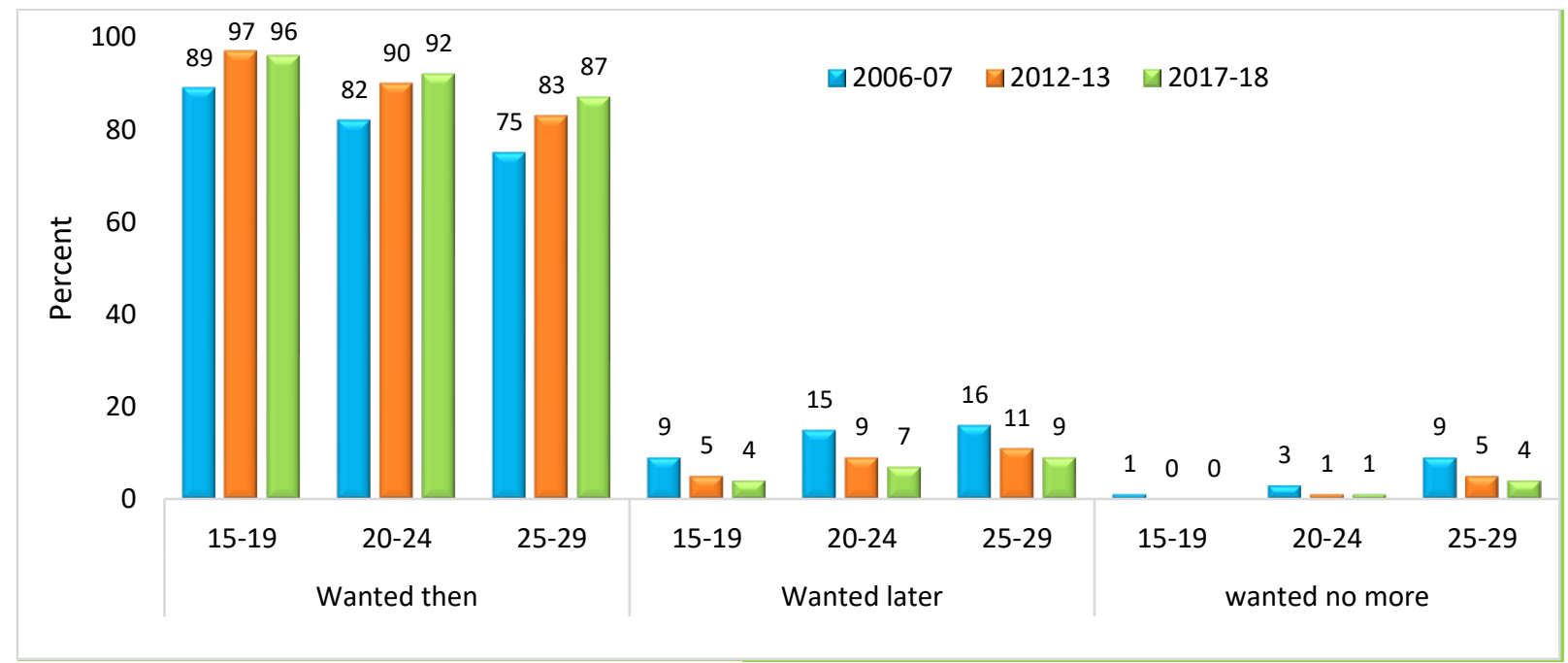

Source: Pakistan DHS 2006-07, 2012-13, and 2017-18.

\section{Family Planning}

Pakistan still has a very high fertility rate and most births in the country are occurring among women of ages 15 to 29 . About 97 percent of currently married women in this age group have heard of at least one method of contraception, modern or traditional (Table 3.2). Knowledge levels rise steadily with age, from about 91 percent of women in the 15 to 19 age group to nearly 99 percent among women of 25 to 29 years. Urbanrural differences are generally narrow. Among the regions, Balochistan and Sindh have the lowest proportions of women aware of contraceptive methods. Among adolescent married women (ages 15-19) knowledge of family planning is lowest in Gilgit-Baltistan followed by Sindh, and Balochistan. On the other hand, surprisingly a high proportion of young women in the relatively less-developed Federally Administered Tribal Areas (FATA) know about at least any one contraceptive method compared even to Punjab and the Islamabad Capital Territory (ICT).

Table 3.2 also shows that women belonging to the lowest wealth quintile and having no education are less aware of contraceptive methods compared to those in the highest wealth quintile and with higher educational attainment. The effects of wealth and education appear to be strongest among women of ages 15 to 19 and wane considerably by the time women reach the 25-29 age group. 
Table 3.2: Percentage of currently married women ages 15 to 29 who have heard of any contraceptive method, by age group and by background characteristics

\begin{tabular}{l|r|r|r|r}
\hline Background Characteristics & $15-19$ & $20-24$ & $25-29$ & $\begin{array}{c}\text { Overall } \\
\text { (15-29) }\end{array}$ \\
\hline Pakistan & 90.9 & 96.5 & 98.8 & 97.0 \\
\hline Residence & \multicolumn{5}{|l}{} \\
\hline Urban & 89.7 & 97.3 & 99.5 & 97.8 \\
\hline Rural & 91.2 & 96.2 & 98.5 & 96.6 \\
\hline Region & \multicolumn{5}{l}{} \\
\hline Punjab & 93.8 & 97.2 & 99.6 & 98.1 \\
\hline Sindh & 82.7 & 96.0 & 97.9 & 95.3 \\
\hline Khyber Pakhtunkhwa & 95.8 & 96.1 & 98.1 & 97.0 \\
\hline Balochistan & 84.3 & 91.6 & 97.7 & 93.1 \\
\hline ICT Islamabad & 90.2 & 94.5 & 99.2 & 97.0 \\
\hline FATA & 95.2 & 100.0 & 99.2 & 98.7 \\
\hline GB & 81.5 & 96.7 & 98.0 & 96.0 \\
\hline AJK & 83.9 & 96.2 & 98.8 & 97.1 \\
\hline Education & \multicolumn{5}{|l}{} \\
\hline No education & 88.7 & 95.4 & 98.2 & 95.8 \\
\hline Primary & 90.5 & 98.9 & 99.6 & 98.1 \\
\hline Middle & 96.1 & 98.2 & 98.6 & 98.1 \\
\hline Secondary & 94.5 & 96.3 & 98.9 & 97.5 \\
\hline Higher & 94.7 & 95.4 & 100.0 & 98.2 \\
\hline Wealth quintile & 84.6 & 95.6 & 96.7 & 94.4 \\
\hline Lowest & 90.6 & 95.4 & 99.3 & 96.5 \\
\hline Second & 93.7 & 98.3 & 98.9 & 98.0 \\
\hline Middle & 92.5 & 96.1 & 99.8 & 97.7 \\
\hline Fourth & 97.7 & 97.2 & 99.2 & 98.4 \\
\hline Highest & \multicolumn{5}{|l}{}
\end{tabular}

Source: Pakistan DHS 2017-18

Trend analysis of the last three series of Pakistan DHS data shows that current use of modern contraceptive methods increases with age among women of ages 15 to 29 (Figure 3.3). The proportion of young married women using modern contraceptive methods increased in 2012-13 compared to 2006-07 however, there is a slight stagnation or decrease in use of modern contraceptives in 2018 than in 2012-13 for all age groups. The reasons for low use of modern contraceptive in Pakistan are explained in a report by Population Council which include; social opposition, access to affordable and quality methods, availability of family planning methods and services, lack of counseling on reproductive health and method use among other important factors (Kamran et al. 2015). 
Figure 3.3: Percent of married women ages 15 to 29 years using any modern contraceptive method by year and age group

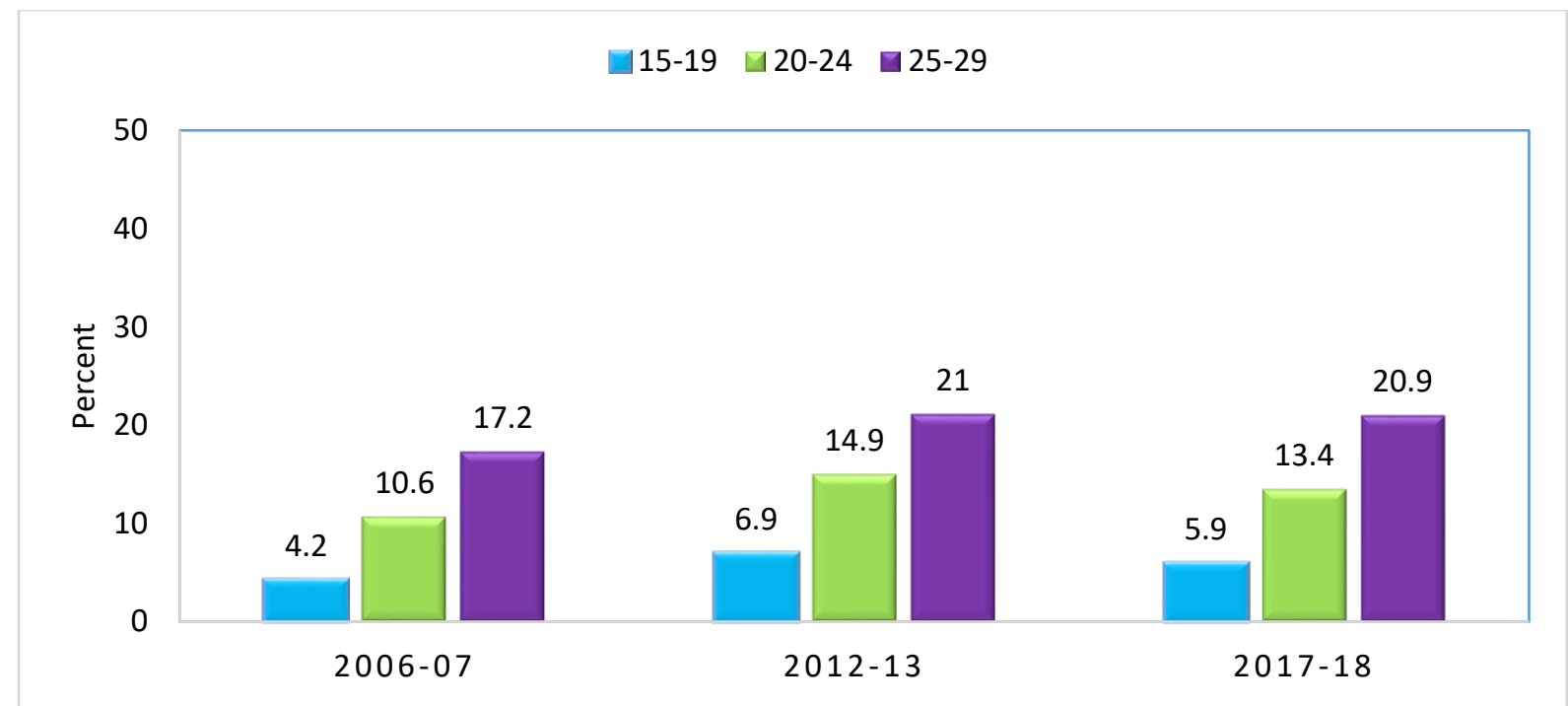

Source: Pakistan DHS 2006-07, 2012-13, and 2017-18.

Table 3.3 shows how contraceptive use (of any method) among married women of ages 15 to 29 varies with their region of residence, educational attainment and wealth status. A little above one fifth (22\%) of the women use any (Traditional or modern) contraceptives. This number is relatively higher in urban areas (29\%) relative to rural areas (19\%). At the regional level, use is lowest in Balochistan at only about 11.4 percent. The regional disparity is most prominent in the 15-19 age group, with a mere 3 percent of adolescent married women using contraceptives in Balochistan compared to 24 percent in ICT, 11 percent in Sindh, and 14 percent in Gilgit Baltistan (GB).

While 30 percent of young women (15-29 years) with higher education are using any contraceptives, only 17 percent of those with no education are doing so. However, surprisingly, in the 15-19 age group, these levels drop to 10 percent for women with higher education and 4 percent for those with no education. Age has strong implications for contraceptive use across residence, region, education, and wealth quintile (Table 3.3). 
Table 3.3: Percent of married women ages 15 to 29 years using any* contraceptive method by age group and by background characteristics

\begin{tabular}{|c|c|c|c|c|}
\hline Background characteristics & $15-19$ & $20-24$ & $25-29$ & Overall (15-29) \\
\hline Pakistan & 7.4 & 18.3 & 28.4 & 22.1 \\
\hline \multicolumn{5}{|l|}{ Residence } \\
\hline Urban & 14.4 & 23.8 & 34.9 & 29.0 \\
\hline Rural & 5.4 & 15.6 & 24.9 & 18.7 \\
\hline \multicolumn{5}{|l|}{ Region } \\
\hline Punjab & 5.5 & 19.7 & 30.0 & 23.9 \\
\hline Sindh & 10.5 & 15.5 & 29.2 & 21.7 \\
\hline Khyber Pakhtunkhwa & 8.5 & 20.6 & 26.3 & 20.9 \\
\hline Balochistan & 2.9 & 9.5 & 16.1 & 11.4 \\
\hline ICT Islamabad & 23.7 & 31.0 & 38.1 & 34.8 \\
\hline FATA & 4.1 & 14.6 & 19.3 & 14.5 \\
\hline GB & 14.0 & 28.1 & 24.3 & 24.6 \\
\hline AJK & 1.5 & 14.4 & 21.8 & 18.0 \\
\hline \multicolumn{5}{|l|}{ Education } \\
\hline No education & 3.6 & 14.5 & 21.8 & 16.5 \\
\hline Primary & 10.3 & 23.3 & 30.2 & 24.7 \\
\hline Middle & 10.7 & 19.1 & 32.3 & 23.9 \\
\hline Secondary & 16.1 & 22.8 & 34.7 & 28.4 \\
\hline Higher & 10.0 & 19.0 & 36.2 & 29.5 \\
\hline \multicolumn{5}{|l|}{ Wealth quintile } \\
\hline Lowest & 2.9 & 9.3 & 18.0 & 12.5 \\
\hline Second & 4.6 & 16.7 & 21.9 & 17.3 \\
\hline Middle & 8.8 & 21.4 & 30.2 & 24.0 \\
\hline Fourth & 6.3 & 23.3 & 32.6 & 26.6 \\
\hline Highest & 24.0 & 20.6 & 37.2 & 30.4 \\
\hline
\end{tabular}

Source: Pakistan DHS 2017-18

*Any traditional and modern method of contraception

According to MICS Punjab, use of any contraceptive method among young women (15-29 years) is same (24\%) as reported by PDHS 2017-18 for Punjab. In rural Punjab, use of any contraceptive method is about 22 percent compared to 27 percent in urban Punjab. Within the province, in the 15-19 age group, among administrative divisions, contraceptive use is lowest in Dera Ghazi Khan division at only 3 percent (See table $4 A$ in Appendix).

\section{Utilization of Maternal Health Services}

\section{Antenatal Care}

Access to antenatal care (ANC) services plays a critical role in maternal and newborn survival. As Figure 3.4 shows, about 89 percent of women of aged 15 to 29 in Pakistan who had a live birth in the 5 years preceding the PDHS 2017-18 received ANC from a skilled provider (i.e., a doctor, nurse, midwife, or Lady Health Visitor). The data indicates a clear advantage among urban women, of whom 95 percent received ANC from a skilled provider, compared to about 86 percent of rural women. Utilization of ANC has increased considerably in 
Pakistan since 2006, when it was 65.4 percent, and the increase has occurred in both urban and rural areas of the country.

Figure 3.4: Trend in percent distribution of married women of ages 15 to 29 who had a live birth in the 5 years preceding the survey who utilized antenatal care services, by residence

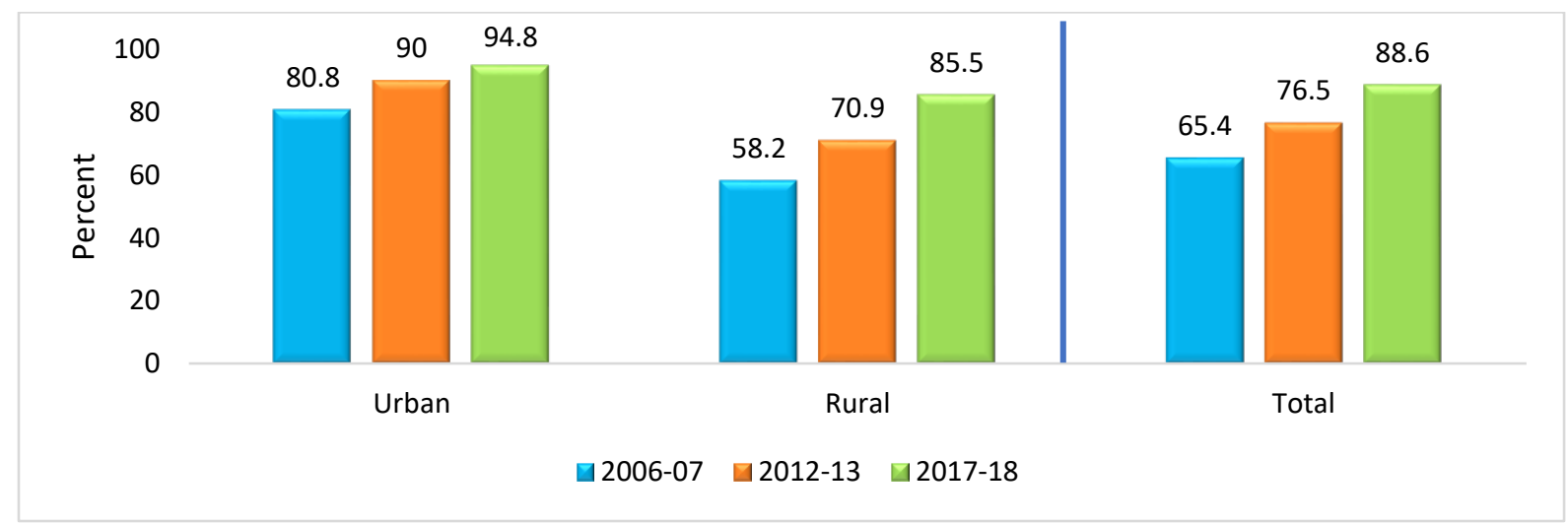

Source: Pakistan DHS 2006-07, 2012-13, and 2017-18.

Figure 3.5 shows that the wealth status has a positive effect on ANC coverage among young women: 74 percent of women in the lowest wealth quintile obtained ANC care compared to about 98 percent of women in the highest wealth quintile. The trend analysis also shows that the poorest households have seen a tremendous increase in access to antenatal care over the years compares to richest households.

Moreover, at the regional level, use of ANC among young women is highest in ICT (87\%) followed by Punjab (71\%), while KP (67\%) and Balochistan (55\%) lags far behind (PDHS 2017-18).

Figure 3.5: Trend in percent distribution of married women of ages 15 to 29 who had a live birth in the 5 years preceding the survey who utilized antenatal care services, by wealth quintile

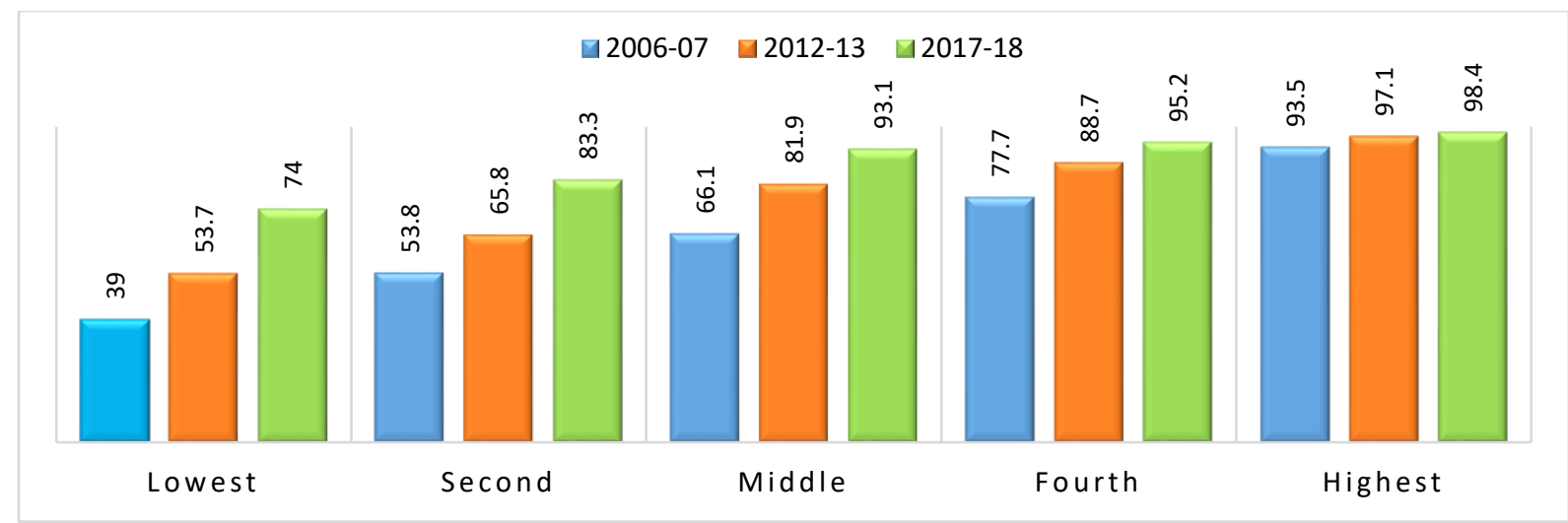

Source: Pakistan DHS 2006-07, 2012-13, and 2017-18.

According to MICS Punjab 2017-18, 89 percent of married women (15-29 years of age) who had live births received ANC from a skilled provider; proportion of these women in urban Punjab is 92 percent and in rural it is 88 percent (See table $2 \mathrm{~A}$ in Appendix).

\section{Delivery Care}

Delivery by a skilled provider under hygienic conditions is important to reduce the chance of infections and associated health risks for mothers and newborns. A little more than two thirds (71.4\%) of total births in Pakistan occur by skilled provider in the age group 15-29, including about 84.4 percent of births in urban 
areas and 65.3 percent in rural areas. The proportion of births in the age group 15-29 years attended by skilled providers is highest in ICT (84\%), compared to about 72 percent in Punjab, 77 percent in Sindh, only 39 percent in Balochistan, KP (72\%) (Table 3.4).

Table 3.4 also shows that educational attainment has a powerful effect: about 59 percent of women with no education deliver with the help of a skilled provider, compared to about 94 percent of highly educated women. Similarly, only half of those in the poorest wealth quintile deliver with the help of a skilled provider compared to about 95 percent in the richest wealth quintile.

Table 3.4: Percentage of births to married women assisted by a skilled provider, by age group and by background characteristics

\begin{tabular}{|c|c|c|c|c|}
\hline Background Characteristics & $15-19$ & $20-24$ & $25-29$ & Overall (15-29) \\
\hline Pakistan & 69.1 & 72.5 & 70.8 & 71.4 \\
\hline \multicolumn{5}{|l|}{ Residence } \\
\hline Urban & 77.8 & 82.2 & 86.3 & 84.4 \\
\hline Rural & 65.7 & 68.0 & 63.5 & 65.3 \\
\hline \multicolumn{5}{|l|}{ Region } \\
\hline Punjab & 68.5 & 70.5 & 73.8 & 72.4 \\
\hline Sindh & 84.0 & 80.6 & 73.9 & 77.0 \\
\hline Khyber Pakhtunkhwa & 74.7 & 80.1 & 66.5 & 71.9 \\
\hline Balochistan & 31.5 & 41.0 & 40.3 & 39.4 \\
\hline ICT Islamabad & 58.2 & 80.9 & 86.0 & 83.5 \\
\hline FATA & 53.6 & 53.2 & 56.2 & 54.6 \\
\hline Gilgit Baltistan (GB) & 90.0 & 80.0 & 68.0 & 73.0 \\
\hline Azad Jammu and Kashmir (AJK) & 51.5 & 59.1 & 66.4 & 63.5 \\
\hline \multicolumn{5}{|l|}{ Education } \\
\hline No education & 61.8 & 63.2 & 55.7 & 58.9 \\
\hline Primary & 71.1 & 74.1 & 70.5 & 72.1 \\
\hline Middle & 75.9 & 81.8 & 81.4 & 81.3 \\
\hline Secondary & 91.9 & 87.7 & 91.0 & 89.9 \\
\hline Higher & 100.0 & 93.7 & 94.1 & 94.0 \\
\hline \multicolumn{5}{|l|}{ Wealth quintile } \\
\hline Lowest & 63.7 & 55.7 & 46.2 & 50.9 \\
\hline Second & 51.1 & 69.9 & 55.3 & 60.5 \\
\hline Middle & 82.4 & 69.8 & 73.6 & 72.5 \\
\hline Fourth & 77.1 & 84.9 & 85.5 & 84.9 \\
\hline Highest & 94.9 & 91.7 & 96.0 & 94.7 \\
\hline
\end{tabular}

Source: Pakistan DHS 2017-18

Trend analysis depicts an upward surge in deliveries assisted by skill providers (Figure 3.6a). This increase is seen across various segments of the population, i.e., both urban and rural areas, among women with both low and high educational attainment, and across all wealth quintiles. However, despite impressive increases, Figures 3.6a to $3.6 \mathrm{c}$ also show that efforts to improve access to skilled delivery service providers must continue, especially for rural women in the age group 15-19, those with only elementary or no education, and especially for the poorest women. 
Figure 3.6a: Percent distribution of live births assisted by a skilled provider to married women ages 15 to 29 in the 5 years preceding the survey by region

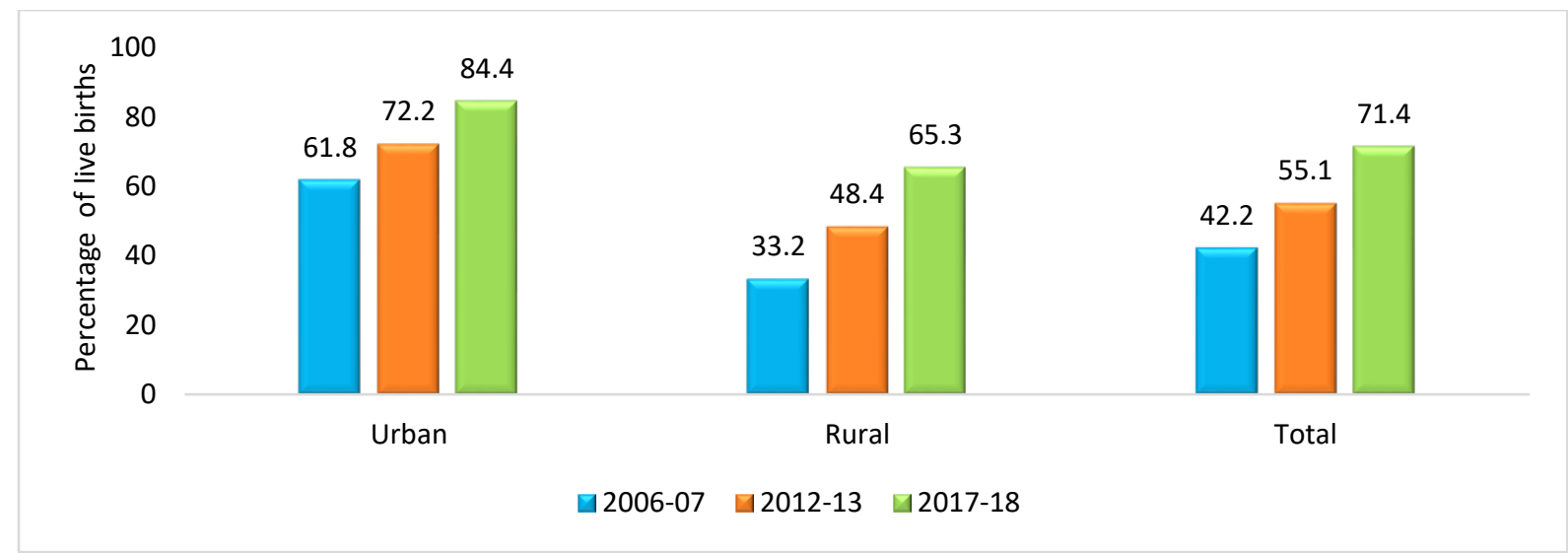

Source: Pakistan DHS 2006-07, 2012-13, and 2017-18.

Figure 3.6b: Percent distribution of live births assisted by a skilled provider to married women ages 15 to 29 in the 5 years preceding the survey by wealth status

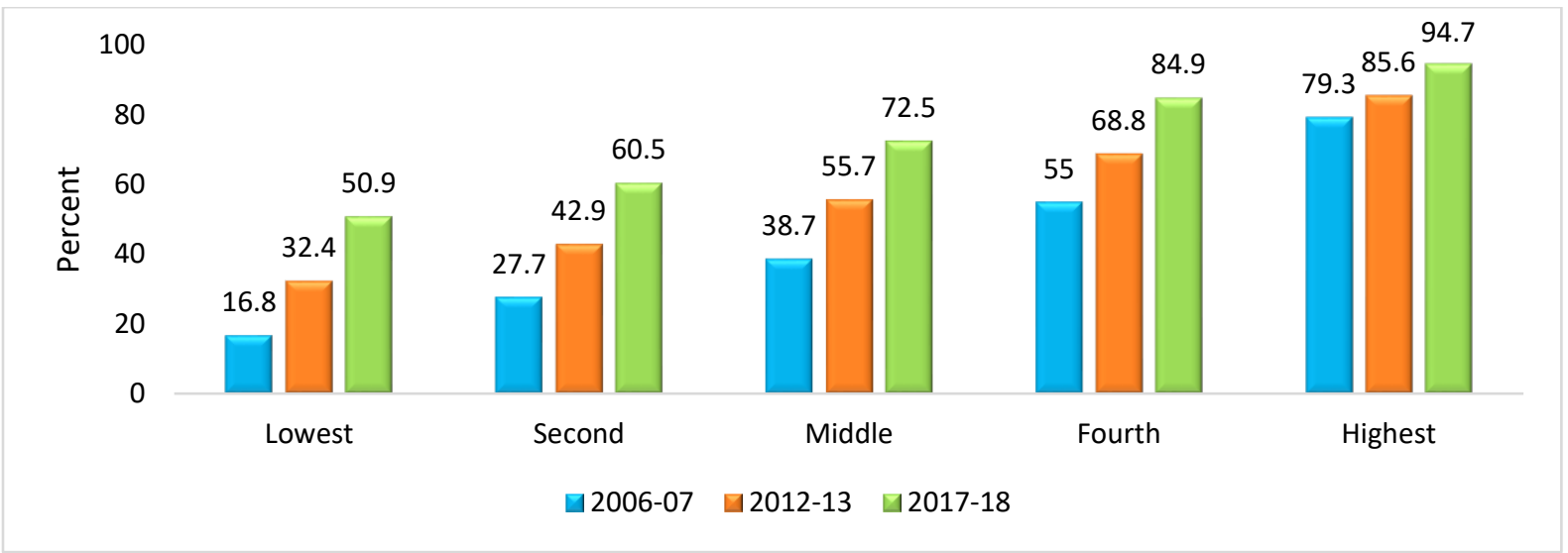

Source: Pakistan DHS 2006-07, 2012-13, and 2017-18.

Figure 3.6c: Percent distribution of live births assisted by a skilled provider to married women ages 15 to 29 in the 5 years preceding the survey, by educational attainment

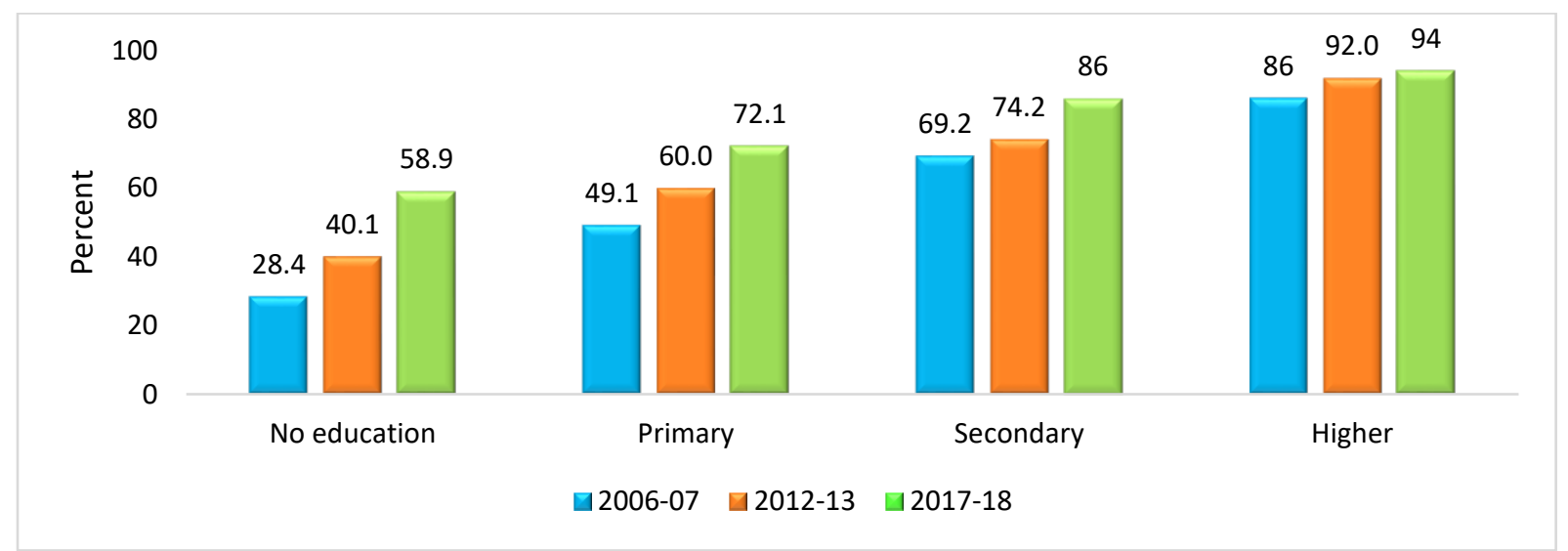

Source: Pakistan DHS 2006-07, 2012-13, and 2017-18. 
According to the Punjab MICS 2017-18, almost three fourths (77\%) of deliveries in the province occur by skilled providers. The proportion of births in urban areas that occur by skilled provider is higher in Punjab (85\%) than the rural proportion (73\%) (See table 3A in Appendix). Furthermore, in province of Sindh (MICS2014) shows that about $64 \%$ deliveries are institutional and 81 percent are in urban areas of Sindh and 50 percent in rural areas of Sindh province.

\section{Awareness of Rights}

Available data sets for Pakistan do not provide information on rights awareness among young people. In this analysis, we have used access to mass media, including radio, TV, and newspapers, as a proxy for knowledge about rights, since a number of private channels, leading daily newspapers and FM radio channels share messages related to HIV/AIDS; gender-based violence.; and legal, education, and health rights of young and adolescents. Among recent examples, drama serials have been aired recently on private TV channels on gender-based violence such as sexual abuse of young girls, harassment and acid throwing etc., male impotency, and intimate partner violence. An FM radio program has also been aired related to gender-based violence.

Based on PDHS 2017-18 data shows the proportion of women of ages 15 to 29 who read a newspaper, watch television, or listen to the radio at least once a week. About 4 percent of these women read the newspaper, almost half (50\%) watch TV, and 5 percent listen to the radio. Access to media is higher in urban areas, with 5 percent reading the newspaper, 70 percent watching TV, and 7 percent listening to the radio; in rural areas, these proportions are 4 percent, 40 percent, and 3 percent, respectively. Access to all three forms of media increases with education and wealth, although the effect is slight in the case of radio. Among women with no education, about 30 percent watch TV and about 4 percent read newspaper while $<1$ percent listen to radio. In the lowest wealth quintile, 16 percent of women watch TV and 3 percent read newspaper; in the highest wealth quintile these proportions are about 78 percent and 5 percent, respectively) (See 3B in Appendix).

In Punjab, MICS data shows that watching TV is a common practice among women 15 to 29; 71 percent watch TV at least once a week. Young women have lowest access to any kind of media in Dera Ghazi Khan Division and relatively highest in Rawalpindi Division (See table 5A Appendix). 


\section{Gender-based Violence}

As they transition from childhood to adult roles and relationships, such as marriage and employment, adolescents and youth may be particularly vulnerable to gender-based violence (GBV). According to PDHS 2017-18, about 26 percent of women 15-29 years old have faced GBV in Pakistan (See table 2B in appendix).

Figure 3.7 shows that percentage of married of ages 15-29 years who reported experience of gender-based violence by age groups and by residence status. Data suggests that the proportion facing violence is higher among married adolescents (32\%) while gender-based violence is higher in later age groups (20-24 and 25$29)$ in rural areas than urban areas.

GBV against young married women is most widely reported from FATA (55\%), Khyber Pakhtunkhwa (45\%), and Balochistan (40\%), and has the lowest prevalence in Azad Jammu and Kashmir (AJK) (10\%) and GB (15\%). Women belonging to the highest wealth quintile and having higher education are less likely to face violence compared to the poorest women and those with no education (See table 2B in appendix).

Figure 3.7: Percentage of married women of ages 15 to 29 who experienced gender-based violence by age group and by residence

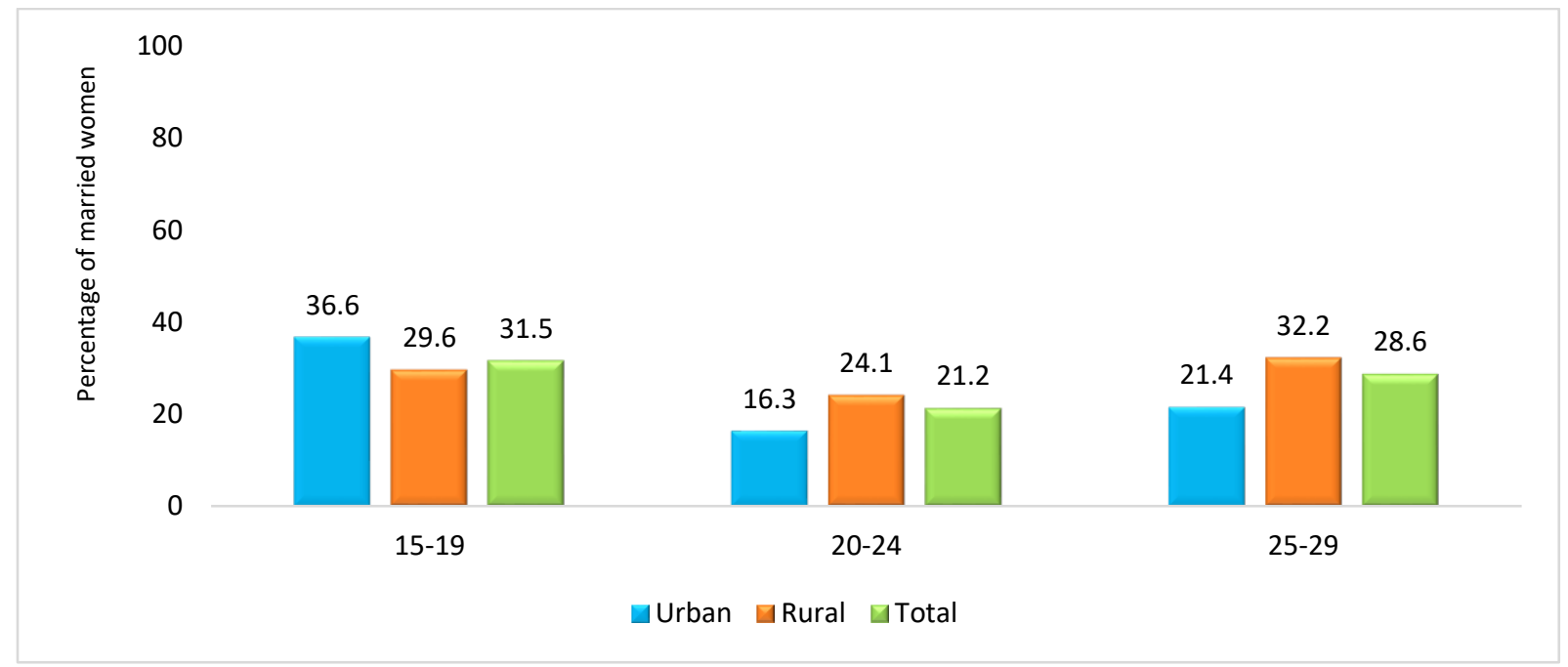

Source: Pakistan DHS 2017-18.

Comparison of the 2012-13 and 2017-18 PDHS shows that women's experience of physical violence has decreased in age groups of 15-19 and 20-24 however, still, slightly over one fifth of women in the 15-19 and 20-24 age groups and about one quarter of women in the 25-29 age group experience physical violence. 
Figure 3.8: Percentage distribution of married women ages 15 to 29 who have ever experienced physical violence by their husbands, by age group

50

40

30

24.4

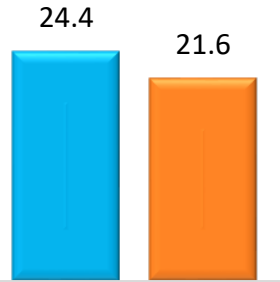

20

10

0

$15-19$

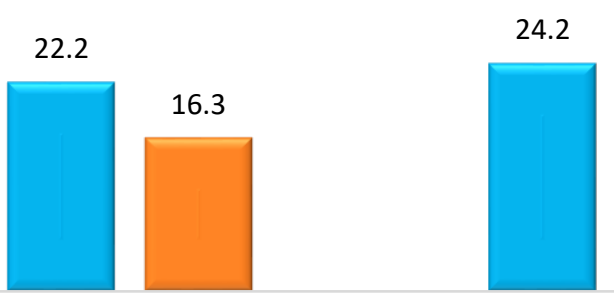

24.4

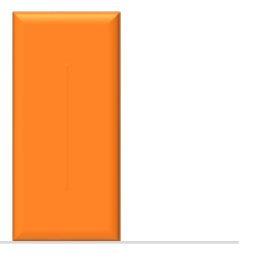

$20-24$

$25-29$

口2012-13 $\square$ 2017-18

Source: Pakistan DHS 2012-13 and 2017-18.

Punjab MICS data 2017-18 provides insights into attitudes about wife beating. The survey asks women respondents whether wife beating is justified in five hypothetical scenarios, including if the wife (i) goes out of the house without telling the husband; (ii) neglects the children; (iii) argues with the husband; (iv) refuses sex; or (v) burns the food. Among married women of ages 15 to 29, 22 percent felt that wife beating is justified in at least one of these five scenarios. This acceptance increases with age in both urban and rural areas. Overall, acceptance of wife beating is higher among rural women in Punjab (29\%) compared to urban women (13\%). Among the administrative divisions, D.G Khan and Sargodha have the highest level of acceptance of wife beating in any age group whereas Gujranwala and Lahore have the lowest. The data also indicates that educational attainment and acceptance of wife beating attitude are inversely related: as their educational attainment increases, women show lower acceptance of wife beating. This is also true for wealth: 35 percent of women belonging to the lowest wealth quintile accept any kind of wife beating compared to 11 percent in the highest wealth quintile (See table 6A in Appendix).

\section{Gaps in Available Data}

A number of gaps need to be addressed in existing data sets to help improve our understanding of the sexual and reproductive health of young people. (See Table 1A in Appendix). These include the following:

- Puberty (boys and girls) and menstrual hygiene issues for adolescent girls are not covered in any of the DHS, MICS and PSLM data.

- There is no information or longitudinal data available for the same men and women from infancy to adolescence or youth.

- Violence data are available only for married girls in PDHS and about perception of violence in the Multiple Indicator Cluster Survey (MICS), but no such data are available for unmarried females or males (15-29 years) in PDHS, MICS, or PSLM. (In addition to spousal violence, gender-based violence may be inflicted by parents, siblings, persons in the neighborhood, at school, or other public places. Children living with in extended family settings and not with their biological parents could also be victims of violence.) Moreover, available data does not cover frequency of violence or knowledge for taking recourse measures, such as awareness of laws against violence, helplines, etc. 
- PDHS and MICS cover mostly married men and women of ages 15-49. There are limited data available on sexual and reproductive health knowledge among unmarried males and females. PDHS and MICS must include the awareness as well as knowledge of adolescent and youth about their sexual and reproductive health and rights.

- There are no data available on knowledge among adolescent boys and girls about their sexual and reproductive health (especially very young boys and girls of 10-14 years of age). There is also a paucity of data regarding where they get information about sexual and reproductive health and rights. Data about adolescents in remote and rural areas are particularly lacking.

- Data are lacking on the extent to which the health sector (including public and private sector, as well as community-based workers) caters to the sexual and reproductive health information, counseling, and services needs of young people, especially if they are unmarried.

- Data are also needed on the role of social media (Twitter, Facebook, Instagram), if any, in creating awareness about sexual and reproductive health among men and women of all ages.

- Data on access to media are available in PDHS and MICS but details about the time spent and purpose for using various media are lacking.

- In addition, there is a dire need to conduct studies about the health challenges of Pakistan's transgender population, which was counted, for the first time, in the population census of 2017 (PBS 2018). 


\section{CHAPTER- 4}

\section{TRANSITION FROM CHILDHOOD TO ADOLESENCE - EXPERIENCES AND ISSUES}

After presenting literature review and secondary data analysis, chapters 4 and 5 are based on findings from qualitative study with focus on perspectives of unmarried adolescent boys and girls (ages 15-19), including both school-going and out-of-school individuals, as well as boys and girls with disabilities. Major themes of the research include puberty, marriage, fertility, family planning, utilization of reproductive health services, rights awareness, and gender-based violence. Chapter 4 focuses on knowledge about RH issues and rights among unmarried adolescents, and Chapter 5 describes their perceptions and preferences about RH services.

Puberty was the first reproductive health-related topic about which the study team talked to adolescent boys and girls. Of all the topics discussed, this topic elicited the most detailed and lengthy responses, perhaps because all respondents had first-hand experiences to share. In contrast, responses about issues like contraception and youth rights were relatively limited.

\section{Prior Knowledge of and Information Channels for Puberty}

Knowing in advance what changes puberty will bring to their bodies can help boys and girls be more prepared for the physical transition involved in adolescence. It can protect them from undue psychological or emotional stress when these changes begin to manifest. Accurate prior knowledge is also key for helping them avoid common misperceptions and myths, as well as any high-risk behaviors that could jeopardize their health and wellbeing.

During discussions about prior knowledge of puberty-related changes in their bodies, about two thirds of inschool and out-of-school girl respondents said they did not have any knowledge about menstruation or any other bodily changes until they directly experienced them. This was also the case for about half of the boys and girls with physical disabilities. In such cases, where puberty-related changes were only discussed after they had occurred, the girls commonly reported being shocked when they began menstruating, thinking that something was wrong with them, and not knowing whether to discuss the issue or who to share it with.

"I didn't have any idea at all. When I got my first period, I thought I had somehow got injured and was trying to figure out where I was bleeding from! Then my mother told me this is a natural part of growing up." In-school girl from Peshawar

"I didn't tell anyone when I got my period for the first time. I was in the classroom and got frightened when I saw that my shalwar (trousers) was drenched in blood. When I told my friend, she suggested I tell the teacher. After that, I was sent home and then my mother gave me a pad." In-school girl from Islamabad 
"I didn't know about it earlier. When I first got my period, I cried on the way home. My mother took me to another room and told me about it. In our family, and especially the Pushtoon setup, there's no tradition of sharing such information before you get your period. A school friend did discuss these issues, but I used to ignore her until I myself underwent these changes." In-school girl from Peshawar

The girls who had prior knowledge of puberty-related changes had usually been informed by family members, typically their mothers, older sisters, other older female relatives in their household, or cousins, who told them that they could start menstruating at any time after reaching the age of 10-12. Having prior knowledge of menstruation was not affected by the community to which the girls belonged, or their current schooling status. However, the majority of these girls were in school at the time they got their first period, suggesting that their relatives might have wanted them to be mentally prepared and equipped with supplies should they get their first period in school.

\section{"My mother told me before I went through it." In-school girl from Peshawar}

School-going girls had some advantage in having friends who have already experienced puberty-related changes, even though this channel provided them limited, and often only unclear, information. At times, they were unable to understand completely and therefore did not pay attention to peers. In some cases, schoolteachers became sources of information when they instructed students to come to school prepared with sanitary pads. A few girls from Peshawar also mentioned that they learned about menstruation from TV commercials for sanitary pads-although the commercials did not talk about menstruation, they raised questions that led the girls to find out about menstruation. However, this was not a commonly reported source.

"I knew about it beforehand. All my cousins were older than me. I used to observe them and asked about it. Then they told me that it happens to every girl. When you attain maturity, you will experience it." In-school girl from Peshawar

The information provided to girls about puberty-related changes pertained mainly to management of menstruation. To allay their worries, they were also counseled that all girls experience menstruation and it is necessary for reproduction.

Unlike girls, the majority of boys in each study location reported that they did have prior knowledge about puberty-related physical changes. Most boys had learned about these matters from their friends, religious clerics and mosque leaders, and from teachers and peers at school. Some boys shared that they learned about puberty independently, from their own experiences, or from books, social media (Facebook), or TV. A few boys also mentioned that their parents communicated with them about these changes, but they did so after the boys had reached puberty.

"I was told about these changes by friends and the imam masjid (mosque leader).... When a person gets older and undergoes puberty..., he has a discharge in his sleep and his sexual desire increases. I have heard the imam saying that when a person gets mature, he should be married off soon." In-school boy from Peshawar

"I was told of such changes, especially about nocturnal emissions, from my friends and from my teacher at the madrassa." In-school boy from Peshawar

"This is the era of the Internet and there is no need to ask anyone. We can search on the Internet." In-school boy from Karachi 
"Nowadays, kids are so clever at using the Internet. They also visit shops to download movies in their mobiles. So bad company leads them to become well aware of all these changes ahead of time." In-school boy from Karachi

Boys with disabilities usually reported being informed by male relatives, such as their father, brother, or brother-in-law and also by friends. They mentioned that family members guided them properly and in a positive way but, sometimes, friends gave them information that misled and frustrated them.

In focus group discussions in Islamabad and Lahore, a few boys reported that they had learned about pubertyrelated changes from peers who live in their communities and with whom adolescent boys commonly engage in sexual activities.

Very few boy respondents from Islamabad and Quetta mentioned that they had no prior knowledge of pubertyrelated issues.

"I didn't know of any such changes but now that I am older, I know." In-school boy from Islamabad

"No, I had no knowledge about puberty.... I never asked anyone, but when I myself went through the physical changes, I came to know." In-school boy from Quetta

\section{Puberty-related Health Issues}

The study respondents were asked how they felt about the changes in their bodies and whether they faced any health problems related to puberty.

Girls talked about several health issues that were mainly related to the menstrual cycle, including hormonal imbalances, acne issues, mood swings, blood pressure fluctuation, leucorrhea (white discharge), dysmenorrhea, nausea, backache, headache, pain in legs and abdomen, lethargy, weakness, vaginal infections, and mental discomfort

Vaginal discharge (Leukorrhea) is the most common issue girls report from all study settings (premenstrual stress). Among these issues, leukorrhea was the most commonly reported problem across all study settings. All of the girls with disabilities also mentioned this issue and said they were treated with home remedies.

\footnotetext{
"Excessive bleeding causes low blood pressure (BP). I have fainted many times due to Iow BP and it happens frequently on the first day of my period. It hurts a lot." In-school girl from Peshawar

"One of my friends has a leukorrhea issue. She says she has excessive discharge before getting her period, due to which she can't offer prayers because her trousers get soiled." In-school girl from Peshawar
}

For the treatment of health issues, girls' only source is their mother or other immediate female family members whose first response is to try and treat problems such as pain, weakness, and low blood pressure with home remedies. The girls said their mothers take them to see a doctor only if a problem gets severe and there is fever, infection, or excessive leucorrhea.

"My BP usually drops during my period. I get fever because of the pain. Once, I had some internal issue. My mother took me to the (female) doctor and had an ultrasound 
done. The doctor said I had an infection in my uterus because of which I had bleeding."

Out-of-school girl from Peshawar

"If periods are late it causes many internal problems. (I know) because I have suffered once; it causes weight gain and skin problems. I haven't got my period since two months ago, so I have a skin problem right now. I get better with skin medication." Out-of-school girl from Lahore

In general, boys were quite vocal about their transition through puberty; they were well prepared (having prior information through different channels) and seemed comfortable and satisfied with the change. Most listed multiple changes associated with puberty, including start of nocturnal emissions, hair growth, change of voice, urge to masturbate, increased interest in pornography, and in a few cases, urinary problems.

"After puberty begins, you need to take a bath because of the nocturnal emissions. Boys masturbate; it's a bad thing. After reaching puberty, we boys want to get married soon because, with mobiles and the Internet, boys can watch "foreign" (pornographic) videos and masturbate ... because of which they get weak. This is not a good thing." In-school boy from Peshawar

The majority of boys saw masturbation as a root problem that leads to health issues like weakness, urinary problems, and inadequate growth of reproductive organs. Sometimes, nocturnal emissions can also lead to these issues. The boys generally thought that a man cannot have children if he has masturbated excessively in his youth. In addition, out-of-school boys, particularly from Quetta and Peshawar, said they suffered from weakness, unusual rashes (in one case, in the groin area, especially testicles), and hoarseness. A few boys also complained about bladder infection (cystitis).

"After reaching puberty, I had the issue of nocturnal emissions. I had pain too afterwards, along with a frequent need to urinate. I went to a hakeem (herbalist) for this, and he gave me some herbs after which I recovered." In-school boy from Quetta

Unlike girls, who mainly shared issues with mothers and other close female relatives, boys reported that they share their health issues with friends and sometimes also with their fathers. If a health issue gets serious, they do not just seek treatment from doctors, as girls do, but also go to hakims and local healers.

"I had to frequently pass urine. My father took me to a local hospital where the doctor got my tests done and gave me medicine, and I have recovered." In-school boy from Peshawar

Boys with disabilities mentioned that if no older male relative is there in the family, they face greater problems in dealing with issues like nocturnal emissions and urinary tract infections. If any reproductive health issue seems serious, they visit a homeopath or hakim with their fathers or brothers. Unlike boys without disabilities, who can sometimes visit a hakim with a friend, these boys are always accompanied by a family member.

"I had a urinary tract infection. My father himself is a homeopath so he treated my

problem." Boy with disability from Islamabad

When asked whether they experienced any unique issues in accessing health facilities, boys and girls with disabilities in Karachi referred to hospitals and clinics that have been established by different organizations to especially cater to people with disabilities, where they find it convenient to obtain general health services. They also visit mainstream health facilities but their experiences there vary; at times, people mistreat them and fail to provide prompt services. The girls said they usually visit health facilities in the vicinity of their homes. One girl from Islamabad pointed out the need for ramps at all health facilities. 


\section{How Puberty Affects Adolescent Lives}

Talking about their experience of attaining puberty and how it affected their lives, girls said that they initially disliked the change, particularly the physical discomfort associated with menstruation, such as pain, weakness, and lethargy, which disrupted their normal routines. Menstruation days specifically also affected what they wore (dark colors are used to avoid stain visibility) and restricted them from going out, and hygiene could be difficult to manage, especially at school.

The girls perceive that puberty has led to some undesirable social effects such as restricted mobility; their parents no longer allow them to play outside the home. They are also required to wear the veil, avoid interacting with visitors, and take up domestic responsibilities, particularly if they are out of school.

"We are allowed to go outside in childhood but not now." Out-of-school girl from Islamabad

"When a girl becomes older, she doesn't look good wandering around outside the house. I had to pay attention to household chores, like cooking, taking care of younger siblings... helping my parents." In-school girl from Islamabad

"We are not allowed to go outside. Our elders don't like it. We are not allowed to open the door for visitors, and they also impose responsibilities on us, like doing household chores." Out-of-school girl from Quetta

However, in time, the girls said they started feeling comfortable in their altered situation and got involved in new activities they enjoyed, such as talking to friends, visiting their cousins, and using mobile phones.

"One gets restricted after attaining maturity. Childhood was good, but now it is fine too because I like chitchat with friends." In-school girl from Karachi

The girls perceived themselves to be adults, apparently having internalized social norms that equate onset of menstruation with adulthood. They expressed acceptance of menstruation as a natural process necessary for having the capacity to have children in the future and were aware that irregularity or absence of menstruation is associated with certain health issues, particularly infertility, which can lead to a number of social problems for a girl.

Interestingly, while girl respondents talked more about changes in social roles and responsibilities after reaching puberty, boys discussed both bodily and social changes at length. Their responses suggest that they all feel good about becoming 'mature.' They like their lives as youths, feeling more visible in their communities, and also more capable of shouldering household responsibilities. In particular, out-of-school boys from Karachi, who were engaged in different economic activities, already considered themselves adults. They considered puberty to be a transition from childhood dependence on family elders to a responsible, caretaking role of being bread earners for their households.

"We become young adults and recognized in society. This is a very positive aspect, to think about responsibilities at this age, but there are also some negative things related to this age as I discussed earlier (masturbation), which should be avoided." Out-of-school boy from Lahore

In marked contrast to girls, puberty is associated among boys with attaining more freedom and mobility, which also enables them to share issues related to sexual and reproductive health with friends, and to seek treatment for any health issues independently if required. However, their interaction with female peers does see a decline. Reflecting the stricter gender-segregation norms of Balochistan, a few boys from Quetta 
mentioned that after reaching puberty, their parents no longer allow them to interact with female cousins and ask them to play with boys their age.

"I feel that since I have become a youth, I am restricted from playing with girl cousins. My parents tell me to go outside and play only with boys." Out-of-school boy from Quetta

Some of the boys with disabilities also mentioned that their fathers imposed more restrictions on their interactions and communication with female cousins after they attained puberty.

A number of boys in all the study settings also mentioned saw puberty as a time when boys face risks to their sexual and reproductive health. Masturbation was frequently mentioned as a common bad habit with adverse health effects.

"I have a friend who developed a urinary problem due to uncontrolled masturbation. He visited Dr. Malik and then a government hospital for treatment." In-school boy from Lahore

\begin{tabular}{|l|l|}
\hline \multicolumn{3}{|c|}{ Effects of Puberty on Life - Gender contrasts } \\
\hline $\begin{array}{l}\text { Increased freedom and } \\
\text { mobility; household } \\
\text { economic } \\
\text { responsibilities; } \\
\text { increased propensity to } \\
\text { masturbate, watch }\end{array}$ \\
$\begin{array}{l}\text { pornography and (in a few cases) engage in } \\
\text { unsafe sexual activities including paid sex }\end{array}$ & $\begin{array}{l}\text { Mosponsibility for } \\
\text { household chores; } \\
\text { taking the veil; and } \\
\text { menstruation-related } \\
\text { discomfort, absence }\end{array}$ \\
\hline
\end{tabular}

\section{Menstrual Hygiene Management Issues}

While talking about the effects of puberty on their lives, the majority of the girls said that their lives were particularly affected by menstruation, not only due to associated health problems, but also because of the challenges they face in managing menstrual hygiene.

This problem was more emphasized by in-school girls who reported that the major issues they have to face arise at school. Most girls said they remained anxious at school that their uniform might get stained. For those studying in coeducational schools, this anxiety was especially severe. Many in-school girls said their school had an unsupportive environment, with no proper arrangements for change or disposal of pads in school. Because of this, they often chose to skip school during the earlier days of menses.

"We have no clean washroom. This is a big issue. And if I get my period in school, I bear the pain for half the day there.... I feel sick and want to sleep for seven days straight." Inschool girl from Quetta

“When I get my period, I don't want to get up (because my clothes might be stained). I feel awful. I feel particularly bad because there are boys at my school too. Usually, I get a stain while walking and it can be very awkward since there are boys around. I have to keep arrangements (pads) with me in my bag. My teacher also advises us to keep them and tells us to go to the washroom and change." In-school girl from Islamabad 
"We tried to not change our pad in college because there was no disposal arrangement. It was an order by the Principal and all the girls were forbidden to dispose of sanitary pads in the bin." Out-of-school girl from Quetta

However, in a few cases, where girls were attending private sector schools (in Peshawar and Karachi), they said their school environment was supportive: they had access to a bathroom facility, water supply, and sanitary napkins if they needed them, and so faced no challenge in menstrual hygiene management.

"I have never experienced any hindrance in school. Ma'am provides me a sanitary pad if I ever need it. Usually, I bring napkins with me to school." Out-of-school girl from Karachi

A few in-school and out-of-school girls also mentioned that they feel uncomfortable even at home during menses, afraid that their fathers or brothers might guess their condition. They found it difficult to change and wash their cloth pads because they could not occupy the bathroom for too long as other family members might want to use it.

"I can't take too long in the bathroom because someone else might want to use it." Out-ofschool girl from Islamabad

Some of the girls with disabilities mentioned that their mothers help them maintain menstrual hygiene.

\section{General Observations about Respondents with Disabilities}

Among the respondents in this qualitative study were 15 girls and 17 boys with physical disabilities, such as deafness, inability to speak, paralysis, blindness, and polio disability. These adolescents were identified through organizations working with people with disabilities in Islamabad and Karachi and asked the same questions as other participants in the study through two focus group discussions.

As a group, young people with disabilities were better informed, more communicative, and participated more actively in discussions than respondents who did not have disabilities. One reason could be that learning to live independently and confidently is an important part of their lives, and in the process, they receive more focused attention, guidance, and exposure for navigating health and other issues. The organizations working with them also conduct special activities designed to develop their communication skills, as well as awareness of their rights.

Notably, none of the participants mentioned any reproductive health challenge that was different from other respondents in this study. Their perceptions about puberty, early marriage, contraception, and other reproductive health aspects were the same as respondents without disabilities. In general, the boys and girls did not perceive their disability to be an obstacle in marriage.

It was observed, however, that young people with disabilities are slightly more dependent on family members for information related to reproductive health. While they do use social media, friends appear to play a more limited role in their lives compared to adolescents without disabilities. The girls rely on mothers, sisters, and cousins for information, while boys mention fathers, cousins, social media, and to lesser degree, friends as their main sources. 
Summary of Key Differences, by Gender

\begin{tabular}{|c|c|c|}
\hline $\begin{array}{l}\text { Prior Knowledge of } \\
\text { Puberty-related Changes }\end{array}$ & $\begin{array}{l}\text { Girls } \\
\text { Two-thirds did not have prior } \\
\text { knowledge of menstruation }\end{array}$ & $\begin{array}{l}\quad \text { Boys } \\
\text { Majority knew in advance about } \\
\text { puberty-related physical changes, } \\
\text { mainly from friends }\end{array}$ \\
\hline $\begin{array}{l}\text { Common Sources of } \\
\text { Information about } \\
\text { Puberty }\end{array}$ & Mothers, older sisters & Friends, social media \\
\hline $\begin{array}{l}\text { Puberty-related Health } \\
\text { Issues }\end{array}$ & $\begin{array}{l}\text {-Leucorrhoea, } \\
\text {-Menstrual issues including pain in } \\
\text { abdomen feelings of weakness, } \\
\text { pain in legs } \\
\text {-Psychological issues including } \\
\text { feeling of shame associated with } \\
\text { menstruation }\end{array}$ & $\begin{array}{l}\text {-Concerns with Nocturnal Emissions } \\
\text {-Masturbation related issues } \\
\text {-Urinary tract infections } \\
\text {-Sexually transmitted diseases } \\
\text {-Concerns with appearances/ delays } \\
\text { of secondary sexual characteristics }\end{array}$ \\
\hline $\begin{array}{l}\text { Effects of Puberty on } \\
\text { Life }\end{array}$ & $\begin{array}{l}\text { Mobility restrictions; responsibility } \\
\text { for household chores; taking the } \\
\text { veil; and menstruation-related } \\
\text { discomfort, absence from school, } \\
\text { and hygiene management } \\
\text { challenges }\end{array}$ & $\begin{array}{l}\text { Increased freedom and mobility; } \\
\text { household economic responsibilities; } \\
\text { increased propensity to masturbate, } \\
\text { watch pornography and (in a few } \\
\text { cases) engage in unsafe sexual } \\
\text { activities including paid sex }\end{array}$ \\
\hline
\end{tabular}




\section{CHAPTER- 5 REPRODUCTIVE HEALTH ASPECTS - KNOWLEDGE AND PREFERENCES}

The adolescent girls and boys engaged in this study have yet to experience post-puberty stages of their reproductive lives, such as marriage, reproduction, and maternal health care. However, their awareness, knowledge, and views about these subjects are relevant as predictors of future behaviors, and also to identify $\mathrm{SRH}$ information and counseling needs of young people. With this objective, the qualitative study asked boys and girls about early marriage and related issues, contraception, youth rights, cyber bullying and preferred sources to get reproductive health information.

\section{Early Marriage}

To gauge the study respondents' awareness about health implications of early marriage on girls, they were first asked about their perceptions about early marriage, specifically, which age they considered to be too early for girls to get married, their reasons for thinking so, and also how they had become aware of the issues. Girls were a focus of this topic early marriage has a toll on their health.

\section{Definition of Early Marriage}

The majority of girls and boys were of the view that a marriage is early if the girl is under 18 years of age. However, the girls generally defined early marriage as one in which the bride was under 18 years of age while boys generally defined an under-age bride as under 15 (Table 5.1).

\section{My sister got married at 15 and my mother also got married at a young age, but I think a girl should enjoy her life thoroughly before marriage because after that she can't do it." Out-of-school girl from Peshawar}

There were some additional interesting variations in responses by city. From Islamabad, in-school boys and girls seem to set a lower age limit than their out-of-school peers. In Peshawar, only in-school boys mentioned 18 years; everyone else defined a lower age. The highest age was suggested by the respondents from Karachi. In Lahore, responses varied more by gender and schooling status.

Adolescents with disabilities considered a marriage early if the girl was 15 to 18 years of age.

A most encouraging finding of this study is that almost all boys and girls, regardless of schooling status and study setting, were not only against early marriage of girls but were also able to identify the implications of such marriages in detail. However, a few girls mentioned that, while they personally saw it as inappropriate, early marriage was a custom followed in their family and culture. 
“One should get married at 20 but it is our family's custom to tie the knot before 18.

My cousin is younger than 18 years, but her age is reported as older in her marriage

papers." Out-of-school girl from Karachi

\section{Awareness of Issues Related to Early Marriage}

When asked why they felt marriage was "early" when the girl was less than a certain age, and what problems they thought were associated with early marriage, adolescent boys and girls spoke at length about both health and social implications. Importantly, boys were as aware as girls of the repercussions of early marriage. However, young people with disabilities generally only discussed health issues associated with early marriage.

Adolescents are all well aware of the health risks of adolescent pregnancy for both young mothers and their children and also social difficulties associated with this practice.

The majority of adolescent girls considered early marriage a root cause of various health issues, which they had observed. Notably, out-of-school girls talked about broader issues while in-school girls were able to articulate more specific problems. Out-of-school girls emphasized that young girls are physically weaker and mentally immature for heavy responsibilities of bearing and nurturing children. They were of the view that teenaged married girls usually experience medical issues like anemia, nausea, vomiting, miscarriages and malnourishment, depending on their pre-marriage health. When a young girl becomes pregnant or a mother, she becomes thin, weak, anemic, and unable to do domestic chores due to fatigue.

"My sister got married at a young age. She got pregnant, had a serious blood deficiency, and often got dizzy. She had to visit the doctor every two days." Out-of-school girl from Peshawar

"We see in our surroundings and have observed relatives and also overheard them say that a young girl can't take good care of herself or her children. She can neither give proper attention to her home, nor raise her children properly." Out-of-school girls from Quetta

"I have seen one of my cousins. She became thin and developed a vitamin deficiency (after she got married). She is very sick and now has freckles on her face." Out-of-school girl from Lahore

In-school girl respondents across the cities were well-acquainted with the possible severe health issues associated with early marriage. Most of them mentioned pregnancy and delivery-related complications, such as miscarriage, severe pain during delivery, and blood deficiency. They also identified problems like vitamin deficiency, weakness and fatigue, and nausea. A few respondents noted that girls who marry early become overweight, develop osteopenia (weakness of the bones), and experience excessive leukorrhea, and pregnancy can cause symptoms like breathlessness, vomiting, and blood pressure fluctuations.

Girls and boys with disabilities from Islamabad were also knowledgeable about medical repercussions of early marriage, such as complications a girl can face during pregnancy and delivery. They were of the view that a young girl is not physically developed enough to safely give birth to a child.

The in-school girls also associated early marriage with abuse of the child-bride. Moreover, a few respondents perceived that teenage pregnancy had added risk of miscarriage as well as birth defects.

"Not only is it child abuse, but girls also face many diseases and other health problems after marriage, like (difficult) delivery, weakness, and anemia." In-school girl from Peshawar 
"(Girls who get married early) sometimes have a miscarriage or give birth to a child with disabilities, and at times have to face other problems." In-school girl from Islamabad

"I heard from my friend that teenage girls face problems in delivery." In-school girl from Islamabad

"My cousin's wife was married young and got pregnant. She gave birth to twin girls. She died during the delivery and then her daughters too." In-school girl from Karachi

Discussions with boys suggest that they are quite knowledgeable about the implications of early marriage of girls, particularly if they are in school. Although they discussed issues in less depth than girls, most could identify a number of major problems caused by early marriage, including added health risks during delivery, increasing risks of maternal or neonatal mortality, and the likelihood that a teenage mother and her baby would be physically weak. The boys even mentioned that girls married at an early age faced mental health risks. A few pointed out that chances of disabilities were higher among children of teenage mothers.

"I observed the experience of my cousin, who was married in her teens. She died during pregnancy because she was not strong enough." In-school boy from Karachi

"A girl faces many issues. For example, she is not able to face the severe pain of delivery." In-school boy from Karachi

"Girls get anemic after early marriages and their blood pressure frequently fluctuates....A girl was married at an early age in our neighbor's household, and that's why she had a child with disabilities." In-school boy from Peshawar

"A mother's life can be at risk during delivery if she was married at an early age." In-school boys in Quetta

"Certainly, it will affect her health. She will become anemic and calcium-deficient. And girls become weak after a C-section too." Out-of-school boy from Lahore

Respondents spoke more about health implications of early marriages, but some also talked about associated social problems, mainly related to a girl's lack of mental and physical capacity to assume the heavy responsibilities of managing household chores and take care of children. Most respondents emphasized that a teenage girl could not run a house, and a few were also of the view that a teenage couple may face financial problems. Their responses also hinted at the stress a young wife and mother might feel, her emotional immaturity for bearing the burden of adult relationships and responsibilities, and the toll such a situation could take on her mental health and the marriage.

"They become weak and are unable to nurture their children. They argue and get depressed and give birth to an unhealthy child." In-school girl from Karachi

"Before 15-16 years, a girl cannot understand how to look after the children or household." Out-of-school boys from Peshawar

"Early marriage has many negatives. At a young age, a girl can try to understand and learn many new things, but she has to handle altogether different situations after marriage and may not be able to cope. Sometimes, she gets divorced." In-school boys from Peshawar 
"I know a girl. She got married at a young age and gave birth to twins, but after their birth she gave them up to someone else because she couldn't take care of them." In-school girl from Peshawar

"A girl from my village was tortured by her mother-in-law and brother-in-law if she did not perform the household chores perfectly." Out-of-school boy from Karachi

\section{Information Channels about Early Marriage}

When they were asked how they came to learn of issues related to early marriage, most girls and boys said they had learned from observing actual cases of early marriage in their family, network of friends, or community. They also learned about cases of early marriage from friends their age. Some of those who were in school also mentioned that the issue was discussed by their teacher, or that they had read about it in a textbook or other source, such as a newspaper article.

"My friend and I used to go together for Quran lessons. She got married at 16 and gave birth to twins. The doctor gave her an injection, but they couldn't handle her case and she died." In-school girl from Lahore

"My aunt got married in her teens. She was telling my mother about her problems on the phone. I heard their conversation." In-school boy from Islamabad

"We came to know about early marriage problems from friends at the madrassa (religious seminaries). We used to discuss it and worry when something happened to a girl who got married at a young age." Out-of-school girl from Peshawar

"I read an article in a newspaper about early marriage." In-school boy from Peshawar

Both girls and boys shared that their parents and other relatives did not commonly discuss such matters with them in their homes. However, they did occasionally overhear their mothers or elderly women in their household talk about these issues with other family members.

"We listen when the elders discuss these issues with each other at home, and sometimes we come to know about these things through the media." In-school girl in Quetta

"I overheard my mother talking to another woman about early marriage and the circumstances of a girl." In-school boy from Peshawar

A few respondents also mentioned that news and other programs on TV had built their awareness about early marriage and related health and social outcomes, especially coverage of incidents in their communities. In particular, young people with disabilities said that news and soap operas on TV were their main source of information about health complications associated with early marriage.

"There was an advertisement on TV in which a teenage girl was playing and also looking after a baby in a cradle." In-school boy from Peshawar

"I saw on TV that some people involved in early marriages were arrested by the police." Inschool boy from Quetta 


\section{Perspectives on Contraception}

\section{Knowledge of Concept of Family Planning}

A very positive finding is that all of 252 adolescent boys and girls who participated in the qualitative study were familiar with the concept of family planning. Everyone had at least a broad idea what FP is. However, unlike the topic of puberty, which they discussed in detail, the girls and boys had only limited knowledge about contraception. This is likely because they spoke about puberty from their own first-hand experiences, while phases like family planning have yet entered their lives.

Both adolescent boys and girls perceive contraception necessary to ensure a healthy interval between births and also to limit family sizes so that children could be well looked after.

"I heard that if a mother wants to give proper attention to her child, she should maintain a 2-year interval between children." In-school girl from Quetta

"There should be an interval between the first delivery and the next birth. Being human, (the urge for) intercourse may be uncontrollable so the couple should use condoms to space births." In-school boy from Karachi

Not only were girls and boys aware of the concept of family planning, they were also able to name a few specific family planning methods. The boys and girls generally mentioned oral pills, condoms, injectables, and intrauterine contraceptive devices (IUCD) however only one out-of-school girl mentioned implants. Respondents with disabilities had also heard about condoms, pills, and injectable contraceptives.

"I know there are injectables, pills, and the ring." In-school girl from Karachi

Observations by the research team during discussions with boys suggest that more of them may have known about condoms want to mention or disclose this fact. Further, school-going girls and boys were more aware of family planning concept than those who were out of school.

"I don't have complete knowledge about this topic... But I did see a poster at a BHU (Basic Health Unit) about family planning and the importance of a small family.... Also, I have heard from my (older) friend that he wants to space his children... Other than this, I don't know anything." In-school boy from Peshawar

\section{Information Channels on Contraception}

Generally, there was not much difference in the sources of information about contraception mentioned by girls and boys. Mainly, they had come to know about birth spacing through TV commercials and programs, friends, the Internet, and cousins. Some boys and girls also said they had overheard conversations about contraception between their mothers or other female relatives in the household and the LHW. A few girls from Quetta and some boys from Peshawar also mentioned that they came to know about family planning from posters about it at health facilities.

"Many a time, there are advertisements about the importance of family planning on TV." Out-of-school boy from Quetta

"My aunt told me that she had an injectable administered from hospital." In-school girl from Islamabad 
"My sister has a child two and a half years old. My mother told her she should ensure a gap of three years between her children." Out-of-school girls from Lahore

"A woman was talking to another woman in this advertisement, and she was saying, the next child will come when the first child is able to attend school." In-school boy from Peshawar

While sources such as TV, radio, posters, and overheard conversations gave the respondents a general idea of family planning, they had found out about specific contraceptive methods from close friends and social media channels.

Notably, girls from Lahore and Karachi also shared that youth organizations work in their areas and they conduct awareness sessions on girls' issues. They mentioned about family planning under the topic of health.

"A female representative of the PYG (Progressive Young Girls) Center used to tell us about girls' issues. She went door-to-door to gather people." In-school girl from Lahore

\section{Perceived Importance of Contraception}

Discussions with girls and boys suggest that they not only understand what family planning is, but also perceive it to be very important and can justify this view in some depth.

The majority, including adolescents with disabilities, are aware that the health of the mother and child are better preserved if births occur after a certain interval. Respondents mentioned that, in the absence of birth spacing, children might be undernourished, the mother might get thin and weak, and the health of both mother and child could be adversely affected. One also mentioned the risk of maternal death. Importantly, all respondents were aware that a certain interval is required between births to maintain good health, even though few were aware of the recommended length of that interval. In one case, a boy with disabilities had learned from a TV message that the birth interval should be two and a half years.

"With birth spacing, a girl remains healthy. Spacing of two years (also) makes her mentally strong." In-school girl from Islamabad

"A woman faces health-related issues.... She ages faster than men because of childbirth, because she gets weak from repeated deliveries... She can neither give attention to herself nor to her home.... and she suffers from anemia, dental issues, and joint problems." Outof-school girl from Peshawar

The respondents also mentioned grounds other than health for family planning, pointing out that when too many children are born without intervals, they cannot be nurtured properly. A few boys from Karachi also mentioned that family planning is important for a household's financial sustainability.

"Birth spacing is good for mother and child health. A mother can take better care of fewer children." In-school girls from Islamabad

"It is torture for children when there are 10-12 of them and the parents are unable to fulfill their basic needs. Those children don't live a prosperous life. We are nine brothers and sisters. My elder brother and sisters could not complete their education because my parents didn't have the resources." Out-of-school boys from Karachi

"It is necessary to practice family planning. One has to take care of all family members and (especially) the children." In-school girl from Lahore 
Interestingly, a school-going boy from Islamabad was aware that the Chief Justice of Pakistan had recently taken notice of Pakistan's high population growth rate.

"Once, the Chief Justice himself said the population is growing so fast, each household should have no more than two children." In-school boy from Islamabad

\section{Intention to Use Contraception in Future}

The respondents were asked whether they would use contraception when they got married. Almost all girls and boys, regardless of schooling status and city, shared not only that they would practice family planning but also that they preferred to have only two children because then they would be able to fulfill their needs and provide them a good education, and also ensure the health of the mother. The data do not indicate any significant difference in this intention by gender, schooling status, or region. Young people with disabilities also said they wanted to adopt family planning in the future, with the boys even saying they would elicit the help of their cousins or other male family members to obtain information at the time. Most felt that a family should have two to three children, although the boys said the decision should depend on the resources available for the children's education and upbringing.

Interestingly, girls and boys from all cities were keen to use family planning methods to protect their future health, and that of their future wives. They especially mentioned that they would like to use contraceptives because intervals are necessary to allow mothers to rest.

"I will use condoms to keep an interval between births." Out-of-school boy from Islamabad

"Yes, I will keep gap an interval of 2-3 years between births to live a healthy life because a woman becomes weak with alternate frequent deliveries." In- school boy from Islamabad

Boys even mentioned that they would avail family planning services with the help of doctors and family members after they got married, indicating how earnest they are in their intention to space births-and also underscoring the importance of male outreach in family planning service provision.

"First of all, we'd like to learn about the details of family planning from any quality source." In-school boy from Lahore

\section{Knowledge about Youth Rights}

Before young people can assert their rights or raise voices to ask for them, they must know what their rights are. In discussions and interviews with young people, they were asked what they believed to be their rights, and the extent to which they felt their rights were protected in society. Respondents were first asked what they considered to be part of basic human rights, and then asked to describe what they believed were their rights as youth, and also their rights as young women or men.

It is noteworthy that the majority of respondents had far less to say on this topic than they did for others. This could be because the other topics discussed with them related to concrete aspects of life that they have either experienced or at least observed, and which they have heard discussed among people around them. On the other hand, rights are not commonly discussed with them, and awareness building activities are largely lacking. However, boys and girls with disabilities were generally more knowledgeable on this subject.

\section{General Human Rights}

When asked about human rights, the girls and boys mentioned a few general rights based on their own understanding and opinions, but not on knowledge of any charter, law, or other formal source of rights. Girls and especially boys from Islamabad and Peshawar were more vocal on this subject. In-school as well as out- 
of-school girls and boys gave similar responses. The majority were of the view that human rights refer to the right to fulfilment of basic needs such as food, shelter, education, and inheritance. However, some did mention more abstract rights, such as freedom of religious practice, consent in marriage, the right to employment, and freedom from harassment.

"In my view basic human rights only include the right to have healthy food, good clothing, (a basic) standard (of) living, and above all, quality education." In-school boy from Quetta

"In my view, a basic human right is to attain education... other than this, the right to earn, access to food and water, right to acquire a residence, health, and to marry with one's own will-these are among the primary human rights." In-school boy from Islamabad

"It is included in human rights that one should have access to two meals a day, be able to practice one's religion, attain education, have employment, and no one should harass a person." Out-of-school boy from Peshawar

Compared to other groups, boys with disabilities from Islamabad were more aware about human rights, especially the rights of people with disabilities. They shared that people with disabilities are often looked down upon or ignored. Instead, they wanted to be considered equal to other people and provided equal opportunities to education, movement (mobility), health services, marriage, and job opportunities, and also facilitated at public places through special arrangements.

"People say that persons with disabilities should not get married, but every person should get a chance." Boy with disability from Islamabad

"We should get the same employment opportunities that are given to others. We are just as 'normal' as others-the only difference is that we are differently able! People consider us inferior, but every individual has dignity and feelings, regardless of whether they have a physical disability." Boy with disability from Islamabad

Among general human rights, boys with disabilities were aware that there are laws in Pakistan to protect women's rights, prohibit child labor, and ensure free education of children. They were also aware that it is the responsibility of the government to protect human rights, but enforcement mechanisms are lacking.

Unlike the boys, girls with disabilities from both locations did not know much about human rights. However, they spoke about the right to education and to mobility.

\section{Rights of Youth}

In discussing the rights of youth, the girls and boys emphasized three key spheres marking their transition to adulthood, including education, marriage, and employment. They spoke about the rights of young people to education, their right to choose their spouse, and the right to suitable opportunities for employment. A few respondents elaborated that youth have the right to obtain proper jobs commensurate with their educational attainment, and the government should provide such opportunities to all youth. In addition, a few boys from Peshawar also mentioned the right to free speech, having a residence, and health services.

"The government should provide us a job. Homeless people's right to shelter and health should be protected." Out-of-school boy from Lahore

"I know that youth rights are protected in Pakistan in terms of education, nationality, and inheritance." In-school boy from Karachi 


\section{Gender-specific Rights}

When asked about any specific rights related to their gender, both girls and boys spoke specifically of girls' rights. This could be because much of the discourse around gender-specific rights in Pakistan tends to revolve around improving the status of girls and women. While in-school adolescents were relatively more vocal on this subject, responses from all respondents were most specific and heartfelt in this part of the discussion.

The right mentioned most frequently and by the majority of girls and also by boys was girls' right to choose their spouses, through girls' involvement in marriage-related decision-making. Girls from all settings complained that they are not permitted to exercise this right and stressed that parents should ask the will of a girl about her spouse. While a girl's consent is legally required for marriage in Pakistan, these responses suggest that it is not ensured in practice.

"A girl should have the right to choose her life partner and education should be provided to girls just like boys." Out-of-school girl from Islamabad

In addition, a few girls in Lahore were aware that there is a law prohibiting marriage of girls under the age of 18.

"Until a girl reaches the age of 18 , she is not allowed to get married according to Pakistani law." Out-of-school girl from Lahore

Other frequently mentioned rights included girls' right to education and to their share in inheritance. Some of the respondents spoke against the culture of gender discrimination and said that girls should be given equal rights to education and mobility.

“Sometimes people don't focus on the education of girls, although our Prophet (peace be upon him) said that getting an education is mandatory for both men and women." In-school boy from Islamabad

"Girls should have the same rights as boys. They should be provided a good education, healthy diet, and a share in inheritance. In-school girl from Quetta

"Getting an education is our right." In-school girl from Lahore

"Girls should have the right to get an education, but parents say we will marry you soon. Islam also allows girls to get an education. Parents should ask the girl who she wants to marry." Out-of-school girls from Lahore

Notably, in a few cases, the girls expressed the confidence to assert their rights against the odds; notably, they were aware that the rights were likely to be infringed by their own male relatives.

"I can claim my inheritance right through the police if I'm denied by my brother... and if my husband doesn't value me and treat me well, I can go to court and avail my due rights." Out-of-school girl from Peshawar

A very small number of boys from Peshawar and a few girls from Islamabad further mentioned girls' right to be safe from sexual harassment, and to be protected against the risk of rape, which they considered to be too common in some districts of Pakistan.

"Many girls get abused, so there should be protection for them, and they should be provided justice. Aid should be provided to victims. One should take stand for the sufferers and help them." In-school girl from Islamabad 


\section{Protection of Rights in Pakistan}

When the respondents were asked whether they knew of any mechanism, law, or institution dedicated to safeguarding their rights, the majority responded in the negative.

"I think that there is no law or institute that safeguards human rights." Out-of-school boy from Peshawar

"Rights are not provided in Pakistan. Islam talks about equality but there is no institution that works for girls' rights." Out-of-school girl from Islamabad

"Girls and boys have the same and equal rights to everything.... but I don't know of any institution that protects one's rights, though there may be many present." In-school boy from Peshawar

Only a few respondents were aware that laws exist in Pakistan to protect their rights. The respondents were unable to name any law that protected their rights. However, they did identify the police department as a mechanism that works to protect people's rights.

"Rights are given to females in Pakistan and there is the police to protect citizens." Out-ofschool girl from Quetta

"The police is there to protect individual rights. The police is the only department that can help protect individual rights." Out-of-school boy from Karachi

However, a few respondents from Islamabad and Peshawar were aware of laws in Pakistan against child labor.

"Existing laws prohibit the forceful involvement of children in work. If any culprit is found he or she can be sent to jail for six months." In-school girl from Islamabad

\section{Cyberbullying and Harassment}

The topic of cyberbullying was of special interest to the majority of adolescent girls and boys. Almost all respondents, including those with disabilities, were aware of at least some ways in which cyberbullying can be carried out. They discussed the forms of cyberbullying, who the victims and perpetrators were, and the effects of cyber bullying on a victim's life. In general, the respondents talked about cyberbullying carried out through mobile phones, and the majority considered boys to be perpetrators and girls to be victims. When respondents discussed the effects of cyberbullying on a victim's life, they spoke exclusively of cases where girls had been the target.

\section{Forms of Cyberbullying}

The most frequent forms of cyberbullying mentioned by the majority of both boys and girls included undesirable mobile text messages, calls, and messages on social media, particularly WhatsApp and Facebook, from fake accounts created to harass others. Most respondents said cyberbullying or teasing is very commonly perpetrated by boys and sometimes by girls as well. A school-going boy from Karachi was of the view that people are more susceptible to cyberbullying in Pakistan because they are less informed of digital technologies and the ways they can be manipulated. On the other hand, some boys with disabilities commented that mobile service providers had made social media access highly affordable, enabling users to indulge in negative activities for free. 
The different manners of teasing or bullying mentioned in discussions included use of abusive language, sending unwanted messages, taking photographs or making videos of girls and then blackmailing them, spreading word or rumors about girls being in a relationship with the perpetrator, and sharing offensive videos and pictures through WhatsApp and Facebook-mainly by boys.

"Boys blackmail girls by taking their pictures." Out-of-school girl from Peshawar

"Some girls give their mobile number to boys, who then share it with other boys." Out-ofschool girl from Islamabad

\section{Perpetrators and Victims}

Almost all the respondents across all cities shared that mainly girls are at the receiving end of cyberbullying, in the form of harassing messages and calls on social media from boys. Girl respondents also perceived that since boys have more frequent and easier access to mobile phones, they are more likely to perpetrate cyberbullying or harassment.

"It is a common thing now... people do harass ... and stoop to low down activities, especially boys who use mobiles to harass girls." Out-of-school girl from Karachi

"Boys call unknown girls and try to strike acquaintance with them." In-school girl from Karachi

"There are many fake accounts on social media. I think girls suffer more due to lack of information and awareness." In-school girl from Quetta

However, a few of the boys reported that such issues are found among both boys and girls, and both fool each other through social media.

\section{Effect on Lives of Girls}

In general, respondents were clear that girls are more likely to be the target of cyberbullying. Both boys and girls were able to discuss the effects of such bullying or harassment on the lives of girls, but girls were far more articulate, frequently drawing on their own experiences or observed experiences of girls in their circle, which enabled them to offer insights that boys were less aware of. Importantly, both in-school and outof-school girls participated actively in this discussion, sharing several actual incidents where somebody in their family or

Girls being victim generally lack support and fear punishment from parents, which can range from greater restrictions on their mobility and mobile use to beatings, being withdrawn from school, and even being forced into early marriage. among their friends had faced some form of distress as a result of cyberbullying.

Respondents alluded to a wide range of specific life impacts of cyberbullying. Girls confront psychological stress from the bullying, but this stress escalates further if their parents or other family members discover the situation. Respondents universally conveyed that girls can expect no support from parents or other relatives. On the contrary, even as targets of cyberbullying, they are likely to be blamed and punished in a range of possible ways including physical beating, restrictions on mobile use and going out, withdrawal from school, and even early marriage as a 'solution' for avoiding scandal.

"A boy used to tease a girl on phone.... and her family pulled her out of school." Out-ofschool girl from Quetta 
"If there is a call from any unknown number and a girl picks up, and family members find out, they think the worst of her... They give her a hard time." Out-of-school girl from Lahore

"A boy made a fake account on Facebook and asked my friend for her picture. She sent him her photograph because she didn't know it was a boy. She stopped using social media after that incident." In-school girl from Lahore

"Boys often record the voice of a girl or share a picture she has shared with the other boys. This badly affects that girl's life." Out-of-school boy from Karachi

"Parents don't allow girls to go outside, even for shopping." In-school girl from Islamabad

"It is usually mothers who come to know about these things, and they say that the girl can't stay at home any longer so she should get married." Out-of-school girl from Lahore

Girl respondents elaborated that cyberbullying not only causes psychological stress at the time it occurs but can do lasting social damage by tarnishing a girl's reputation, particularly, if her pictures are being shared through social media. These may be ordinary pictures that a girl has shared with somebody she believes to be a female friend, who is actually a boy with a fake account, or a secret boyfriend who makes her pictures or numbers public to harass her. At times, cyberbullies may even create compromising pictures of girls by editing their photographs. Suffering such an attack can greatly diminish the social acceptability of girls, affecting their marriage and life prospects, and causing great distress to them and their parents. A number of girls, particularly from Quetta, mentioned a recent incident where videos of some girls were recorded by hidden cameras at an academic institution, and then shared on social media by perpetrators demanding a heavy pay-off. The resulting psychological trauma was so great for girls and their parents that one girl committed suicide.

"If a girl is being considered for marriage and her pictures are seen by her prospective inlaws on Facebook or WhatsApp, then she might be assumed to be having a bad character." Out-of-school girl from Lahore

"Girls are restricted to their homes, and some girls commit suicide." In-school girl from Islamabad

Even when girls are not being cyberbullied, interacting with boys on social media or mobile phones exposes them to great risks. This is highlighted in some of the cases mentioned by the girls from their own surroundings, especially in Lahore and Karachi.

"My friend used to talk to a guy. She shared her personal matters, and her parents came to know about it, and then they forced her to marry another boy." In-school girl from Karachi

"A friend of mine used to talk to a boy and one day they fought with each other. Afterwards, that boy threw acid at her." In-school girl from Karachi

Girls and boys do not have to look far to learn about cyberbullying; they find examples close at hand among their own families, neighbors, and peers. Clearly, it is mostly girls who bear the brunt of the repercussions. Discussions with boys suggest that, in many cases, they think they are simply indulging in harmless fun to tease girls or engage in a relationship with them, not realizing the serious impacts on girls' lives. There is a need to educate both girls and boys about the adverse effects of cyberbullying, especially on girls and their parents, and also how to cope. 


\section{Preferred Sources for Reproductive Health Information}

The boys and girls were asked what channels they would like to receive information from about reproductive health, in order to identify the sources that they can access comfortably and also trust. Interestingly, boys mentioned a wider range of sources compared to girls, whose choices were mainly limited to mothers, educational institutions, and community-level information services. The preferred sources mentioned by girls and boys, including those with disabilities, are discussed below.

Health professionals and forums were preferred by the majority of girls and boys, who said information should be provided to young people by doctors or a health center. Boys particularly suggested that health centers should be available in the vicinity of communities, which should organize medical camps and awareness sessions in the community from time to time. Services and information should be provided without charge, and through separate facilities for girls and boys. Respondents from Lahore shared that many people visit hakeems for treatment of puberty-related weakness and other problems. Therefore, hakeems can counsel or treat them well for other reproductive health related issues as well.

\section{"If boys and girls are separately given this information by male and female doctors then it will be beneficial for girls because they will be comfortable getting this information from a lady doctor." Out-of-school boy from Islamabad \\ "People should be gathered at a specified place in the community to give this information." In-school girl from Islamabad}

Family members and peers were mentioned as a preferred source by both in-school and out-of-school girls and boys from all settings. Girls mainly wanted to be informed by their mothers or sisters, and boys by fathers or brothers. Both also preferred to get information from married friends, although boys were also willing to learn from unmarried friends of their own age.

Information and communication technology and media were mainly preferred by boys, who wanted to obtain information about reproductive health from the Internet, mobile phones, TV, newspapers, and social media. They also suggested toll-free helplines where they could ask questions without any pressure or embarrassment. In addition, they wanted printed handouts about reproductive health.

Education forums and venues: Both boys and girls proposed that information about reproductive health should be provided by teachers at school, in separate sessions for boys and girls. Some of the adolescents with disabilities even suggested that information about reproductive health should be incorporated in school syllabi and learning materials should be accurate and socio-culturally appropriately worded.

"Teachers should talk about reproductive health once a week." In-school girls from Islamabad

"Awareness regarding reproductive health should be created among boys and girls by teachers." In-school girls from Quetta

Notably, a few boys also proposed religious educational forums, such as madrassas and Quran teachers as preferred sources, while one respondent urged that books be provided to young people.

"I read a book written by Dr. Zakir Naik (religious scholar). All types of relations between husband and wife and other necessary information were mentioned in this book." Inschool boy from Islamabad 
Private organizations: NGOs can provide this information, Girls mentioned that all should be gathered at one place and tell them about these changes. This information should be conveyed in this way that one doesn't hesitate.

"NGOs should provide this sort of information about puberty-related issues and their possible treatment. (There could be) a community-based focal person, similar to the WASH representative who gave us information about malaria." In-school boy from Quetta

"Doctors and hospitals should be more approachable. Medicines should be provided for free. Parents should take out time for children and tell them about these issues." In-school girls from Islamabad

"Females should be assigned to tell these things to girls." In-school girls from Islamabad.

Notably, out-of-school girls especially pointed out that many girls are homebound and cannot go out to obtain information. For such girls, measures should be taken to provide them information at their homes.

"There are those who are not allowed to go outside, so information should be provided at their home." Out-of-school girls from Islamabad 


\section{CHAPTER- 6 DISCUSSION AND RECOMMENDATIONS}

\section{Discussion}

Young people of ages 15 to 29 comprise 27 percent of Pakistan's population. Of these 56 million young people, 46 percent of women and 24 percent of men are currently married. Secondary data analysis reveals that although the singulate mean age at marriage has risen in Pakistan for both women and men to about 23 years and 27 years, respectively, 14 percent of female and 3 percent of male adolescents of ages 15 to 19 are currently married.

Our discussions with unmarried adolescents in this study suggest that they do not generally condone marriages in which the girl is too young. They are all well aware of the health risks associated with early childbearing and to some extent also the social difficulties a child bride might face negotiating the role of a wife and a mother. However, in a few cases, they believe that a girl who is 15-17 years of age is not too young to be married. This suggests a need to convey more detailed information to young people about why early marriage is not only legally prohibited, but also medically inadvisable, and why contraception must be used by young married couples.

While boys, along with girls, were not in favor of early marriages, several of them mentioned that religious teachers in their community suggested they should get married early to avoid being driven to temptations such as viewing pornography and masturbation. On the other hand, girls mentioned that parents sometimes married their daughters off early if they suspected their daughters were getting involved in romantic relationships. These observations suggest that, to some extent, early marriages may be a preemptive measure by parents who are afraid that their children's growing interest in the opposite sex might 'corrupt' them.

Virtually all the unmarried adolescents who participated in this study were aware and supportive of the concept of family planning. They felt it was necessary to ensure a healthy interval between births and also to limit family sizes so that children could be well looked after. They were also aware of some specific methods and highly motivated to use contraception, especially the boys, who said they would consult health professionals to ensure birth spacing and the good health of their future wife.

There is some good news: between 2006-07 and 2017-18, age-specific fertility rates for women of ages 15-19, 20-24, and 25-29 have declined, respectively, from 51 to 46,178 to 171 , and 237 to 215 births per 1,000 women. Moreover, half of young married women (15-29 years) want to space or limit births. A little above one fifth (22\%) of married women of ages 15 to 29 in Pakistan use any 
contraceptive method of family planning. Contraceptive use among married women of ages 15 to 29 rises with age, varies by region of residence, higher with more educational attainment and wealth quintile. Meanwhile, 17.9 percent of married women of ages 15 to 19, 18.6 percent of women of ages 20 to 24, and 20.4 percent of women of ages 25 to 29 have unmet need for family planning.

Access to maternal care has greatly improved in Pakistan in recent years. Nevertheless, 13 percent of women aged 15 to 29 years do not use antenatal care services and close to one third of births among them occur without the aid of a skilled service provider. A closer look at the data shows that these gaps are wider in rural areas, in some regions-especially Balochistan, and among women who are less educated and poorer. Collectively, the low use of contraception among married adolescent girls, combined with the higher risks pregnancy poses to their health, and the still significant proportions who do not utilize antenatal or delivery care indicate high maternal health risks for young married women. It is therefore not surprising that most respondents in the qualitative study had observed cases of poor maternal health among young mothers in their own circles.

In qualitative discussions, puberty was the one subject on which unmarried adolescents could speak at length from their own experiences. In doing so, they not only identified the specific health issues they face but indirectly also provided insights into how the lack of open discussion of sexual and reproductive health exposes young people to unnecessary shock, pain, and guilt in negotiating natural physiological changes. For example, most girls confessed they were shocked when they began menstruating because nobody had told them it would happen. Several studies have documented girls' lack of knowledge about the menstrual cycle as well as menstrual hygiene management (e.g., Latif, Mayedah, and Bano 2018). Some girls report being anxious about stains at school because there are no arrangements to change their sanitary napkins-one respondent even mentioned that the school head forbade students from changing at school due to lack of disposal arrangements. Even at home, girls must hide their condition from fathers and brothers. There is no mention of basic measures that could alleviate some of their problems, such as tracking their cycle on a calendar or app to be prepared ahead of time, or taking over-the-counter pain medication for cramps.

Many girls also complained about vaginal discharge (Leucorrhea), although they said this is generally not considered a reason to go to the doctor. Girls need to be oriented by health care providers so they can distinguish normal, healthy discharge from symptoms that require medical attention. This is particularly important because, according to the PDHS, a large proportion of men and women who suspect they have sexually transmitted infections (STIs) do not visit a health practitioner.

While available research about boys' issues in puberty is sparse, our study indicates that they too can struggle with health issues such as urinary tract infections and skin conditions, as well as weakness and other issues that they at times incorrectly perceive to be linked to nocturnal emissions and to masturbation. Boys commonly have a number of misperceptions about the health effects of masturbation and clearly experience a lot of guilt over it for which they need counseling. They also need guidance to avoid urinary tract infections. 
Upon reaching puberty, girls experience greater restrictions on their mobility, attire, and interactions with outsiders, including on mobile phones and social media. In marked contrast, boys find greater freedom to go outside and begin to be seen as bread-earners, with associated prestige. However, the newfound freedom can also introduce risks. At this sensitive time in their psychological development, when negative exposures can influence their perceptions, behaviors, and later relationships, many boys shared that their peers are attracted to pornography. Use of pornography has been found to be associated with perpetration of violence, and it is possible that boys' indulgence distorts their ideas about masculinity and brings them into interaction with individuals who might further mislead them. Sexual activity outside marriage is a punishable offence in Pakistan and therefore not openly documented in data. Yet, even in the limited sample of our qualitative study, we found that some respondents in Islamabad and Lahore-all of them out-ofschool boys-mentioned about engagement of their friends in high-risk sexual activities including paid sex, and relying on their peers to provide them information about contraception and other reproductive health related topics. One respondent even shared that his friend contracted HIV after engaging in unsafe paid sex and eventually died of AIDS.

These alarming reports suggest that adolescent boys, especially those out of school and on the streets, may be informed about not indulging in unsafe practices and about the importance of screening for STIs and HIV/AIDS, and counseled about the risks associated with their behavior, as well as provided health services. All individuals including boys, girls and transgenders engaged in selling sex are also in urgent need of education about health care to promote safe practices.

Another negative pursuit that adolescents are involved in is cyberbullying. According to most respondents, it is largely perpetrated by boys, who have more easy access to mobile phones. Girls may be tricked by fake accounts or blackmailed by former boyfriends with threats of publicly sharing their edited photographs. The girls generally lack support and fear punishment from parents, which can range from greater restrictions on their mobility and mobile use to beatings, being withdrawn from school, and even being forced into early marriage. There is a need to educate young people and also parents about the ways in which social media can be manipulated and the measures they can take to reduce their vulnerability and block or report perpetrators.

The boys and girls are broadly aware of basic human rights, such as the right to education, food, and shelter, but more vocal about their rights as youth. Girls especially speak more of their right to education and to consent in their marriage, while boys frequently mention the right to employment. However, relatively few respondents spoke about the right to be safe from child labor, harassment and violence, and none talked about domestic violence. At the same time, when they speak of gender rights, the respondents refer only to girls, apparently not observing that boys too can face gender-related hardships, such as being expected to earn for the household while they are still minors.

In general, respondents were not aware what forum or organization might help them secure their rights except in the case of inheritance, regarding which some girls voiced optimism that they could go to court against male relatives if their right was denied. On the whole, however, the responses did not indicate that the boys and girls have rights-based attitudes. Young people's awareness of rights, laws, and also justice institutions and redress mechanisms need to be built. 
For information about reproductive health matters, girls largely rely on their mothers, sisters and cousins, and to a limited extent also their friends, while boys learn from friends, brothers and fathers, mosque leaders, and the Internet. If a health issue gets serious, the girls are taken to doctors by their mothers. Boys can talk to fathers and brothers but also with friends. If they have a serious health issue, they are usually taken by their fathers to doctors, hakims, and homeopaths, and can eventually visit these practitioners alone or with friends. It is interesting that the boys more frequently mentioned visiting hakims and homeopaths for reproductive health issues than medical doctors. Hakeems and homeopaths are predominantly male providers, and one reason for visiting them could be that the mainstream reproductive health sector is oriented towards women and not catering enough to men and boys. The current usage pattern suggests that hakeems and homeopaths should be included in efforts to make reproductive health services accessible to boys.

\section{Recommendations}

Our two broad recommendations pertain to making reproductive health information and services more accessible to young people. Health care providers and facilities need to have mechanisms in place to cater to the counseling, information, and service needs of unmarried young people. Health staff must also be trained in adolescents' reproductive health related counseling and treatment modalities.

\section{Reach out to adolescents through the health system}

- Girls need counseling on menstrual hygiene management, period tracking, and pain relief. Very young adolescents need to be told about menstruation before it occurs. Girls also need to be counseled about leucorrhea and when they should see a health care provider.

- Similarly, young adolescent boys need to be counseled in advance at youth-friendly health centers about the changes their body will go through, and how to cope with any problems such as nocturnal emissions, the urge to masturbate, and how to avoid urinary tract infections. Boys going through puberty need male providers who can counsel, inform, and treat them in a friendly, pragmatic, and open manner.

- Where feasible, toll-free helplines can be set up to counsel both boys and girls.

- Adolescents who are out of school may require special interventions. For example, girls may be more homebound and less educated. In such cases, some way needs to be found to reach them within their homes, for example through community health workers. Lady Health Workers (LHWs) could be trained for this purpose.

- Likewise, medical camps could be organized to reach out to street children (male and female) and transgender individuals, with a special focus on providing them the information and counseling they need to avoid unsafe sexual practices.

- Young couples must also receive information and counseling about family planning before they are married. Apart from sharing specific methods of birth spacing, these sessions can be used to orient them to other aspects of sexual and reproductive health care as well, encourage them to make fertility decisions together after marriage, and also alert them to the kinds of social pressures they might face to commence childbearing early, and how to resist such pressures. 
- In view of the high incidence of spousal emotional and physical violence, as well as the frequently reported cases of sexual violence against young boys and girls, health service providers must be trained to recognize and empathetically cater to survivors of gender-based violence. There should be a mechanism and guidelines for allowing GBV survivors legal redressal based on existing protocols such as Essential Services Package for Women and Girls Subject to Violence, Protocols on Clinical Management of Rape Survivors, and the National Clinical Handbook for Health Care Provision to GBV survivors in Pakistan.

- Psychological health facilities for adolescents should also be created at tehsil and district headquarters level. In addition, safe spaces should be created at community level for them to network with peers and be mentored. Opportunities for healthy activities can be created here such as sports, young people's associations, and clubs.

- Both young people and service providers should be oriented to client rights, and rights-based attitudes and approaches encouraged.

\section{Develop a locally acceptable model of Life skills-based education for adolescents of ages 10-19}

In Pakistan, as in other conservative societies, the idea of comprehensive life skills-based education may at first be considered incompatible with sociocultural norms. However, there is a need for stakeholders to realize that whether or not sexuality education is provided formally to young people, they will learn about sexual and reproductive health matters from other sources, which might not always be the best-informed or best-intentioned.

- Measures should be taken to cultivate, through a wide-ranging consultative and participatory process, an indigenously owned and locally-acceptable narrative and model of comprehensive LSBE education for young people in Pakistan which should form the basis of the curricula for life skill based education to be imparted within schools including religious seminaries throughout the country. To the extent possible, this model should also cover themes related to gender-based violence, not only in its most violent manifestations, such as rape, but also in the shape of culturally condoned or less tangible practices such as early marriage and cyberbullying.

- Most adolescent respondents in our study, both male and female, would prefer to learn more about reproductive health from health practitioners and camps, and from their own close family members of the same sex. They also recommend that information be provided in culturally sensitive ways from school, and in addition boys want to learn through social media and from friends. The respondents also referred often to Quran teachers and mosque leaders who occasionally advise boys about puberty-related issues. In addition, as mentioned earlier, boys have mentioned hakims and homeopaths as frequent sources of treatment for reproductive health issues.

- In order to work, the model developed for sexuality education must draw on all the main sectors on which young people rely for guidance, including their families, especially parents; schools; the health community, including public and private sector doctors and health workers, as well as hakims and homeopaths; and religious scholars and leaders. Involvement and endorsement of the latter is particularly important to destigmatize discourse on sexual and reproductive 
health, and make young people, their families, and communities receptive to the idea of life skills-based education.

- Religious scholars have recently endorsed family planning in Pakistan to promote health timing and spacing of pregnancies (HTSP). Their endorsement of LSBE may be obtained through a similar approach and building on the earlier work of obtaining their support for HTSP.

- In imparting sexuality education, segmented approaches will be needed to reach young people in and out of school, as well as girls, boys and transgenders who can access slightly different channels of information. Educational institutions could be taken on board through schools' life skills education and madrassa curriculums.

- Health education materials can be made available at health facilities.

- NGO forums may be used for peer-based education.

- Media messaging and social media could be used for information sharing.

- Moreover, religious leaders and madrasa teachers can be engaged to better inform and equip seminary students to deal with puberty, bodily changes, menarche, etc. events; and awareness raising sessions such as lighting public buildings on youth days. 


\section{REFERENCES}

Ali, P. A., Naylor, P. B., Croot, E., \& O'Cathain, A. (2015). Intimate partner violence in Pakistan: A systematic review. Trauma, Violence, \& Abuse, 16(3), 299-315.

Ashfaq, S., Iram, K., and Niazi, R. (2018). The International Men and Gender Equality Survey - Pakistan (PAK-IMAGES). Population Council, Rutgers, Rozan, and Ministry of Human Rights, Islamabad.

Bureau of Statistics Punjab, Planning \& Development Board, Government of the Punjab. (2018). Multiple Indicator Cluster Survey Punjab, 2017-18, Survey Findings Report. Lahore, Pakistan: Bureau of Statistics Punjab, Planning \& Development Board, Government of the Punjab.

Chandra-Mouli, V., Plesons, M., Hadi, S., Baig, Q., \& Lang, I. (2018). Building support for adolescent sexuality and reproductive health education and responding to resistance in conservative contexts: Cases from Pakistan. Global Health: Science and Practice, 6(1), 128-136.

Compton, S. N., Walkup, J. T., Albano, A. M., Piacentini, J. C., Birmaher, B., Sherrill, J. T., \& lyengar, S. (2010). Child/adolescent anxiety multimodal study (CAMS): rationale, design, and methods. Child and adolescent psychiatry and mental health, 4(1), 1.

Erken A, Bernstein S, Benomar E, Schensul D, Mogelgaard K, Edmeades J, Luchsinger G, Ryan A.W, Starrs M.A, Jensen J. (2019). Unfinished Business, the pursuit of right and choices FOR ALL, UNFPA, State of World Population 2019.

Government of Balochistan. Balochistan Youth policy (Draft), Environment, Sports and Youth Affairs Department. Government of Balochistan.

Government of Khyber Pakhtunkhwa. (2016). Khyber Pakhtunkhwa Youth policy 2016, Sports, Tourism, Culture, Archeology, Museum and Youth Affairs Department. Government of Khyber Pakhtunkhwa.

Government of Pakistan (2019). Economic Survey of Pakistan 2018-19, Ministry of Finance, Economic Affairs Division, Islamabad, Pakistan.

Government of Pakistan. (2018). Investing in Sustainable Population Growth: National Symposium on Alarming Population Growth in Pakistan: Call to Action, Islamabad, December 5, 2018, Ministry of National Health Services, Regulations and Coordination and Law and Justice Commission of Pakistan.

Government of Punjab (2012). Punjab Youth Policy 2012. Youth Affairs, Sports, Archeology, and Tourism Department. Government of Punjab. Available at: http://www.unescogym.org/wpcontent/uploads/2017/06/.

Government of Punjab (2019). Women's Economic and Social Wellbeing Survey in Punjab 2017-18. Punjab Commission on Status of Women.

Government of Sindh. (2013). The Sindh Child Marriages Restraint Act 2013. Provincial Assembly of Sindh. Available at: http://rtepakistan.org/wp-content/uploads/2014/11/ The-Sindh-Child-Marriages-RestraintAct-2013.pdf.

Government of Sindh. (2018). Sindh Youth Policy 2018. Available at: http://www.unescogym.org/wpcontent/uploads/2017/06/.

Heise, L. (1993). Violence against women: the missing agenda. The health of women: A global perspective, 123.

Huda, S. U., Mobeen, K., Idrees, S., Chagani, P., \& Zafar, M. (2017). Knowledge of Pubertal Changes and Self-Care in Adolescent Boys. Journal of The Liaquat University of Medical and Health Sciences, 16(2), 121125.

IPPF and UNFPA (2017). Global Sexual and Reproductive Health Service Package for Men and Adolescent Boys. London: IPPF and New York City: UNFPA. 
Iqbal, S., Zakar, R., Zakar, M. Z., \& Fischer, F. (2017). Perceptions of adolescents' sexual and reproductive health and rights: a cross-sectional study in Lahore District, Pakistan. BMC international health and human rights, 17(1), 5.

Fearon, J., \& Hoeffler, A. (2014). Benefits and costs of the conflict and violence targets for the post2015 development agenda. Conflict and violence assessment paper, Copenhagen Consensus Center. Available at: http://www.ledevoir.com/documents/pdf/conflict_assessment_hoeffler.pdf

Kamran, I., Parveen, T., Sadiq, M., and Niazi, R. (2018). Adolescent Girls' Voices on Enhancing their Own Productivity in Pakistan. Population Council. Islamabad: Pakistan.

Khan, A., \& Pine, P. (2003). Adolescent and youth reproductive health in Pakistan: status issues policies and programs. Technical Report. March 2003. Available at:

https://www.researchgate.net/publication/316527277_Adolescent_Reproductive_Health_in_Pakistan_St atus_Policies_Programs_and_Issues/citation/download

Latif, S., Mayedah, S., \& Bano, N. (2018). Awareness of Reproductive Health Among Adolescent and Young Adult Females; A Comparative Study in Urban and Rural Areas. Journal of the Society of Obstetrics and Gynaecologists of Pakistan, 8(4), 243-248.

McCarthy, K., Brady, M., \& Hallman, K. (2016). Investing when it counts: Reviewing the evidence and charting a course of research and action for very young adolescents.

Mokari, H., Khaleghparast, S., \& Samani, L. N. (2016). Impact of Puberty Health Education on Anxiety of Adolescents. Health Sciences, 5(5), 284-291.

Mubeen, K., \& Baig, M. (2016). Adolescent Pregnancies: The case of Pakistan. Journal of Asian Midwives (JAM), 3(2), 69-78.

Naqvi, M. M., \& Naseem, A. (2010). Maternal and Fetal Risks Associated with Adolescent and Adult Pregnancy. Journal of Rawalpindi Medical College (JRMC), 14(1), 40-2.

Nasrullah, M., Muazzam, S., Bhutta, Z. A., \& Raj, A. (2014). Girl child marriage and its effect on fertility in Pakistan: findings from Pakistan Demographic and Health Survey, 2006-2007. Maternal and child health journal, 18(3), 534-543.

National Institute of Population Studies (NIPS) [Pakistan] and ICF. 2019. Pakistan Demographic and Health Survey 2017-18, Islamabad Pakistan, and Rockville, Maryland, USA: NIPS \& ICF.

Neal, S., Matthews, Z., Frost, M., Fogstad, H., Camacho, A. V., \& Laski, L. (2012). Childbearing in adolescents aged 12-15 years in low resource countries: a neglected issue. New estimates from demographic and household surveys in 42 countries. Acta obstetricia et gynecologica Scandinavica, 91(9), 1114-1118.

Pakistan Bureau of Statistics (PBS) (2017). $6^{\text {th }}$ Population and Housing Census, Pakistan Bureau of Statistics, Statistics Division, Government of Pakistan, Islamabad.

Pradhan, R., Wynter, K., \& Fisher, J. (2015). Factors associated with pregnancy among adolescents in lowincome and lower middle-income countries: a systematic review. J Epidemiol Community Health, 69(9), 918-924.

Qidwai, W., Ashfaq, T. (2010). Emerging issues in adolescent healthcare: an urgent call for action. Journal of the College of Physicians and Surgeons Pakistan, 20(3), 143-145. Available at:

http://ecommons.aku.edu/pakistan_fhs_mc_fam_med/58

Sathar, Z. A., Wazir, A., \& Sadiq, M. (2013). Struggling against the odds of poverty, access, and gender: Secondary schooling for girls in Pakistan. The Lahore Journal of Economics, 18: SE (September 2013): pp. 67-92.

Sathar, Z. A., Kamran, I., Sadiq, M., \& Hussain, S. (2016). Youth in Pakistan: Priorities, Realities and Policy Responses. Population Council. Islamabad: Pakistan. 
Sathar, Z.A., Kiren, K., and Sabahat H. (2015). Pakistan's shifting family planning landscape: challenges and opportunities, Islamabad, Research and Advocacy Fund (RAF).

Sawyer, S. M., Afifi, R. A., Bearinger, L. H., Blakemore, S. J., Dick, B., Ezeh, A. C., \& Patton, G. C. (2012). Adolescence: a foundation for future health. The Lancet, 379(9826), 1630-1640.

Shah, N., Rohra, D. K., Shuja, S., Liaqat, N. F., Solangi, N. A., Kumar, K., \& Khan, N. (2011). Comparison of obstetric outcome among adolescent and non-adolescent mothers from three tertiary care hospitals of Sindh. Pakistan. Journal of Pakistan Medical Association, 61(10), 963.

Shahid, A., Pirzada, A. G., \& Memon, A. A. (2012). Perception regarding reproductive health among adolescents of rural Sindh, Pakistan. South East Asia Journal of Public Health, 2(1), 39-45.

Shaikh, B. T., Haran, D., \& Hatcher, J. (2008). Where do they go, whom do they consult, and why? Healthseeking behaviors in the northern areas of Pakistan. Qualitative Health Research, 18(6), 747-755.

Sheehan, P., Sweeny, K., Rasmussen, B., Wils, A., Friedman, H. S., Mahon, J., \& Stenberg, K. (2017). Building the foundations for sustainable development: a case for global investment in the capabilities of adolescents. The Lancet, 390(10104), 1792-1806.

Shirkatgah. (2017). Status and Policies related to Adolescent Health in Pakistan 2017. To the Independent Accountability Panel. Available at: www.shirkatgah.org .

Sindh Bureau of Statistics and UNICEF. (2015). Sindh Multiple Indicator Cluster Survey 2014, Final Report. Karachi, Pakistan: Sindh Bureau of Statistics and UNICEF.

Talpur, A. A., \& Khowaja, A. R. (2012). Awareness and attitude towards sex health education and sexual health services among youngsters in rural and urban settings of Sindh, Pakistan. Education, 62(708).

Tufail, A. M. B. E. R., \& Hashmi, H. A. (2008). Maternal and perinatal outcome in teenage pregnancy in a community based hospital. Pak J surg, 24(2), 130-134.

United Nations. (2019). Population Facts No. 2019/1, United Nations Department of Economics and Social Affairs, Population Division.

United Nation.(2019)."Shaping Our Future Together," Available at:

https://www.un.org/en/sections/issues-depth/youth-0/index.html

United Nations. (2010). World Program of Action for Youth, Economic \& Social Affairs. New York, United Nations. Available at: https://www.un.org/esa/socdev/unyin/documents/wpay2010.pdf

United Nations Population Fund. (2013). Motherhood in Childhood: Facing the Challenge of Adolescent Pregnancy. State of the World Population 2013. UNFPA. New York, USA.

United Nations Population Fund. (2015). Girlhood, Not Motherhood: Preventing Adolescent Pregnancy. UNFPA. New York, USA.

United Nations Children's Fund. (2017). State of World Children Report 2017, UNICEF, New York, USA.

United Nations Children's Fund. (2014). Ending Child Marriage: Progress and Prospects, UNICEF New York, USA.

Vignoli, J. R., \& Cavenaghi, S. (2014). Adolescent and youth fertility and social inequality in Latin America and the Caribbean: what role has education played. genus, 70(1), 1-25.

World Bank. (2012). HIV/AIDS in Pakistan. Islamabad, World Bank. Available at: https://www.worldbank.org/en/news/feature/2012/07/10/hiv-aids-pakistan

World Health Organisation. (2019). Handbook for conducting Adolescent Health Service Barrier Assessment (AHSBA) with focus on disadvantageous adolescent (2019). Geneva. World Health Organisation 2019.

World Health Organization. (2019)."Adolescent Health in the South-East Asia Region," Available at: https://www.who.int/southeastasia/health-topics/adolescent-health 
World Health Organization. (2009.) Mental health aspects of women's reproductive health: A global review of the literature. World Health Organisation (WHO), Geneva.

World Health Organization. (2014). Health for the world's adolescents: a second chance in the second decade: summary (No. WHO/FWC/MCA/14.05). World Health Organization.

World Health Organization. (2016). Global Health Estimates 2015: Deaths by Cause, Age, Sex, by Country and by Region, 2000-2015. World Health Organization (WHO). Geneva, Switzerland.

World Population Review. (2014). Pakistan Population 2019. Pakistan Population 2019. Available at: http://worldpopulationreview.com/countries/pakistan-population.

Zaidi, B., Sathar, Z. A., Haque, ul. M., and Zafar, F. (2012). The power of girls' schooling for young women's empowerment and reproductive health: Population Council, Islamabad. Available at:

https://pdfs.semanticscholar.org/a8c4/028a98604c55682dccadc42a1c45e9f759cd.pdf 


\section{APPENDIX-A}

Table 1A: Various aspects of Adolescent and youth covered in available data sets

\begin{tabular}{|c|c|c|c|c|}
\hline Thematic areas & PDHS & MICS & PSLM & Missing Data \\
\hline Infancy & No & No & No & $\begin{array}{l}\text { There is no data set that covers issues of infancy and track individuals' up to their } \\
\text { adolescence or youth. Also, none of these data set covers congenital diseases or } \\
\text { related issues. }\end{array}$ \\
\hline Puberty & No & No & No & $\begin{array}{l}\text { None of the data set provide any data related to puberty its onset and related issues } \\
\text { on gender disaggregated basis. As for boys these are different than girls and thus } \\
\text { needs of both groups are different too. }\end{array}$ \\
\hline Marriage & Yes & Yes & Yes & $\begin{array}{l}\text { Although marriage (child marriage or teen marriage) is covered but there is no way one } \\
\text { can distinguish whether it is watta satta or marriage of choice of both the spouses or } \\
\text { not. The module does not provide any information about whether marriage is love or } \\
\text { arrange. }\end{array}$ \\
\hline Fertility & Yes & Yes & Yes & $\begin{array}{l}\text { This is relatively better covered module in all of these data sets. It covers both fertility } \\
\text { choices and behavior. }\end{array}$ \\
\hline Maternal Health & Yes & Yes & Yes & $\begin{array}{l}\text { This is also nicely covered module that provided relatively vast information related to } \\
\text { pre and post-natal health of mothers. }\end{array}$ \\
\hline Family Planning & Yes & Yes & Yes & $\begin{array}{l}\text { This is very nice module and covers most of the family planning issues related to } \\
\text { married women. The focus is on age group } 15-49 \text { and not on adolescent and youth } \\
\text { where majority of the marriages are taking place. }\end{array}$ \\
\hline Health Seeking Behavior & Yes & Yes & Yes & $\begin{array}{l}\text { This is usually covered for married women or age } 15-49 \text { years but not for unmarried } \\
\text { boys and girls. }\end{array}$ \\
\hline Rights of Adolescent and Youth & No & No & No & None of these data sets have any module that covers rights of adolescent and youth. \\
\hline Gender Based Violence & Yes & Yes & No & $\begin{array}{l}\text { PSLM does not provide cover to gender-based violence. Other data sets like MICS and } \\
\text { PDHS provide gender-based violence modules. MICS only provides perception or } \\
\text { attitudes towards intimate partner violence but not the actual physical occurrence of } \\
\text { the violence. None of these data sets provides frequency of occurrence of violence. } \\
\text { Also, this gender-based violence module covers only intimate partner violence and } \\
\text { hence those adolescent and youth who are not married and living at home with their } \\
\text { parents or guardians are not at all covered in these violence modules. }\end{array}$ \\
\hline
\end{tabular}


Table 2A: Percent distribution of women ages 15 to 29 who had a live birth in the 2 years preceding the survey and received antenatal care from a skilled provider by background characteristics, (Punjab MICS 2017-18)

\begin{tabular}{|c|c|c|c|c|}
\hline Background Characteristics & $15-19$ & $20-24$ & $25-29$ & Overall (15-29) \\
\hline Punjab & 86.3 & 89.7 & 89.0 & 89.1 \\
\hline \multicolumn{5}{|l|}{ Residence } \\
\hline Urban & 86.0 & 92.0 & 92.7 & 92.1 \\
\hline Rural & 86.4 & 88.5 & 87.0 & 87.5 \\
\hline \multicolumn{5}{|l|}{ Division } \\
\hline Bahawalpur & 76.8 & 75.4 & 72.6 & 74.0 \\
\hline DG Khan & 87.3 & 91.3 & 88.0 & 89.2 \\
\hline Faisalabad & 91.2 & 91.9 & 91.9 & 91.9 \\
\hline Gujranwala & 79.2 & 89.1 & 88.9 & 88.6 \\
\hline Lahore & 82.2 & 89.1 & 91.2 & 90.0 \\
\hline Multan & 92.3 & 95.0 & 92.4 & 93.4 \\
\hline Rawalpindi & 93.4 & 94.5 & 95.2 & 94.9 \\
\hline Sahiwal & 89.4 & 93.2 & 90.9 & 91.7 \\
\hline Sargodha & 85.8 & 88.1 & 87.0 & 87.3 \\
\hline \multicolumn{5}{|l|}{ Education } \\
\hline None/Pre-School & 78.9 & 81.3 & 80.5 & 80.7 \\
\hline Primary & 90.6 & 91.8 & 90.0 & 90.8 \\
\hline Middle & 89.0 & 93.7 & 93.6 & 93.4 \\
\hline Secondary & 92.6 & 96.9 & 95.7 & 96.0 \\
\hline Higher & 100.0 & 97.6 & 96.9 & 97.1 \\
\hline \multicolumn{5}{|l|}{ Wealth quintile } \\
\hline Lowest & 72.5 & 79.0 & 75.5 & 76.6 \\
\hline Second & 89.9 & 88.8 & 87.7 & 88.3 \\
\hline Middle & 95.9 & 92.0 & 91.9 & 92.2 \\
\hline Fourth & 87.5 & 92.2 & 91.7 & 91.7 \\
\hline Highest & 91.8 & 97.8 & 96.9 & 97.0 \\
\hline
\end{tabular}


Table 3A: Percent distribution of women ages 15 to 29 who had a live birth in the 2 years preceding the survey and delivery assisted by any skilled attendant by background characteristics, (Punjab MICS 2017-18)

\begin{tabular}{|c|c|c|c|c|}
\hline Background Characteristics & $15-19$ & $20-24$ & $25-29$ & Overall (15-29) \\
\hline Punjab & 70.4 & 78.3 & 77.2 & 77.2 \\
\hline \multicolumn{5}{|l|}{ Residence } \\
\hline Urban & 76.3 & 85.4 & 86.0 & 85.3 \\
\hline Rural & 68.0 & 74.7 & 72.5 & 73.0 \\
\hline \multicolumn{5}{|l|}{ Division } \\
\hline Bahawalpur & 55.3 & 71.3 & 66.8 & 67.7 \\
\hline DG Khan & 44.9 & 56.6 & 47.9 & 51.0 \\
\hline Faisalabad & 87.2 & 78.9 & 81.7 & 80.8 \\
\hline Gujranwala & 82.9 & 88.8 & 88.4 & 88.3 \\
\hline Lahore & 79.0 & 81.1 & 83.2 & 82.2 \\
\hline Multan & 79.5 & 79.8 & 74.5 & 76.9 \\
\hline Rawalpindi & 79.8 & 89.2 & 87.6 & 87.7 \\
\hline Sahiwal & 71.4 & 80.2 & 77.4 & 78.1 \\
\hline Sargodha & 76.7 & 82.0 & 81.2 & 81.2 \\
\hline \multicolumn{5}{|l|}{ Education } \\
\hline No education & 59.2 & 64.5 & 59.6 & 61.4 \\
\hline Primary & 71.8 & 79.3 & 77.3 & 77.6 \\
\hline Middle & 77.5 & 86.3 & 86.1 & 85.7 \\
\hline Secondary & 88.8 & 88.8 & 92.4 & 90.9 \\
\hline Higher & 95.0 & 96.1 & 95.2 & 95.5 \\
\hline \multicolumn{5}{|l|}{ Wealth quintile } \\
\hline Lowest & 52.8 & 57.3 & 50.5 & 53.2 \\
\hline Second & 64.3 & 71.5 & 68.7 & 69.5 \\
\hline Middle & 78.5 & 81.9 & 80.2 & 80.8 \\
\hline Fourth & 81.3 & 88.7 & 88.6 & 88.3 \\
\hline Highest & 95.8 & 95.7 & 95.4 & 95.5 \\
\hline
\end{tabular}


Table 4A: Percentage of adolescents and youth ages 15 to 29 years using any contraceptives by background characteristics, (Punjab MICS 2017-18)

\begin{tabular}{|c|c|c|c|c|}
\hline Background characteristics & $15-19$ & $20-24$ & $25-29$ & Overall (15-29) \\
\hline Punjab & 8.3 & 19.2 & 29.1 & 23.8 \\
\hline \multicolumn{5}{|l|}{ Residence } \\
\hline Urban & 9.9 & 22.0 & 32.2 & 27.2 \\
\hline Rural & 7.7 & 17.8 & 27.3 & 21.9 \\
\hline \multicolumn{5}{|l|}{ Division } \\
\hline Bahawalpur & 12.1 & 24.8 & 30.2 & 26.3 \\
\hline DG Khan & 2.6 & 12.7 & 20.1 & 15.0 \\
\hline Faisalabad & 5.1 & 18.2 & 33.6 & 25.9 \\
\hline Gujranwala & 4.2 & 13.6 & 18.2 & 15.8 \\
\hline Lahore & 12.8 & 22.5 & 36.4 & 29.8 \\
\hline Multan & 13.2 & 24.3 & 36.1 & 29.6 \\
\hline Rawalpindi & 9.0 & 21.6 & 29.2 & 25.3 \\
\hline Sahiwal & 5.1 & 13.6 & 26.9 & 19.9 \\
\hline Sargodha & 9.5 & 20.5 & 26.9 & 22.9 \\
\hline \multicolumn{5}{|l|}{ Education } \\
\hline No education & 6.8 & 16.8 & 26.2 & 21.1 \\
\hline Primary & 7.5 & 18.9 & 33.1 & 24.6 \\
\hline Middle & 9.9 & 22.8 & 30.9 & 25.7 \\
\hline Secondary & 13.6 & 21.9 & 30.3 & 26.1 \\
\hline Higher & 6.9 & 19.5 & 28.3 & 24.8 \\
\hline \multicolumn{5}{|l|}{ Wealth quintile } \\
\hline Lowest & 6.6 & 14.1 & 24.5 & 18.6 \\
\hline Second & 6.5 & 18.0 & 29.5 & 22.6 \\
\hline Middle & 9.4 & 19.7 & 30.8 & 24.7 \\
\hline Fourth & 10.0 & 21.7 & 28.5 & 24.8 \\
\hline Highest & 11.8 & 22.5 & 31.3 & 27.6 \\
\hline
\end{tabular}


Table 5A: Percent distribution of adolescent and youth ages 15 to 29 having access to media* by background characteristics, (Punjab MICS 2017-18)

\begin{tabular}{|c|c|c|c|c|c|c|c|c|c|c|c|c|}
\hline \multirow[b]{2}{*}{ Background characteristics } & \multicolumn{4}{|c|}{ Reads the newspaper } & \multicolumn{4}{|c|}{ Listens to the Radio } & \multicolumn{4}{|c|}{ Watches Television } \\
\hline & $15-19$ & $20-24$ & $25-29$ & $15-29$ & $15-19$ & $20-24$ & $25-29$ & $15-29$ & $15-19$ & $20-24$ & $25-29$ & $15-29$ \\
\hline Punjab & 8.7 & 9.3 & 8.0 & 8.7 & 3.9 & 3.6 & 2.5 & 3.4 & 71.6 & 70.9 & 69.3 & 70.7 \\
\hline \multicolumn{13}{|l|}{ Residence } \\
\hline Urban & 11.2 & 12.9 & 11.6 & 11.9 & 4.7 & 4.3 & 3.0 & 4.0 & 83.8 & 82.3 & 82.8 & 83.0 \\
\hline Rural & 7.2 & 7.1 & 5.7 & 6.7 & 3.5 & 3.2 & 2.1 & 3.0 & 64.1 & 63.7 & 60.9 & 63.0 \\
\hline \multicolumn{13}{|l|}{ Division } \\
\hline Bahawalpur & 5.0 & 4.9 & 4.3 & 4.8 & 1.6 & 2.0 & 1.2 & 1.6 & 63.4 & 64.7 & 62.4 & 63.5 \\
\hline DG Khan & 6.2 & 7.4 & 5.3 & 6.3 & 1.8 & 3.0 & 1.7 & 2.1 & 50.4 & 43.5 & 47.0 & 47.1 \\
\hline Faisalabad & 10.4 & 10.7 & 9.7 & 10.3 & 3.9 & 4.3 & 1.9 & 3.4 & 72.8 & 74.6 & 72.0 & 73.1 \\
\hline Gujranwala & 7.5 & 8.4 & 8.2 & 8.1 & 3.4 & 3.6 & 2.0 & 3.1 & 77.5 & 76.7 & 77.0 & 77.1 \\
\hline Lahore & 11.1 & 12.4 & 11.1 & 11.6 & 4.2 & 3.3 & 2.5 & 3.4 & 80.7 & 77.0 & 77.5 & 78.5 \\
\hline Multan & 11.7 & 11.3 & 6.7 & 10.0 & 5.7 & 4.5 & 4.0 & 4.7 & 69.9 & 69.8 & 65.8 & 68.6 \\
\hline Rawalpindi & 10.4 & 12.3 & 11.0 & 11.2 & 7.9 & 6.0 & 4.4 & 6.1 & 76.6 & 76.9 & 73.3 & 75.6 \\
\hline Sahiwal & 4.5 & 4.7 & 4.8 & 4.7 & 2.2 & 2.1 & 1.7 & 2.0 & 73.9 & 74.1 & 72.4 & 73.5 \\
\hline Sargodha & 7.5 & 7.0 & 5.5 & 6.7 & 4.0 & 3.1 & 2.2 & 3.1 & 65.5 & 66.4 & 62.5 & 64.9 \\
\hline \multicolumn{13}{|l|}{ Education } \\
\hline No education & 0.6 & 0.4 & 0.4 & 0.5 & 1.3 & 1.3 & 1.0 & 1.2 & 49.4 & 49.7 & 49.5 & 49.5 \\
\hline Primary & 3.6 & 3.8 & 3.6 & 3.7 & 3.1 & 2.5 & 2.1 & 2.6 & 65.4 & 66.4 & 67.7 & 66.4 \\
\hline Middle & 8.5 & 6.4 & 5.7 & 7.1 & 4.6 & 3.4 & 2.0 & 3.5 & 75.1 & 76.1 & 77.4 & 76.0 \\
\hline Secondary & 10.2 & 9.2 & 9.0 & 9.6 & 4.3 & 4.2 & 2.8 & 3.9 & 79.2 & 78.4 & 81.2 & 79.4 \\
\hline Higher & 17.5 & 20.6 & 21.9 & 20.0 & 5.7 & 5.8 & 4.8 & 5.5 & 81.8 & 83.2 & 85.4 & 83.4 \\
\hline \multicolumn{13}{|l|}{ Wealth quintile } \\
\hline Lowest & 2.5 & 2.2 & 1.1 & 2.0 & 1.7 & 1.3 & 1.2 & 1.4 & 38.3 & 32.5 & 31.4 & 34.4 \\
\hline Second & 5.9 & 4.8 & 2.5 & 4.6 & 3.4 & 3.0 & 1.6 & 2.7 & 66.3 & 61.5 & 59.2 & 62.7 \\
\hline Middle & 8.6 & 7.8 & 5.8 & 7.5 & 3.7 & 3.3 & 2.5 & 3.2 & 76.5 & 75.3 & 73.4 & 75.2 \\
\hline Fourth & 10.6 & 10.2 & 9.0 & 9.9 & 4.5 & 4.6 & 2.8 & 4.0 & 82.4 & 81.8 & 80.4 & 81.6 \\
\hline Highest & 15.4 & 18.3 & 17.5 & 17.1 & 6.2 & 4.9 & 3.7 & 4.9 & 90.0 & 87.5 & 88.2 & 88.5 \\
\hline
\end{tabular}

*(Reads the Newspaper, Listens to the Radio and Watches Television once a week) 
Table 6A: Percentage of married women ages 15 to 29 who believe a husband is justified in beating his wife by background characteristics, (Punjab MICS 2017-18)

\begin{tabular}{|c|c|c|c|c|}
\hline Background Characteristics & $15-19$ & $20-24$ & $25-29$ & Overall (15-29) \\
\hline Punjab & 19.2 & 22.5 & 25.4 & 22.2 \\
\hline \multicolumn{5}{|l|}{ Residence } \\
\hline Urban & 10.9 & 13.3 & 14.9 & 12.9 \\
\hline Rural & 24.4 & 28.3 & 32.0 & 28.0 \\
\hline \multicolumn{5}{|l|}{ Division } \\
\hline Bahawalpur & 16.9 & 23.9 & 26.7 & 22.2 \\
\hline DG Khan & 27.5 & 37.4 & 40.5 & 34.8 \\
\hline Faisalabad & 20.7 & 23.6 & 26.3 & 23.5 \\
\hline Gujranwala & 10.2 & 12.5 & 13.9 & 12.1 \\
\hline Lahore & 10.5 & 11.6 & 13.6 & 11.8 \\
\hline Multan & 23.3 & 26.4 & 32.6 & 27.3 \\
\hline Rawalpindi & 24.4 & 28.4 & 28.0 & 26.9 \\
\hline Sahiwal & 17.0 & 18.8 & 20.2 & 18.6 \\
\hline Sargodha & 37.2 & 39.2 & 43.8 & 39.9 \\
\hline \multicolumn{5}{|l|}{ Education } \\
\hline No education & 30.3 & 35.9 & 37.4 & 35.1 \\
\hline Primary & 26.7 & 29.8 & 32.9 & 29.6 \\
\hline Middle & 18.8 & 21.2 & 22.8 & 20.6 \\
\hline Secondary & 13.8 & 17.5 & 17.9 & 15.9 \\
\hline Higher & 11.4 & 11.4 & 9.9 & 11.0 \\
\hline \multicolumn{5}{|l|}{ Wealth quintile } \\
\hline Lowest & 30.3 & 35.9 & 37.4 & 35.1 \\
\hline Second & 26.7 & 29.8 & 32.9 & 29.6 \\
\hline Middle & 18.8 & 21.2 & 22.8 & 20.6 \\
\hline Fourth & 13.8 & 17.5 & 17.9 & 15.9 \\
\hline Highest & 11.4 & 11.4 & 9.9 & 11.0 \\
\hline
\end{tabular}

Note: question asked was if a husband is justified in beating his wife if i). She goes out without telling her husband ii). Neglects the children iii). Argues with husband iv). Burns the food v). Refuses sex with her husband. If Women say yes to any one of the questions, she is accepting wife beating by intimate partner violence. 


\section{APPENDIX- B}

Table 1B: Fertility preferences in Pakistan disaggregated by residence status of married women ages 15 to 29 (PDHS 2017-18)

\begin{tabular}{|c|c|c|c|c|}
\hline Background characteristics & $15-19$ & $20-24$ & $25-29$ & $\begin{array}{c}\text { Overall } \\
(15-29)\end{array}$ \\
\hline \multicolumn{5}{|l|}{ Pakistan } \\
\hline Spacing & 32.7 & 34.1 & 25.5 & 29.6 \\
\hline Limiting & 3.8 & 9.9 & 25.9 & 17.3 \\
\hline Wants more & 63.4 & 55.6 & 48.0 & 52.7 \\
\hline Other & 0.1 & 0.4 & 0.6 & 0.5 \\
\hline Total & 100 & 100 & 100 & 100 \\
\hline \multicolumn{5}{|l|}{ Residence } \\
\hline \multicolumn{5}{|l|}{ Urban } \\
\hline Spacing & 32.1 & 41.7 & 26.8 & 32.9 \\
\hline Limiting & 7.8 & 10.1 & 26.8 & 18.9 \\
\hline Wants more & 60.1 & 48.0 & 45.8 & 47.8 \\
\hline Other & 0.0 & 0.3 & 0.6 & 0.4 \\
\hline Total & 100 & 100 & 100 & 100 \\
\hline \multicolumn{5}{|l|}{ Rural } \\
\hline Spacing & 32.9 & 30.4 & 24.8 & 28.0 \\
\hline Limiting & 2.7 & 9.9 & 25.5 & 16.5 \\
\hline Wants more & 64.3 & 59.4 & 49.2 & 55.1 \\
\hline Other & 0.2 & 0.4 & 0.6 & 0.5 \\
\hline Total & 100 & 100 & 100 & 100 \\
\hline
\end{tabular}

Note: wants within 2 years, unsure of timing, undecided = Wants more children Wants no more and Sterilized (respondent or Partner) = Limiting

Wants after $2+$ years $=$ spacing

Declared infecund and missing = others 
Table 2B: Percent of women ages 15 to 29 experiencing gender-based violence, by age and by background characteristics (PDHS 2017-18)

\begin{tabular}{|c|c|c|c|c|}
\hline Background Characteristics & $\begin{array}{c}15-19 \\
(n=142)\end{array}$ & $\begin{array}{c}20-24 \\
(n=563)\end{array}$ & $\begin{array}{c}25-29 \\
(n=682)\end{array}$ & $\begin{array}{l}\text { Overall }(15-29) \\
\quad(n=1387)\end{array}$ \\
\hline Pakistan & 31.5 & 21.2 & 28.6 & 25.9 \\
\hline \multicolumn{5}{|l|}{ Residence } \\
\hline Urban & 36.6 & 16.3 & 21.4 & 20.4 \\
\hline Rural & 29.6 & 24.1 & 32.2 & 28.8 \\
\hline \multicolumn{5}{|l|}{ Region } \\
\hline Punjab & 57.9 & 20.7 & 21.3 & 23.3 \\
\hline Sindh & 0.0 & 7.2 & 18.5 & 12.1 \\
\hline Khyber Pakhtunkhwa & 30.6 & 37.6 & 54.6 & 44.7 \\
\hline Baluchistan & 28.6 & 33.7 & 49.9 & 40.4 \\
\hline ICT Islamabad & 45.5 & 25.6 & 32.5 & 30.8 \\
\hline FATA & 38.2 & 63.4 & 54.5 & 55.2 \\
\hline GB & 13.3 & 8.5 & 20.2 & 14.7 \\
\hline AJK & 5.9 & 4.9 & 15.3 & 9.9 \\
\hline \multicolumn{5}{|l|}{ Education } \\
\hline No education & 27.7 & 26.1 & 38.0 & 32.3 \\
\hline Primary & 46.6 & 24.6 & 29.3 & 30.0 \\
\hline Middle & 33.9 & 27.2 & 30.6 & 29.6 \\
\hline Secondary & 33.2 & 16.3 & 19.7 & 19.2 \\
\hline Higher & 0.0 & 6.2 & 7.7 & 6.8 \\
\hline \multicolumn{5}{|l|}{ Wealth quintile } \\
\hline Lowest & 12.1 & 24.0 & 34.5 & 27.7 \\
\hline Second & 43.0 & 33.1 & 42.9 & 39.1 \\
\hline Middle & 46.6 & 12.6 & 20.5 & 20.5 \\
\hline Fourth & 29.9 & 22.0 & 25.7 & 24.6 \\
\hline Highest & 14.0 & 13.3 & 20.6 & 16.7 \\
\hline
\end{tabular}


Table 3B: Percent distribution of adolescent and youth ages 15 to 29 having access to media* by background characteristics, (PDHS 2017-18)

\begin{tabular}{|c|c|c|c|c|c|c|c|c|c|c|c|c|}
\hline \multirow[b]{2}{*}{ Background characteristics } & \multicolumn{4}{|c|}{ Radio } & \multicolumn{4}{|c|}{ Television } & \multicolumn{4}{|c|}{ Newspaper } \\
\hline & $15-19$ & $20-24$ & $25-29$ & $15-29$ & $15-19$ & $20-24$ & $25-29$ & $15-29$ & $15-19$ & $20-24$ & $25-29$ & $15-29$ \\
\hline Pakistan & 3.3 & 4.7 & 4.9 & 4.7 & 38.1 & 49.1 & 52.9 & 49.7 & 4.5 & 4.1 & 4.1 & 4.1 \\
\hline \multicolumn{13}{|l|}{ Residence } \\
\hline Urban & 6.0 & 5.7 & 8.7 & 7.4 & 61.0 & 65.4 & 74.8 & 70.1 & 3.1 & 4.4 & 4.8 & 4.5 \\
\hline Rural & 2.5 & 4.3 & 2.9 & 3.3 & 31.5 & 41.0 & 41.0 & 39.7 & 4.9 & 4.0 & 3.7 & 4.0 \\
\hline \multicolumn{13}{|l|}{ Region } \\
\hline Punjab & 2.6 & 4.9 & 4.5 & 4.5 & 47.5 & 59.3 & 63.9 & 60.7 & 3.4 & 2.7 & 3.2 & 3.0 \\
\hline Sindh & 3.7 & 5.1 & 6.6 & 5.7 & 47.5 & 47.1 & 54.3 & 50.8 & 3.9 & 5.3 & 4.5 & 4.7 \\
\hline Khyber Pakhtunkhwa & 5.0 & 4.7 & 3.8 & 4.3 & 25.1 & 27.2 & 25.2 & 25.8 & 4.0 & 5.2 & 2.5 & 3.7 \\
\hline Baluchistan & 0.2 & 2.4 & 4.2 & 2.8 & 24.7 & 27.3 & 29.3 & 27.8 & 9.7 & 9.9 & 14.2 & 11.9 \\
\hline ICT Islamabad & 13.4 & 13.6 & 13.7 & 13.6 & 80.4 & 72.9 & 77.8 & 76.4 & 6.5 & 9.2 & 4.1 & 5.9 \\
\hline FATA & 0.2 & 1.0 & 1.8 & 1.2 & 6.1 & 6.3 & 5.1 & 5.8 & 11.1 & 5.8 & 10.1 & 8.7 \\
\hline GB & 5.8 & 4.4 & 3.0 & 3.7 & 40.2 & 59.0 & 45.9 & 50.0 & 10.7 & 2.4 & 3.6 & 3.9 \\
\hline AJK & 1.0 & 8.0 & 6.7 & 6.9 & 24.3 & 50.5 & 53.5 & 50.9 & 6.8 & 6.5 & 7.1 & 6.9 \\
\hline \multicolumn{13}{|l|}{ Education } \\
\hline No education & 0.4 & 0.4 & 0.4 & 0.4 & 27.1 & 30.5 & 29.6 & 29.6 & 5.0 & 3.0 & 3.4 & 3.5 \\
\hline Primary & 4.3 & 3.9 & 4.2 & 4.1 & 43.2 & 50.9 & 56.0 & 52.3 & 4.7 & 2.9 & 5.5 & 4.3 \\
\hline Middle & 4.1 & 7.0 & 4.1 & 5.3 & 51.8 & 63.6 & 68.3 & 64.1 & 2.7 & 8.3 & 4.1 & 5.5 \\
\hline Secondary & 10.8 & 10.0 & 7.3 & 8.7 & 60.6 & 72.7 & 79.8 & 75.3 & 4.2 & 6.3 & 5.4 & 5.6 \\
\hline Higher & 15.1 & 13.7 & 16.0 & 15.2 & 58.0 & 72.7 & 78.9 & 76.1 & 2.7 & 3.6 & 3.4 & 3.5 \\
\hline \multicolumn{13}{|l|}{ Wealth quintile } \\
\hline Lowest & 0.0 & 0.5 & 0.0 & 0.2 & 12.2 & 18.9 & 14.2 & 15.7 & 2.8 & 3.1 & 3.2 & 3.1 \\
\hline Second & 1.9 & 2.0 & 0.5 & 1.3 & 32.4 & 34.4 & 32.2 & 33.1 & 4.9 & 2.8 & 4.6 & 3.9 \\
\hline Middle & 4.8 & 3.8 & 2.5 & 3.3 & 40.0 & 49.7 & 55.4 & 51.2 & 5.5 & 4.6 & 4.6 & 4.7 \\
\hline Fourth & 4.3 & 7.7 & 9.8 & 8.5 & 66.2 & 70.3 & 72.6 & 71.1 & 5.9 & 3.8 & 3.7 & 3.9 \\
\hline Highest & 10.0 & 10.4 & 10.4 & 10.4 & 67.7 & 74.5 & 81.8 & 78.3 & 3.0 & 6.9 & 4.3 & 5.1 \\
\hline
\end{tabular}

*(Reads the Newspaper, Listens to the Radio and Watches Television once a week) 


\section{Disclaimer}

This document has been funded by UKaid from the UK government; however the views expressed herein do not necessarily reflect the UK government's official policies. 